AUTARQUIA ASSOCIADA À UNIVERSIDADE DE SÃO PAULO

DETERMINAÇÃO EXPERIMENTAL E ANÁLISE DOS TEMPOS DE GERAÇÃO DE NÊUTRONS DO NÚCLEO E DO REFLETOR E DA FRAÇÃO DE RETORNO DO REFLETOR EM VÁRIAS CONFIGURAÇÕES DO REATOR IPEN/MB-01 E SEUS IMPACTOS NA DETERMINAÇÃO DA REATIVIDADE DO SISTEMA

Eduardo Gonnelli

Tese apresentada como parte dos requisitos para obtenção do Grau de Doutor em Ciências na Área de Tecnologia Nuclear - Reatores

Orientador:

Prof. Dr. Adimir dos Santos 
INSTITUTO DE PESQUISAS ENERGÉTICAS E NUCLEARES

Autarquia associada à Universidade de São Paulo

\title{
DETERMINAÇÃO EXPERIMENTAL E ANÁLISE DOS TEMPOS DE GERAÇÃO DE NÊUTRONS DO NÚCLEO E DO REFLETOR E DA FRAÇÃO DE RETORNO DO REFLETOR EM VÁRIAS CONFIGURAÇÕES DO REATOR IPEN/MB-01 E SEUS IMPACTOS NA DETERMINAÇÃO DA REATIVIDADE DO SISTEMA
}

\author{
Eduardo Gonnelli
}

Tese apresentada como parte dos requisitos para obtenção do Grau de Doutor em Ciências na Área de Tecnologia Nuclear - Reatores

Orientador:

Prof. Dr. Adimir dos Santos 


\section{Agradecimentos}

À Fundação de Amparo à Pesquisa do Estado de São Paulo (FAPESP), pelo financiamento concedido a este projeto ( $\left.n^{\circ} 2013 / 14908-4\right)$, sem o qual não teria sido possível a sua realização.

Ao Instituto de Pesquisas Energéticas e Nucleares (IPEN/CNEN-SP) por fornecer a infraestrutura adequada para a realização deste trabalho.

Aos meus avós e aos meus pais pelo apoio e por sempre terem acreditado em $\operatorname{mim}$.

À Dra. Letícia Negrão Pinto, pelo apoio, companheirismo, discussões sobre física de reatores e pela parceria científica que resultou em diversas publicações de artigos e participações em eventos internacionais.

Ao meu irmão, Prof. MSc. Orlando Gonnelli Netto, por sempre acreditar no meu potencial e pelos conselhos e discussões sobre física, a vida, o Universo e tudo mais.

Ao meu orientador Dr. Adimir dos Santos e à equipe do reator nuclear IPEN/MB-01 pelo profissionalismo e colaboração. 


\author{
DETERMINAÇÃO EXPERIMENTAL E ANÁLISE DOS TEMPOS DE \\ GERAÇÃO DE NÊUTRONS DO NÚCLEO E DO REFLETOR E DA FRAÇÃO \\ DE RETORNO DO REFLETOR EM VÁRIAS CONFIGURAÇÕES DO \\ REATOR IPEN/MB-01 E SEUS IMPACTOS NA DETERMINAÇÃO DA \\ REATIVIDADE DO SISTEMA
}

EDUARDO GONNELLI

\begin{abstract}
RESUMO
O presente trabalho propõe o desenvolvimento de uma nova metodologia para a medida da reatividade no reator IPEN/MB-01 baseada nas técnicas de análise de ruído microscópico e macroscópico e no modelo de duas regiões das equações de cinética pontual. Diferentemente dos demais modelos teóricos da cinética pontual, o modelo de duas regiões adotado neste trabalho considera o reator como um sistema acoplado, sendo possível explicitar o núcleo e o refletor matematicamente nas equações de cinética. $O$ estudo do efeito do refletor e da sua contribuição na reatividade é inédito e, para que seja viável, os parâmetros cinéticos relacionados ao refletor devem ser obtidos. A principal vantagem da metodologia proposta é a obtenção dos parâmetros cinéticos do refletor de modo puramente experimental. Com a finalidade de validar este novo método, uma série de experimentos envolvendo diferentes tipos de refletores foi realizada no reator IPEN/MB-01. Foram utilizados os refletores de água leve, aço inox (SS-304) e de água pesada. Utilizou-se a técnica de análise de ruído Rossi- $\alpha$ em vários estados subcríticos para a obtenção dos parâmetros do refletor. Empregou-se também a técnica de Densidades Espectrais para a comparação entre os dados experimentais. Além disso, foi utilizado o código computacional de física de reatores MCNP-5, com a biblioteca de dados nucleares ENDF/B-VII.0, para o cálculo da reatividade a partir do fator de multiplicação efetivo $\left(k_{e f f}\right)$ para cada uma das configurações realizadas experimentalmente. A partir das equações de cinética pontual do modelo de duas
\end{abstract}


regiões foram obtidas as expressões teóricas, que foram utilizadas para o ajuste por mínimos quadrados aos dados experimentais. $O$ tempo de vida dos nêutrons no refletor $\left(\tau_{\mathrm{r}}\right)$ e no núcleo $\left(\tau_{\mathrm{C}}\right)$ e a fração desses nêutrons que retornam ao núcleo $(f)$ foram obtidos como parâmetros do ajuste e utilizados para o cálculo da reatividade a partir da equação Inhour de duas regiões. São apresentados os resultados experimentais e teóricos referentes ao núcleo padrão com refletor de água leve, refletor de aço inox e refletor de água pesada. Todos os experimentos utilizaram a configuração de $26 \times 28$ varetas combustíveis com detectores operando em modo pulso. 


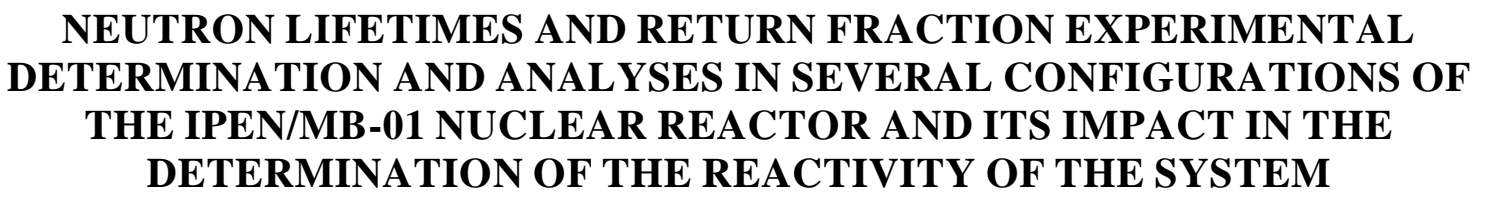

\title{
EDUARDO GONNELLI
}

\begin{abstract}
This work proposes the development of a new methodology for measurement of the reactivity in the IPEN/MB-01 research reactor facility, based on microscopic and macroscopic noise experiments and the Two-Region point kinetic equations model. Differently from the other point kinetic theoretical models, the Two-Region model assumed in this work takes into account the nuclear reactor how a coupled system, which constitute the theoretical basis of all mathematical development, contemplate both regions of the reactor (core and reflector).The study of the reflector effect and its impact in the reactivity is an original fact and, to make possible the viability of this study, the kinetic parameters related to the reflector must be obtained. The main advantage of this new methodology is to obtain the kinetic parameters from the reflector in a purely experimental way. In order to validate this new method, a series of experiments involving different types of reflectors was performed in the IPEN/MB-01 reactor. The reflectors constituted by Light Water, Stainless Steel (SS-304) and Heavy Water were employed. The Rossi- $\alpha$ neutron noise technique were applied in several subcritical states to obtain the parameters of the reflector. Furthermore, the Auto Power Spectral Densities were also used for a comparison between the experimental data. Moreover, the MCNP-5 nuclear reactor physics code with the ENDF/B-VII.0 library neutron data was employed to calculate the reactivity through the $k_{\text {eff }}$ multiplication factor for each experimental configuration. In this way, from the Two-Region point kinetic equations model were obtained the theoretical expressions in which were used for least squares fit of the experimental data. The neutron lifetimes in the reflector $\left(\tau_{\mathrm{r}}\right)$ and in the core $\left(\tau_{\mathrm{C}}\right)$, and the
\end{abstract}


neutron return fraction from the reflector to the core $(f)$ were obtained as least squares fitted parameters and then employed for the reactivity calculation through the Inhour two region equation. The presented experimental and theoretical results are referring to the standard core configuration with aforementioned reflectors of Light Water, Stainless Steel (SS-304) and Heavy Water. For all experiments the $26 \times 28$ fuel rod configuration was employed with the detectors operating in pulse mode. 


\section{SUMÁRIO}

RESUMO................................................................................................................................. ii

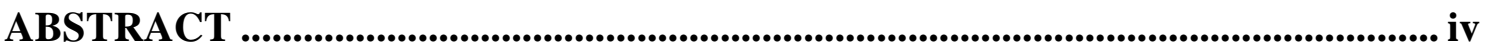

LISTA DE FIGURAS................................................................................. 1

1. INTRODUÇÃO .......................................................................................................... 4

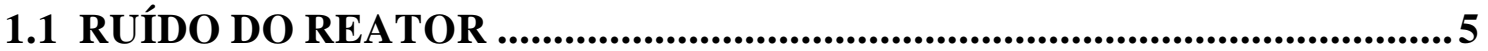

1.2 PROJETO DE PESQUISA.........................................................................

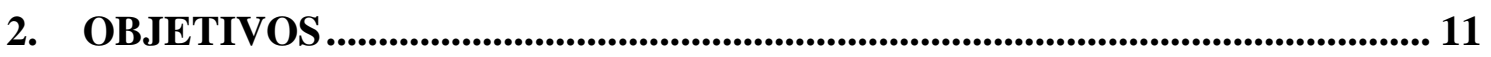

3. JUSTIFICATIVAS ........................................................................................... 12

4. EQUAÇÃO INHOUR COM NÚCLEO REFLETIDO.......................................... 13

5. TÉCNICA DE ROSSI-ALPHA _............................................................................... 20

6. DENSIDADES ESPECTRAIS ..................................................................... 23

7. ANÁLISE DAS INCERTEZAS DA REATIVIDADE DO SISTEMA ........... 26

8. APLICAÇÃO DAS EQUAÇÕES DE AJUSTE PARA A OBTENÇÃO DOS PARÂMETROS CINÉTICOS DO REFLETOR ..................................................... 28

9. PROCEDIMENTO EXPERIMENTAL ................................................................. 30

9.1 ARRANJO EXPERIMENTAL - AÇO INOX (SS-304).................................... 31

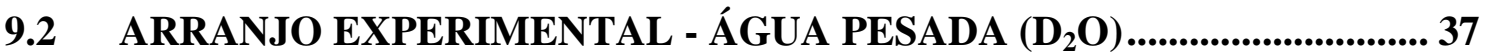

10. RESULTADOS …................................................................................................. 42

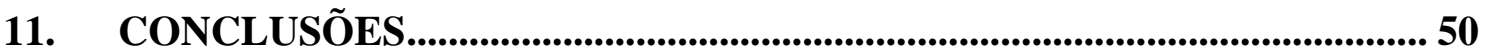

ANEXO A - MATRIZES DE COVARIÂNCIA E CORRELAÇÃO......................... 52 ANEXO B - TESTE DE CONSISTÊNCIA DAS RAÍZES DA EQUAÇÃO INHOUR DE DUAS REGIÕES ........................................................................59 ANEXO C - CARACTERIZAÇÃO DOS DETECTORES DE NÊUTRONS ..... 66

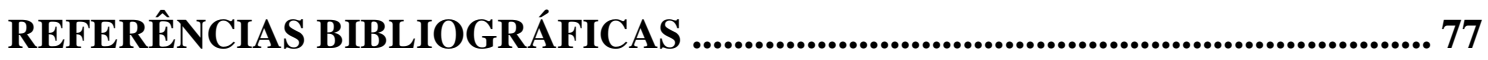




\section{LISTA DE FIGURAS}

Figura 1 - Representação de um sistema refletido. 13

Figura 2 - Balanço da probabilidade de migração dos nêutrons entre núcleo e refletor 14 Figura 3 - Os primeiros quatro termos das possíveis histórias do nêutron resultando na sua absorção no núcleo. 15

Figura 4 - Distribuição Rossi- $\alpha$ mostrando os eventos de nêutrons detectados em função do tempo em uma situação arbitrária. $\mathrm{R}$ representa os eventos correlacionados e A representa os eventos não correlacionados. A letra $\mathrm{P}$ no eixo do tempo mostra a região do tempo morto da eletrônica associada ao sistema de medida (detectores, amplificadores, mono canais).

Figura 5 - Curva de distribuição Rossi- $\alpha$ adquirida com os bancos de controle na posição de $17.5 \%$ retirados e com refletor de água leve.

Figura 6 - Densidade espectral do tipo APSD adquirida com os bancos de controle na posição de $17.5 \%$ retirados e com refletor de água leve.

Figura 7 - Visão axial da configuração experimental do núcleo do reator IPEN/MB-01.

Figura 8 - Visão axial da configuração experimental do núcleo do reator IPEN/MB-01. Ao lado esquerdo da figura (face oeste) estão representadas as 32 placas de aço inox. A linha pontilhada representa a região central do núcleo e à direita (face leste) está posicionado o detector de hélio-3.

Figura 9 - Á esquerda está representada uma ilustração da placa de aço inox com as respectivas dimensões, dadas em centímetros. A figura da direita ilustra uma visão frontal da placa de aço inox em comparação com a região ativa do núcleo do reator nuclear IPEN/MB-01. 33

Figura 10 - (a) A foto da esquerda mostra a montagem do aparato experimental mockup com algumas placas de aço inox. (b) A foto do meio representa o sistema de 
compressão das placas. (c) Na foto da direita pode-se observar o local de encaixe das placas (canaletas ou groove) 35

Figura 11 - Caixa refletora vista em perspectiva, dimensões das chapas de alumínio e indicações das partes que a constituem [61] 38

Figura 12 - Vista superior, laterais da caixa refletora [61] 39

Figura 13 - Ilustração tridimensional mostrando um corte do tanque moderador onde se encontra o núcleo e o posicionamento da caixa de água pesada na face oeste [61] ....... 40 Figura 14 - Ilustração do procedimento de enchimento da caixa refletora com água pesada [61].

Figura 15 - Valores das reatividades obtidos pela simulação do código computacional MCNP5 para as três configurações do núcleo. Núcleo padrão, com refletor de água leve (quadrado), com refletor de aço inox (círculo) e com refletor de água pesada (triangulo).

Figura 16 - Valores de reatividade para o núcleo padrão com refletor de água leve. .... 43 Figura 17 - Valores de reatividade para o núcleo padrão com refletor de aço inox. ..... 45 Figura 18 - Valores de reatividade para o núcleo padrão com refletor de água pesada. 47 Figura 19 - Foto dos detectores utilizados no processo de caracterização. A distância medida pela fita métrica é de $110 \mathrm{~cm}$. 68

Figura 20 - Ilustração representando o diagrama da eletrônica, aquisição de dados e sistema de processamento de dados utilizados nas medidas de análise de ruído neutrônico.

Figura 21 - Esquema do processamento de dados das densidades espectrais e curvas Rossi- $\alpha$.

Figura 22 - Fotos do sistema de aquisição de dados com os módulos nucleares (esquerda) e o arranjo experimental entre o detector e a fonte de nêutrons (direita).... 70 Figura 23 - Fotos do interior do cilindro de polietileno com a fonte de nêutrons (esquerda) e da distância entre detector e fonte, utilizando uma fita métrica (direita)... 70 Figura 24 - Curvas de tensão de operação para o detector de $\mathrm{BF}_{3}$ (esquerda) e de ${ }^{3} \mathrm{He}$ (direita). 71 
Figura 25 - Espectros energéticos dos detectores de $\mathrm{BF}_{3}$ (esquerda - C) e de ${ }^{3} \mathrm{He}$ (direita - B)

Figura 26 - Espectro energético do detector de ${ }^{3} \mathrm{He}(\mathrm{A})$

Figura 27 - Gráfico dos eventos correlacionados e determinação do tempo morto para o detector de ${ }^{3} \mathrm{He}$ (esquerda - B) e para o detector de $\mathrm{BF}_{3}$ (direita - C). 72 Figura 28 - Gráfico dos eventos correlacionados e determinação do tempo morto para o detector de ${ }^{3} \mathrm{He}$ 73

Figura 29 - Resultados de reatividade para cada passo de inserção de banco de controle. 


\section{INTRODUÇÃO}

A primeira observação das flutuações estatísticas do numero de nêutrons em um reator nuclear ocorreu através do experimento denominado de Rossi-alpha. Este experimento foi nomeado por Bruno Rossi, que propôs e criou os aparatos experimentais para este tipo de medida no inicio dos estudos referentes ao ruído em Los Alamos. Os estudos teóricos originais foram formulados por Fermi, Feynman e de Hoffman em 1944 [1], e em 1946 novamente por de Hoffman [2], no qual tem como foco do seu estudo a intensidade das flutuações nas cadeias de fissão. Durante este mesmo período, de Hoffman também emitiu dois relatórios em Los Alamos, denominados por LADC-269 e por LADC-256. Estes permaneceram confidenciais e restritos durante vários anos, assim como toda a produção científica e literária produzida nesta época a respeito deste tema.

O primeiro material não confidencial foi produzido posteriormente, e também teve a contribuição de de Hoffman em 1949 [3], que acabou sendo publicado no segundo volume do The Science and Engineering of Nuclear Power. Este foi totalmente elaborado a partir do material contido no relatório LADC-256 e, sete anos mais tarde, ocorreu a publicação aberta do relatório LADC-269 no Journal of Nuclear Energy, assinado por Feynman, de Hoffman e Serber em 1956 [4]. Já em 1957, John Orndoff [5]

refaz o experimento de Rossi-alpha em Los Alamos utilizando o esquema do aparato original desenvolvido 13 anos antes, e publica seus resultados na Nuclear Science and Engineering. Desde então, a análise de ruído do reator foi finalmente oficializada.

Ruído é de fato uma palavra versátil e pode apresentar vários significados e que pode indicar alguma alteração em relação à estrutura técnica na qual se está lidando. Em acústica, ruído significa: som, especialmente de barulho, sons não identificáveis ou um grupo não harmonioso ou dissonante de sons [6]. Ruído também pode ser interpretado como um errático intermitente, oscilações estatisticamente randômicas ou flutuação no sinal de resposta de um detector quando a radiação incidente é estacionária [7].

Esclarecimentos mais detalhados sobre ruído e flutuações são fornecidos por Van der Ziel [8]. Ele diz que a utilização do termo flutuações espontâneas, embora seja 
mais apropriada, não é comumente usada na prática; geralmente, é simplesmente chamado de ruído, que foi obtido como resultado de efeitos acústicos anexados às flutuações elétricas em receptores. O nome descritivo de ruído é utilizado mesmo quando um efeito acústico não está envolvido, como por exemplo, na televisão [8].

No ramo da física nuclear a definição mais concisa e brilhante foi dada por Cohn em 1971 [9]. Ele define que "o ruído do reator são as flutuações de nêutrons. A causa básica das flutuações estatísticas na população de nêutrons é a aleatoriedade de todas as reações de interações dos nêutrons. Haveria flutuações mesmo se todas as fissões produzissem o mesmo numero de nêutrons".

O problema mais geral sobre o estudo do fenômeno de flutuação é introduzido por Landu e Lifshitz (1959) [10]. Eles afirmam que as quantidades físicas que descrevem um corpo macroscópico em equilíbrio são praticamente constantes e, com grande precisão, aos seus valores médios. No entanto, pelas flutuações serem pequenas e apresentarem desvios em relação a estes valores médios, surge a questão fundamental de encontrar a distribuição de probabilidade para estas flutuações.

\subsection{RUÍDO DO REATOR}

Ruído do reator é um termo utilizado para flutuações no sinal de saída de um detector de nêutrons ou outro sensor posicionado no interior ou próximo a um reator nuclear, e é um ramo bem estabelecido de estudos e aplicações no campo da física de reatores nucleares. A meta final da análise de ruído do reator é medir constantes que dependem do tempo e características dinâmicas do sistema, assegurando a sua operação segura e correta, além de diagnosticar e prever irregularidades no funcionamento do sistema e fornecer um aviso prévio de anomalias, sem precisar de qualquer excitação externa ou perturbação do sistema. Esta última característica é o que torna a analise de ruído uma técnica valiosa, especialmente em usinas termonucleares, porque não alterna ou interrompe a produção de energia.

Medidas de ruído permitem que a aquisição de dados em um sistema nuclear e seu monitoramento sejam realizados com segurança, exercendo não apenas uma relevância científica, mas também um notável impacto social. $\mathrm{O}$ baixo custo do 
monitoramento por ruído, em comparação com o alto custo de falhas e/ou paradas de uma central termonuclear, desempenha um papel favorável de apoio à análise de ruído.

A avaliação do estado de um reator nuclear pode ser assimilada aos processos estocásticos e pode ser descrita matematicamente por um conjunto de equações estocásticas. A maior parte dos problemas de física de reatores pode ser resolvida em termos do comportamento dos valores médios das variáveis relacionadas ao seu estado, ou seja, o fluxo de nêutrons, temperatura do combustível, do refrigerante e moderador, assim como a pressão e fluxo, além da fração de vazio. Estas considerações reduzem o estudo dos processos estocásticos para uma análise determinística.

A motivação e o interesse especial nas flutuações das variáveis de estado do reator ocorrem porque estas contêm informações importantes do mesmo. Não apenas informações adicionais, mas uma maior gama de informações do que as contidas no comportamento dos valores médios. Um exemplo muito interessante que valida esta declaração foi dada por Williams em 1974 [11], que lida com um dos processos estocásticos mais simples, ou seja, o processo de nascimento e morte. Ele mostra que para indivíduos de uma dada população, que apresenta uma probabilidade constante de nascimento e morte por unidade de tempo, a análise temporal do valor médio desses indivíduos contém informações sobre o balanço entre as taxas de nascimento e morte. Além disso, somente a analise temporal das flutuações da população, isto é, da variância, leva a separar a medição das duas probabilidades.

A determinação do estado de um reator de potência zero geralmente é descrita pelo seu comportamento temporal e pelo número de nêutrons. Se os problemas são resolvidos e definidos em termos do valor médio do número de nêutrons, esta área de estudo é chamada de cinética de reatores.

Se o interesse é estendido para o numero da flutuação de nêutrons, esta área mais ampla de pesquisa pode ser chamada de cinética estocástica de reatores. Stacey [12] em 1963 relatou os avanços no campo da teoria da cinética estocástica de reatores, principalmente no caso dos modelos de reatores que não apresentam dependência energética e espacial. Ele também destacou muito apropriadamente a ramificação da teoria explorando formalismos diferentes, voltado para os especialistas que estavam lidando diretamente com o problema da flutuação da população de nêutrons. Sua lista 
pode ser completada e desenvolvida a fim de mostrar como a física matemática da teoria do ruído de nêutrons em reatores vem crescendo nos últimos anos.

O precursor de todo o embasamento matemático está contido no trabalho desenvolvido por Courant e Wallace em 1947 [13], onde os autores definem as equações de balanço de probabilidade e formulam a equação diferencial substancialmente equivalente à obtida posteriormente pelo método estocástico.

Atualmente, os trabalhos relacionados ao ruído do reator englobam as técnicas de Rossi-a [14, 15, 16], Feynman-a [16, 17, 18, 19], Densidades Espectrais [20, 21], simulações computacionais $[22,23,24]$, e até mesmo técnicas desenvolvidas para a área de Neurociência e Econometria [25].

\subsection{PROJETO DE PESQUISA}

Em todo o mundo existem aproximadamente 245 [26] reatores nucleares de pesquisa, distribuídos em 55 países. Considerando o advento de inúmeros e novos reatores de pesquisa de pequeno porte e de alto fluxo de nêutrons, tais como, OPAL (Austrália), Jules Horowitz (França), Pallas (Holanda), HANARO (Coréia do Sul), dentre outros, surge a necessidade de novos modelos físicos e matemáticos para a descrição dinâmica destes sistemas.

Considerando o contexto de nosso país, no Brasil está sendo desenvolvido o primeiro Reator Multipropósito Brasileiro (RMB) de grande porte, que terá $30 \mathrm{MW}$ de potência e capacidade para atender à demanda nacional em vários setores de interesse. O propósito deste reator de pesquisa não está relacionado à geração de energia em larga escala, mas ao aproveitamento dos nêutrons e das radiações geradas pelas reações nucleares para a produção de radioisótopos. De uma maneira geral, proporcionará benefícios para toda a sociedade nas áreas da saúde, indústria e agricultura. Além de complementar a formação e treinando de recursos humanos para atender às necessidades do Programa Nuclear Brasileiro.

Sistemas multiplicativos como os mencionados acima possuem a característica comum de serem compactos e de apresentarem alta fuga de nêutrons. Uma vez que estes 
sistemas têm como função principal a produção de feixes de nêutrons, a maioria dos reatores de pesquisa também necessita de um material refletor para reduzir a perda de nêutrons do núcleo. O refletor exerce importância preponderante no comportamento da população de nêutrons desses sistemas, reduzindo a fuga dos nêutrons do sistema. Com o retorno dos nêutrons para o núcleo, estes nêutrons podem ser reaproveitados para a geração de novas cadeias de fissão, reduzindo-se, assim, o tamanho crítico do reator e, consequentemente, resultando na economia de combustível nuclear.

A maioria dos modelos físicos e matemáticos que descrevem a dinâmica da população de nêutrons desses pequenos reatores se apoia no modelo de cinética pontual de uma região, na qual o refletor não é levado em consideração explicitamente nas equações. Como reatores refletidos constituem uma das classes mais importantes de reatores nucleares, e desde os primórdios da era nuclear tais tipos de reatores têm sido sistematicamente estudados utilizando o modelo de cinética pontual [27], busca-se o desenvolvimento de um modelo matemático adequado e mais fidedigno para tratar este tipo de problema.

Experimentos realizados em reatores refletidos durante décadas mostraram, contudo, que o modelo de cinética pontual não descreve de modo satisfatório alguns resultados experimentais [28]. Os múltiplos modos de decaimento em distribuições Rossi- $\alpha$ e em experimentos com fontes pulsadas [29, 30, 31, 32], o desvio das densidades espectrais nas regiões de alta freqüência [28, 33], e a discrepância entre os tempos de vida dos nêutrons preditos pelo modelo de uma região (cinética pontual) e os dados experimentais $[34,35]$ são alguns exemplos.

Devido a essas discrepâncias, numerosas teorias e modelos têm sido desenvolvidos para sistemas refletidos [28], os quais explicam uma ou outra anomalia observada. Contudo, parece que um desses modelos é capaz de explicar de forma satisfatória algumas anomalias. Trata-se do modelo de duas regiões proposto por Avery $[36,37]$ para sistemas acoplados, o qual foi posteriormente adaptado por Cohn [38, 39] e Spriggs [28] para sistemas refletidos. Basicamente, o formalismo de Cohn e Spriggs considera que o reator é representado por duas regiões (núcleo e refletor), que são expressas nas equações de cinética. Os nêutrons existentes no núcleo podem ser absorvidos, induzir fissões, ou escapar para o refletor, enquanto os nêutrons presentes no refletor podem ser absorvidos, retornar ao núcleo ou escapar do sistema. As duas 
regiões são então acopladas, sendo que os coeficientes de acoplamento representam as probabilidades de que nêutrons desapareçam de uma dada região e apareçam, ou não, em outra. A determinação dos parâmetros de acoplamento e os lifetimes neutrônicos é baseada nas relações de probabilidade que descrevem a migração de nêutrons entre o núcleo e o refletor.

O modelo de duas regiões já foi aplicado em experimentos realizados no reator IPEN/MB-01 em três trabalhos distintos: dois envolvendo as densidades espectrais do ruído neutrônico [33, 40] e um envolvendo as técnicas de Rossi- $\alpha$ [41] e Feynman- $\alpha$ [42].

No trabalho envolvendo as técnicas de Rossi- $\alpha$ [41] e Feynman- $\alpha$ [42], o modelo de duas regiões permitiu identificar a existência de duas raízes distintas da equação Inhour e o comportamento não linear entre a constante de decaimento de nêutrons prontos e a reatividade. Além disso, mostrou-se que os efeitos do refletor se tornam evidentes apenas em níveis de reatividade muito subcrítica. Em baixos níveis de subcriticalidade, ou perto da região de criticalidade, as equações de cinética pontual apresentam resultados suficientemente bons.

No caso dos trabalhos da aplicação das densidades espectrais, pôde ser observado no primeiro experimento [33], o comportamento anômalo em altas frequências (acima da frequência correspondente ao parâmetro $\beta_{\text {eff }} / \alpha$, onde $\beta_{\text {eff }}$ é a fração efetiva total de nêutrons atrasados e $\alpha$ é o tempo de geração de nêutrons prontos), sendo que os lifetimes encontrados não corresponderam ao esperado. Como as medidas de densidades espectrais foram realizadas apenas em estados críticos, e talvez por isso, o efeito do refletor sobre os lifetimes não se tornou evidente. Já no segundo experimento utilizando as densidades espectrais [40], as medidas foram realizadas para níveis de subcriticalidade próximos de -5000 pcm com detectores operando em modo pulso. Baseando-se no modelo de duas regiões para sistemas refletidos em função da reatividade [43], obtiveram-se alguns dos parâmetros cinéticos relacionados ao refletor (tempo de geração de nêutrons prontos $\Lambda$, constante de decaimento dos nêutrons no refletor $\lambda_{\mathrm{r}}$ e a fração de retorno dos nêutrons $\beta_{7}$, sendo que este último parâmetro foi considerado como um pseudo-grupo de nêutrons atrasados). Evidenciou-se também a diminuição da diferença entre os dois patamares característicos das densidades espectrais do tipo APSD (o primeiro patamar é devido aos nêutrons atrasados e o 
segundo ocorre por conta do ruído não correlacionado) à medida que a inserção de reatividade negativa aumentava $(\sim-6000 \mathrm{pcm})$, dificultando a realização dos ajustes não lineares pelo método de mínimos quadrados.

Levando em conta todos os avanços até aqui realizados, o presente trabalho propõe a verificação da influência do refletor do reator IPEN/MB-01 na reatividade do sistema a partir da obtenção experimental dos parâmetros relacionados ao refletor. Optou-se pelas medidas de densidades espectrais do tipo APSD (Auto Power Spectral Density) e das curvas Rossi- $\alpha$ com detectores operando em modo pulso para vários níveis de subcriticalidade. Adotou-se a configuração padrão de $28 \times 26$ varetas combustíveis para todos os experimentos e realizou-se a aquisição de dados experimentais para vários tipos de refletores, tais como: refletor de água leve, chapas refletoras de aço inox e uma caixa refletora de água pesada. Os resultados experimentais foram comparados com os resultados simulados teoricamente pelo código computacional MCNP5 utilizando a biblioteca de dados nucleares ENDF/B-VII.0. Com isso, foi possível obter os parâmetros cinéticos relacionados ao refletor, visando contribuir para uma melhor compreensão do efeito do refletor sobre a reatividade do reator IPEN/MB-01. 


\section{OBJETIVOS}

Os objetivos do trabalho desenvolvido podem ser enumerados como:

1. Obtenção experimental das densidades espectrais (Auto Power Spectral Density -APSD) e das curvas Rossi- $\alpha$, , com detectores operando em modo pulso, em várias configurações subcríticas do reator IPEN/MB-01;

2. Utilizar o modelo de Spriggs para reatores refletidos para a obtenção dos parâmetros cinéticos relacionados ao refletor $\left(\tau_{\mathrm{c}}, \tau_{\mathrm{r}} \mathrm{e} f\right)$;

3. Determinação experimental dos tempos de geração de nêutrons do núcleo e do refletor e da fração de retorno de nêutrons em várias configurações do reator IPEN/MB-01. Essas configurações englobam refletores com água leve, refletores de aço inox e refletores de água pesada;

4. Interpretação e análise dos resultados experimentais e dos resultados simulados teoricamente pelo código computacional MCNP5, utilizando a biblioteca de dados nucleares ENDF/B-VII.0 


\section{JUSTIFICATIVAS}

1. A escolha do reator IPEN/MB-01 consiste no fato de, além de ser uma instalação versátil, com núcleo de alta fuga de nêutrons, a descrição geométrica e de seus materiais são bem conhecidos. O reator IPEN/MB-01 já foi objeto de várias avaliações pelo IRPhE (International Reactor Physics Experiments), e ICSBEP (International Criticality Safety Benchmark Evaluation Project) e em decorrência dessas analises se tornou benchmark internacional;

2. A utilização de detectores modo pulso, devido à grande variedade disponível no Reator IPEN/MB-01, proporcionará uma grande versatilidade na montagem dos experimentos, permitindo grande variação nos níveis de subcriticalidade;

3. Dar continuidade ao processo de modernização do sistema de aquisição e processamento de dados do Reator IPEN/MB-01;

4. A compreensão do efeito do refletor em reatores de pesquisas irá contribuir para o avanço, desenvolvimento e elaboração de projetos mais versáteis e econômicos.

5. A análise do impacto da determinação da reatividade utilizando a cinética de reatores refletidos em varias situações de interesse para a área de Física de Reatores é um fato inédito; 


\section{EQUAÇÃO INHOUR COM NÚCLEO REFLETIDO}

Em um sentido geral, existem apenas duas maneiras pelas quais um nêutron pode ser perdido do sistema - através da absorção, ou por fuga. No entanto, em um sistema refletido, nêutrons podem migrar do núcleo para o refletor, ou do refletor para o núcleo. Portanto, no que diz respeito à região de núcleo no sistema parcialmente refletido, representada pela figura 1 , um nêutron originado no núcleo (ou refletido pelo refletor) pode sofrer apenas uma das seguintes ações: ser absorvido no núcleo, na qual é representado pela probabilidade $f_{c a}$, fugir do sistema (partes superior e inferior da figura 1), na qual é representado pela probabilidade $f_{c i}$, ou pode migrar do núcleo para o refletor, na qual é representada pela probabilidade $f_{c r}$ [28]. Por definição, a soma destas probabilidades deve ser igual a 1 e, deste modo, temos que:

$$
1=f_{c a}+f_{c i}+f_{c r}
$$

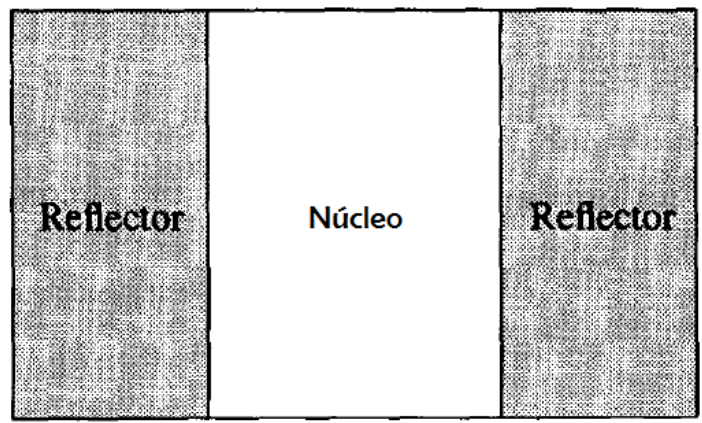

Figura 1 - Representação de um sistema refletido.

Se um nêutron migrar do núcleo para o refletor, ele poderá também sofrer apenas uma das seguintes interações: ser absorvido no refletor $\left(f_{r a}\right)$, fugir para fora do sistema $\left(f_{r i}\right)$ ou ser espalhado de volta para o núcleo $\left(f_{r c}\right)$. Sendo a somatória destas probabilidades igual a 1 , temos que:

$$
1=f_{r a}+f_{r i}+f_{r c}
$$

Os membros do lado direito das equações $(01)$ e (02) se referem à média de probabilidades de uma só passagem, pois representam a probabilidade média de um resultado em particular relacionado com uma única passagem do nêutron através de uma 
dada região. No entanto, deve-se ressaltar que estas probabilidades de uma só passagem não representam a fração de nêutrons final que foi perdida por fuga ou por absorção em uma região particular. Os nêutrons podem ser refletidos para dentro ou para fora do núcleo ou mesmo para regiões refletoras por muitas vezes antes de serem definitivamente perdidos. A fração absorvida de nêutrons em uma dada região ou a fração de fuga do sistema é definida em função da média das probabilidades de uma só passagem e o número médio de vezes que um nêutron passou através desta região.

Do ponto de vista de um sistema integral, podemos escrever a equação de equilíbrio de nêutrons simplificada que é responsável por todos os desfechos que um nêutron pode apresentar em um sistema refletido, como ilustrado na figura 2.

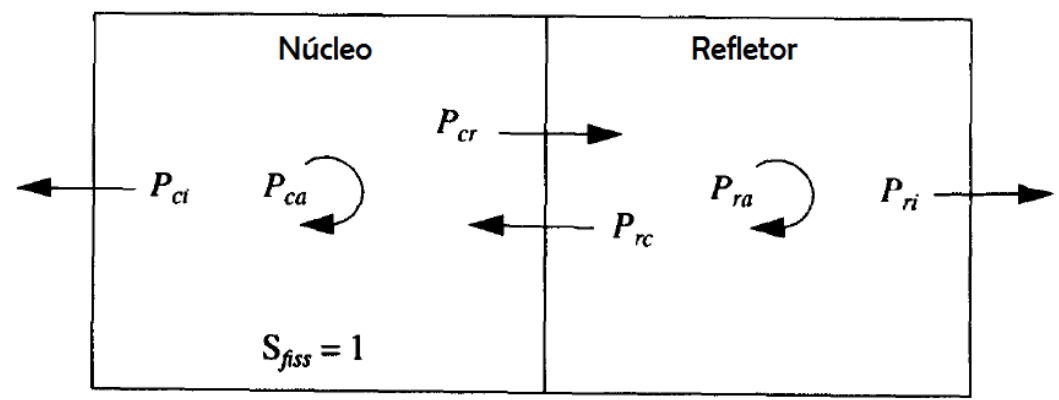

Figura 2 - Balanço da probabilidade de migração dos nêutrons entre núcleo e refletor

Considerando as probabilidades de migração, temos que:

$$
1=\mathrm{P}_{\mathrm{ca}}+\mathrm{P}_{\mathrm{ci}}+\mathrm{P}_{\mathrm{ra}}+\mathrm{P}_{\mathrm{ri}}
$$

onde $\mathrm{P}_{\mathrm{ca}}$ é a fração de nêutrons do sistema que são absorvidos no núcleo, $\mathrm{P}_{\mathrm{ci}}$ é a fração de nêutrons do sistema que escapam do núcleo diretamente para o infinito (fuga do sistema), $\mathrm{P}_{\mathrm{ra}}$ é a fração de nêutrons do sistema que são absorvidos no refletor, e $\mathrm{P}_{\text {ri }}$ é a fração de nêutrons do sistema que escapam do refletor diretamente para o infinito (fuga do sistema). Deve-se ressaltar que a taxa de fluxo na interface núcleo/refletor não aparecem nessa equação, pois o balanço de nêutrons é realizado no sistema como um todo (integral).

As relações descritas acima podem ser relacionadas com a média das probabilidades de uma só passagem através da soma da fração de nêutrons envolvidos em um resultado particular sobre cada caminho em potencial que conduz a esse resultado. A figura 3 ilustra os processos de migração entre o núcleo e o refletor, com absorção no núcleo. 


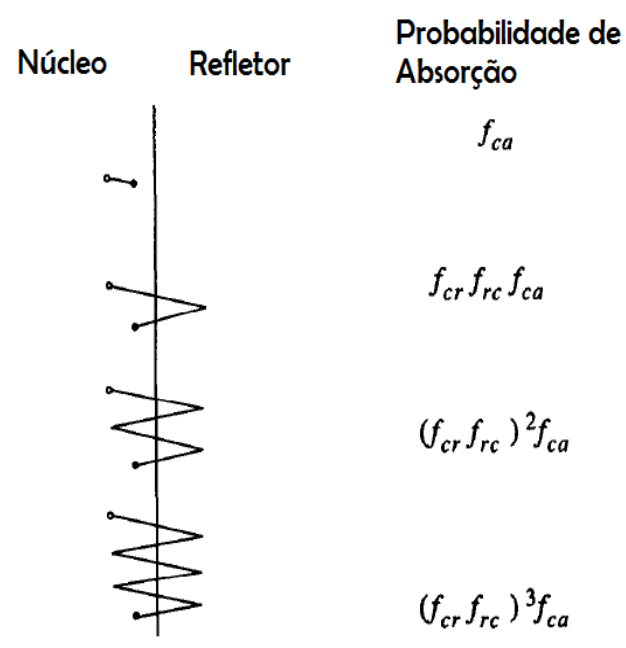

Figura 3 - Os primeiros quatro termos das possíveis histórias do nêutron resultando na sua absorção no núcleo.

Analisando os processos da figura 3, obtêm-se a série infinita dada por:

$$
P_{c a}=f_{c a}\left[1+f_{c r} f_{r c}+\left(f_{c r} f_{r c}\right)^{2}+\left(f_{c r} f_{r c}\right)^{3}+\ldots\right]
$$

O produto $f_{c r} f_{r c}$ aparece com bastante frequência no modelo de cinética de duas regiões. Do ponto de vista físico, este produto representa a fração de nêutrons que se originou no núcleo, se propagou para o refletor e, posteriormente, foi refletida para o núcleo. Por conveniência, iremos definir este produto como fração de retorno do refletor, denotado por $f[28]$.

O modelo teórico que será utilizado neste trabalho foi desenvolvido por Cohn [38,44] e Spriggs [28], onde as equações cinéticas para o núcleo, o refletor e para concentração de precursores de nêutrons atrasados são dadas, respectivamente, por:

$$
\begin{gathered}
\frac{d N_{c}}{d t}=\left[k_{c}\left(1-\beta_{e f f}\right)-1\right]\left(\frac{N_{c}}{\tau_{c}}\right)+f_{r c}\left(\frac{N_{r}}{\tau_{r}}\right)+\sum_{i} \lambda_{i} C_{i}+S, \\
\frac{d N_{r}}{d t}=f_{c r}\left(\frac{N_{c}}{\tau_{c}}\right)-\left(\frac{N_{r}}{\tau_{r}}\right), \\
\frac{d C_{i}}{d t}=k_{c} \beta_{e f f}^{i}\left(\frac{N_{c}}{\tau_{c}}\right)-\lambda_{i} C_{i},
\end{gathered}
$$

onde,

$N_{c}=$ número total de nêutrons no núcleo;

$N_{r}=$ número total de nêutrons no refletor; 
$\tau_{c}=$ tempo de vida ponderado dos nêutrons no núcleo;

$\tau_{r}=$ tempo de vida ponderado dos nêutrons no refletor;

$k_{c}=$ fator de multiplicação do núcleo;

$f_{c r}=$ fração de nêutrons que passam do núcleo para o refletor;

$f_{r c}=$ fração de nêutrons que passam do refletor para o núcleo;

$\mathrm{C}_{\mathrm{i}}=$ concentração de precursores de nêutrons atrasados ponderada do i-ésimo grupo;

$\beta_{\text {eff }}^{\mathrm{i}}=$ fração de nêutrons atrasados do i-ésimo grupo;

$\lambda_{\mathrm{i}}=$ constante de decaimento do i-ésimo grupo de precursores de nêutrons atrasados;

$S=$ intensidade da fonte de nêutrons ponderada (intrínseca e externa).

A equação Inhour, segundo o modelo de duas regiões, pode ser obtida através da metodologia padrão da Transformada de Laplace [27, 45]. Este procedimento é o mesmo utilizado no Modelo de Cinética Pontual padrão.

A transformada de Laplace de $N_{c}(t)$, equação (05), é dada por:

$$
N_{c}(s)=\frac{\frac{\tau_{c}}{k_{c}}\left[N_{c o}+\frac{f_{r c} N_{r o}}{\tau_{r} s+1}+\sum_{i} \frac{\lambda_{i} c_{i o}}{s+\lambda_{i}}+\frac{s}{s}\right]}{s\left[\frac{\tau_{c}}{k_{c}}+\frac{f \tau_{r}}{k_{c}\left(\tau_{r} s+1\right)}\right]+\sum_{i} \frac{\beta_{e f f}^{i} s}{s+\lambda_{i}}-\left(\frac{k_{c}+f+1}{k_{c}}\right)},
$$

onde $N_{c o}$ e $c_{i o}$ são, respectivamente, a densidade de nêutrons e a concentração de precursores do i-ésimo grupo em $t=0$, onde ocorre um passo (step) de reatividade.

O denominador da equação (08) é a equação Inhour e apresenta $m+2$ raízes reais distintas, onde $m$ é o número de grupos de nêutrons atrasados. Então, $N_{c}(s)$ tem $m+2$ polos simples no eixo real de $s$. Para cada raiz $s=\omega_{j}$, o denominador da equação (08) é zero, onde $\omega_{j}$ deve satisfazer a equação:

$$
\frac{k_{c}+f-1}{k_{c}}=\omega \frac{\tau_{c}}{k_{c}}+\omega \frac{f \tau_{r}}{k_{c}\left(\tau_{r} \omega+1\right)}+\sum \frac{\beta_{i} \omega}{\omega+\lambda_{i}},
$$

Definindo $k_{c}$ como, $k_{c}=k_{\text {eff }}(1-f)$ podemos reescrever o lado esquerdo da equação (09) como: 


$$
\frac{k_{c}+f-1}{k_{c}}=\frac{\frac{k_{c}}{1-f}-1}{\frac{k_{c}}{1-f}}=\frac{k_{e f f}-1}{k_{\text {eff }}}=\rho,
$$

Agora, se $k_{c}$ for substituído no lado direito da equação (09), obtêm-se a equação Inhour para o sistema núcleo-refletor:

$$
\rho=\omega \frac{\tau_{c}}{k_{e f f}(1-f)}+\omega \frac{f \tau_{r}}{k_{e f f}(1-f)\left(\tau_{r} \omega+1\right)}+\sum \frac{\beta_{i} \omega}{\omega+\lambda_{i}},
$$

A partir da equação (11), é possível definir o tempo de geração de nêutrons prontos no núcleo $\left(\Lambda_{c}\right)$ e o tempo de geração de nêutrons no refletor $\left(\Lambda_{\mathrm{r}}\right)$ em função do tempo de vida ponderado dos nêutrons no núcleo $\left(\tau_{c}\right)$ e em função do tempo de vida ponderado dos nêutrons no refletor $\left(\tau_{r}\right)$, respectivamente.

$$
\Lambda_{c}=\frac{\tau_{c}}{k_{e f f}(1-f)} \quad \text { e } \quad \Lambda_{r}=\frac{\tau_{r}}{k_{e f f}(1-f)}
$$

Assim, a equação (11) pode ser reescrita como:

$$
\rho=\omega \Lambda_{c}+\omega \frac{\Lambda_{r} f}{\left(\tau_{r} \omega+1\right)}+\sum \frac{\beta_{i} \omega}{\omega+\lambda_{i}}
$$

Similarmente às probabilidades de uma passagem, $\tau_{\mathrm{c}}$ e $\tau_{\mathrm{r}}$ representam, respectivamente, a expectativa de vida média do nêutron por passarem pela região do núcleo e do refletor. Cada nêutron do sistema aparecerá, em média, nessas regiões 1/(1$f)$ vezes. Assim, $\tau_{\mathrm{c}} /(1-f)$ e $\tau_{\mathrm{r}} /(1-f)$ representam o tempo total que um nêutron irá gastar na região do núcleo e do refletor, respectivamente, antes de ser retirado do sistema.

Deve-se ressaltar também, que para $f$ maior que zero, um termo adicional, que está associado ao refletor aparecerá na equação Inhour. Quando agrupados de acordo com a escala de tempo, é mais provável que este termo extra do refletor seja semelhante ao termo contendo o tempo de geração de nêutrons prontos no núcleo do que qualquer um dos termos dos nêutrons atrasados. Portanto, o tratamento do termo de retorno de 
nêutrons do refletor como um grupo extra de nêutrons atrasados pode não ser o mais apropriado e, na maior parte das situações, complicaria a interpretação dos resultados obtidos nos experimentos Rossi- $\alpha$ e também de fonte pulsada de nêutrons.

Por fim, analisando a equação (12), pode-se inferir que quanto menor o valor de $f$, ou seja, a medida que se aproximam de zero, os termos relacionados ao refletor desaparecem. Logo, a equação Inhour para um sistema de duas regiões se torna a equação Inhour de uma região (cinética pontual padrão). A interpretação física para o termo $f=0$ significa que a probabilidade de um nêutron migrar do núcleo para o refletor e, posteriormente, retornar ao núcleo, é zero. Por conta disso, não existe refletor no sistema.

A reatividade será calculada levando em consideração os parâmetros cinéticos do refletor e, assim, será possível analisar e estudar a contribuição dos nêutrons, que retornam do refletor para o núcleo. Após uma série de manipulações algébricas da equação (12), foi possível isolar a reatividade em função de todos os parâmetros de interesse.

$$
\rho=\left(\frac{\omega \tau_{c}\left(\tau_{r} \omega+1\right)+\omega f \tau_{r}+\left(\tau_{r} \omega+1\right)(1-f) \beta_{e f f}}{\omega \tau_{c}\left(\tau_{r} \omega+1\right)+\omega f \tau_{r}+\left(\tau_{r} \omega+1\right)(1-f)}\right)
$$

A equação Inhour para um sistema refletido possuirá apenas duas raízes, $\omega_{7} \mathrm{e}$ $\omega_{8}$. Explicitando a dependência de $\Lambda_{\mathrm{c}}$ e $\Lambda_{\mathrm{r}}$ em $\rho$, podemos resolver a equação (11) para tais raízes.

A equação do segundo grau obtida é dada por:

$$
\omega^{2}\left\{\tau_{c} \tau_{r}(1-\rho)\right\}+\omega\left\{(1-\rho)\left(\tau_{c}+\tau_{r} f\right)+\tau_{r}\left(\beta_{\text {eff }}-\rho\right)(1-f)\right\}+\left\{(1-f)\left(\beta_{e f f}-\rho\right)\right\}=0,
$$

de modo que as soluções das raízes são:

$$
\omega_{7,8}=\frac{1}{2 \tau_{c} \tau_{r}(1-\rho)}\left(\begin{array}{l}
-\left\lfloor(1-\rho)\left(\tau_{r} f+\tau_{c}\right)+\tau_{r}\left(\beta_{e f f}-\rho\right)(1-f)\right\rfloor \pm \\
\pm \sqrt{\left.(1-\rho)\left(\tau_{r} f+\tau_{c}\right)+\tau_{r}\left(\beta_{e f f}-\rho\right)(1-f)\right]^{2}-4 \tau_{c} \tau_{r}(1-f)(1-\rho)\left(\beta_{e f f}-\rho\right)}
\end{array}\right),
$$

Os sinais positivo e negativo da raiz quadrada da equação (15) se referem, respectivamente, a $\omega_{7}$ e $\omega_{8}$. 
A demonstração algébrica para a obtenção da equação (14) a partir da equação (11) está descrita no Anexo B deste trabalho. Deve-se ressaltar que também foram incluídos os testes de consistência que satisfazem a condição da equação do segundo grau da equação (14). Os valores dos parâmetros utilizados nos testes de consistência foram obtidos experimentalmente para os refletores de água leve, aço inox e água pesada. 


\section{TÉCNICA DE ROSSI-ALPHA}

A técnica Rossi- $\alpha$ foi sugerida pela primeira vez por Bruno Rossi, e a teoria estatística das cadeias de nêutrons foi heuristicamente desenvolvida por Feynman, de Hoffman e Serber [4].

Quando ocorre a contagem do primeiro nêutron oriundo de uma dada cadeia de fissão, em um dado instante inicial, $t=0$, existe uma probabilidade para que o detector, em um dado instante de tempo t posterior, detecte um dos dois tipos de eventos possíveis: um nêutron aleatório (ou seja, de uma cadeia de fissão diferente do primeiro nêutron) ou um nêutron correlacionado a esta mesma cadeia de fissão inicial (ou seja, um nêutron oriundo da mesma cadeia de fissão que produziu a primeira contagem em $t$ $=0)$.

A probabilidade de se detectar um evento não correlacionado é dada por $A \Delta t$, onde $A$ é a taxa de contagem média do detector e $\Delta t$ é o intervalo de tempo de realização da medida, ou seja, o tempo de abertura de um único canal do sistema de aquisição. Uma vez que a média da população de nêutrons prontos deve decair exponencialmente, a probabilidade de se detectar um evento relacionado a esta cadeia de fissão diminui de acordo com $e^{-\alpha t}$. Consequentemente, a probabilidade total para detectar um nêutron (aleatório ou relacionado a uma cadeia) num intervalo de tempo $\Delta t$ é:

$$
p(t)=A \Delta t+B e^{-\alpha t} \Delta t
$$

onde $A \Delta t$ representa as contagens de nêutrons não correlacionados e que podem ser removidos para deixar apenas o termo exponencial a partir da qual a constante de decaimento $\alpha$ pode ser determinada. Observa-se também que o termo relacionado aos eventos não correlacionados depende da taxa de fissão (ou seja, nível de potência em um reator no estado crítico ou a intensidade da fonte em um reator no regime subcrítico) enquanto os eventos correlacionados ou termo correlacionado são independentes da 
potência. Assim, diminuir a taxa de fissão irá acarretar no aumento da relação sinal ruído da medida.

Particularmente, quando existe a presença de um refletor no sistema, os dados experimentais podem ser descritos pela equação a seguir [29]:

$$
p(t)=A e^{-\omega_{7} t}+B e^{-\omega_{8} t}+C
$$

A equação (17) será utilizada pra a realização do ajuste de mínimos quadrados e obtermos os valores de $\omega_{7}$ e $\omega_{8}$.

A figura 4 ilustra uma curva de distribuição Rossi- $\alpha$ experimental segundo a equação (17).

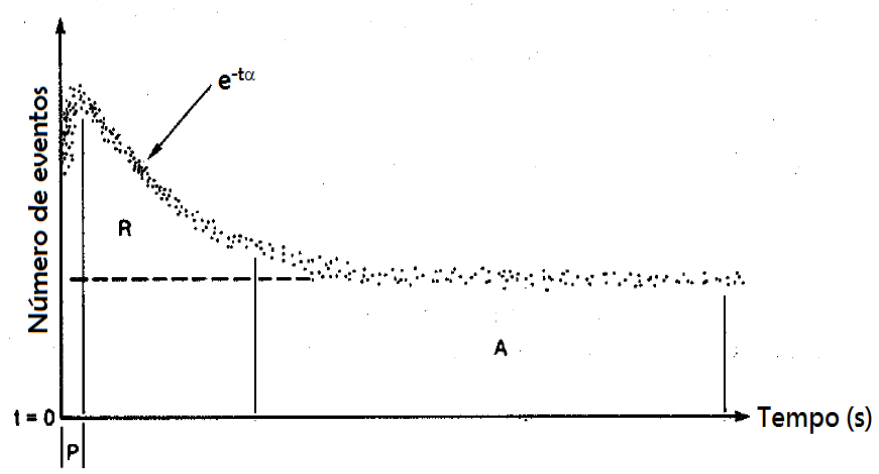

Figura 4 - Distribuição Rossi- $\alpha$ mostrando os eventos de nêutrons detectados em função do tempo em uma situação arbitrária. $\mathrm{R}$ representa os eventos correlacionados e A representa os eventos não correlacionados. A letra $\mathrm{P}$ no eixo do tempo mostra a região do tempo morto da eletrônica associada ao sistema de medida (detectores, amplificadores, mono canais).

Ao realizar as medidas Rossi- $\alpha$ com sistemas de aquisição mais modernos, onde o tempo morto da eletrônica é muito menor, a figura 4 passa a ser afetada apenas pelo tempo morto do detector. Nestas situações, os dados experimentais relacionados a esta região podem ser excluídos. No entanto, torna-se imprescindível a determinação do tempo morto dos detectores, pois a presença de dois modos de decaimentos exponenciais faz com que o refletor seja evidenciado em estados subcríticos próximo à região de tempo morto do detector. Por conta disso, a região de tempo morto deve ser bem conhecida para que os dados das curvas Rossi- $\alpha$ não sejam excluídos de forma 
errônea ou os dados referentes ao tempo morto seja levado em consideração na análise. O tempo morto dos detectores de nêutrons utilizados nesse trabalho foi obtido experimentalmente a partir de um procedimento experimental considerando uma fonte de nêutrons de Amerício-Berílio em conjunto com a técnica de Rossi- $\alpha$. Os resultados estão contidos no Anexo C. Este Anexo também trata sobre a caracterização dos novos detectores adquiridos para a mudança do núcleo do reator IPEN/MB-01 pelo protótipo do núcleo do Reator Multipropósito Brasileiro (RMB).

A figura 5 representa uma curva Rossi- $\alpha$ obtida experimentalmente para o núcleo contendo o refletor de água leve. O detector de ${ }^{3} \mathrm{He}$ foi utilizado para a realização desta medida, com os bancos de controle na posição de $17.5 \%$ retirados. Realizou-se o ajuste pelo método de mínimos quadrados empregando as equações com 01 modo e 02 modos de decaimento.

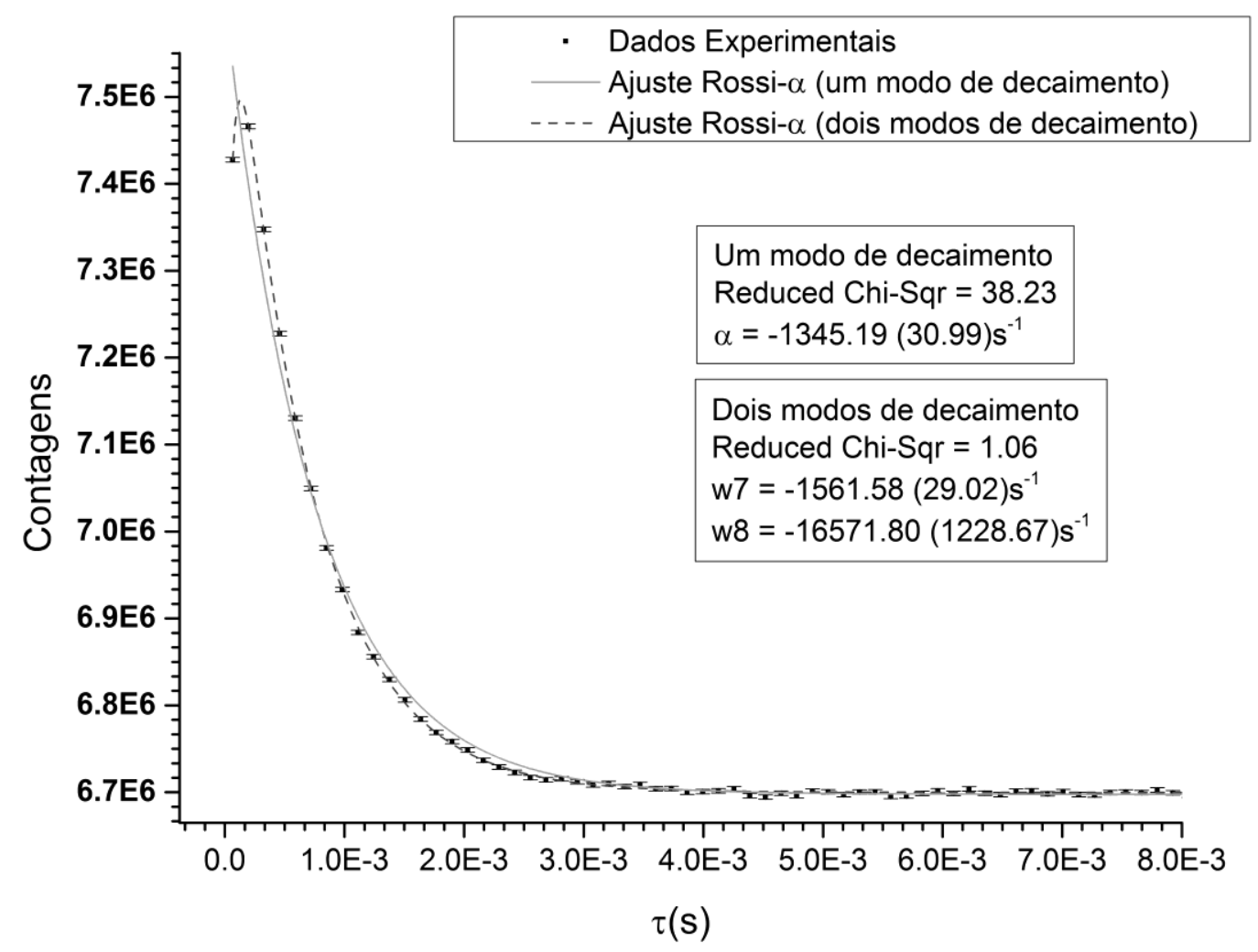

Figura 5 - Curva de distribuição Rossi- $\alpha$ adquirida com os bancos de controle na posição de $17.5 \%$ retirados e com refletor de água leve. 


\section{DENSIDADES ESPECTRAIS}

Informações sobre o comportamento dinâmico do reator podem ser obtidas estudando-se a sua resposta em relação a pequenas perturbações que ocorrem na reatividade. Em particular, conclusões a respeito da estabilidade do reator quando este está operando a um determinado nível de potência podem ser obtidas a partir da resposta de pequenas perturbações introduzidas no sistema. As características da resposta são então resumidas em termos da função transferência. O estudo desse tipo de função pode ser tanto experimental quanto teórico e é de grande importância para o controle de reatores nucleares. A primeira consideração na análise do aspecto da dinâmica de reatores ocorre quando a potência do reator é muito baixa (potência zero) e é influenciada por pequenas oscilações na reatividade.

Supondo que o sistema em questão esteja no estado crítico, sem a presença da fonte, e considerando que a reatividade se altera muito pouco; se a potência também variar pouco por conta desta pequena alteração da reatividade, as condições são tais que o processo de linearização das equações de cinética pontual pode ser aplicado [27].

Ao se trabalhar com função auto correlação, estamos lidando com o comportamento da função no domínio temporal. Uma abordagem alternativa seria trabalhar no domínio da frequência e separar o sinal nos seus componentes. Normalmente, para uma função não periódica, é necessário aplicar a transformada de Fourier para que a função seja convertida do domínio do tempo para o domínio da frequência, desde que esta represente um intervalo contínuo de frequência. No entanto, no caso em que um processo estacionário aleatório ou algum processo estocástico, definido por $x(t)$, não possa se tornar um valor arbitrariamente pequeno para um valor grande de $t$, as propriedades estatísticas devem manter-se constantes ao longo do tempo.

Portanto, $\int_{-\infty}^{\infty}|x(t)| d t$ não irá convergir, e a transformada de Fourier não existirá nessa situação [46]. 
Este problema pode ser contornado definindo uma nova função, chamada de Densidade Espectral, designada pelo símbolo $\Phi(w)$, como a transformada de Fourier da função Auto Correlação.

Existem várias técnicas que podem ser utilizadas para a medida da função transferência. Comumente introduz-se um sinal de entrada conhecido ao sistema e quantifica-se a resposta fornecida pelo sistema por conta deste sinal de entrada. A resposta (ou sinal de saída) de qualquer sistema físico para um sinal aplicado (sinal de entrada) a este sistema é expressa pela função de transferência. No presente trabalho, utiliza-se a função transferência [47] dada por:

$$
\Phi_{x x}(f)=\frac{A}{B^{2}+(2 \pi f)^{2}}+C
$$

onde $\Phi_{x x}(f)$ representa a APSD (Auto Power Spectral Density), $f$ a frequência, A e C são constantes determinadas pelo ajuste de mínimos quadrados. O parâmetro B é conhecido como constante de decaimento de nêutrons prontos [28, 47], usualmente denotado por $\alpha$, e é definido como:

$$
B=\alpha=\frac{\rho-\beta_{e f f}}{\Lambda}
$$

onde $\rho$ é a reatividade, $\beta_{\text {eff }}$ a fração de nêutrons atrasados e $\Lambda$ o tempo de geração de nêutrons prontos para o reator nuclear IPEN/MB-01 no estado próximo do crítico.

Através de $\alpha$, e por intermédio de análises subsequentes, é possível determinar experimentalmente alguns parâmetros cinéticos importantes como $\beta_{\text {eff, }} \Lambda$ e a razão $\beta_{\text {eff }} / \Lambda$; ou ainda realizar medidas de reatividade subcrítica. Por este motivo as equações (18) e (19) serão utilizadas para o cálculo da reatividade para cada etapa de movimentação das barras de controle durante os experimentos deste trabalho. No entanto, a teoria da densidade espectral contemplará no seu desenvolvimento apenas as 
equações de cinética pontual. Por conta disso, os valores da reatividade serão utilizados apenas como uma estimativa da reatividade, que é obtida pelo ajuste não linear pelo método de mínimos quadrados.

A figura 6 representa uma curva de Densidade Espectral do tipo APSD obtida experimentalmente para o núcleo contendo o refletor de água leve. $\mathrm{O}$ detector de ${ }^{3} \mathrm{He}$ foi utilizado para a realização desta medida, com os bancos de controle na posição de $17.5 \%$ retirados. Realizou-se o ajuste pelo método de mínimos quadrados empregando a equação (18).

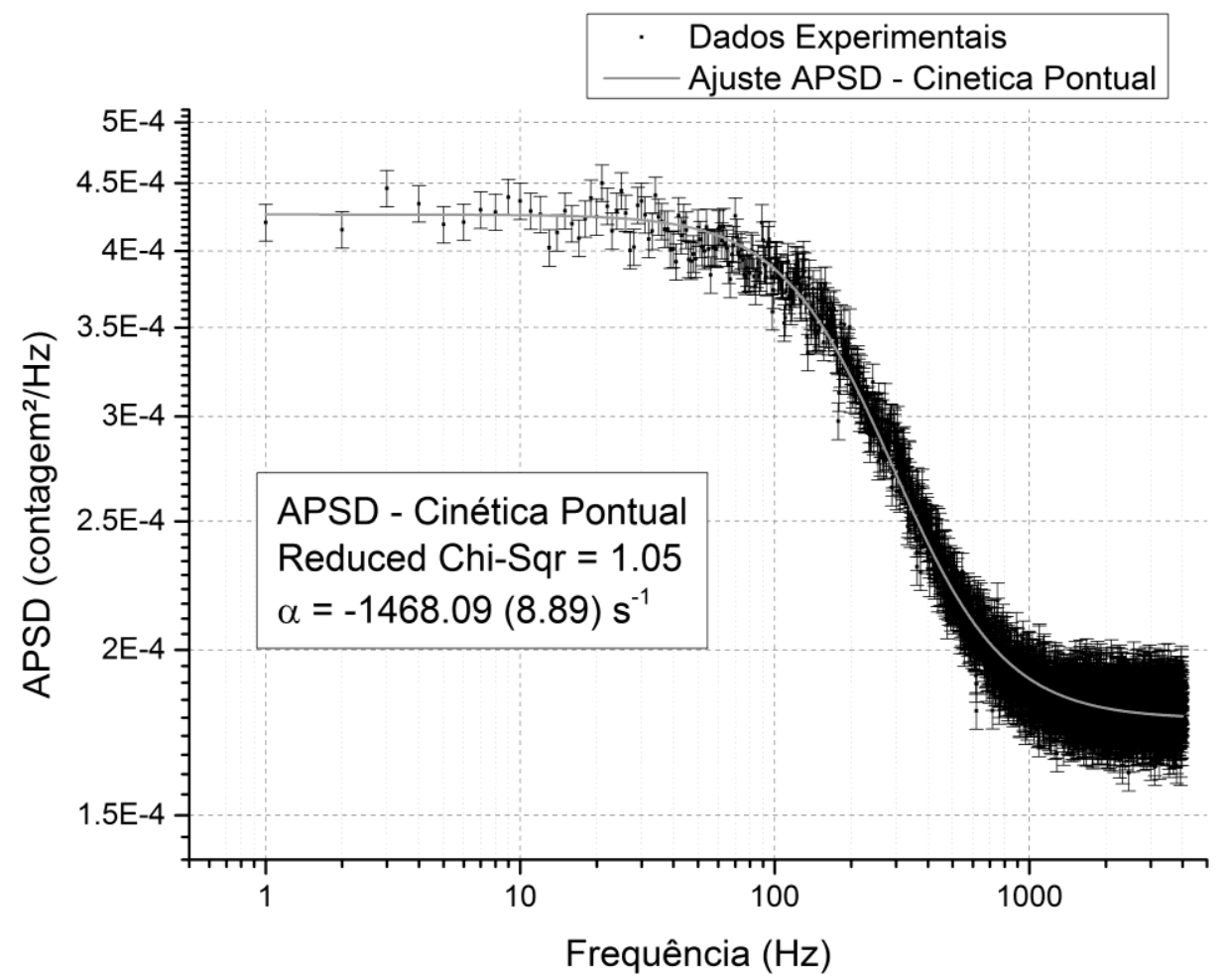

Figura 6 - Densidade espectral do tipo APSD adquirida com os bancos de controle na posição de $17.5 \%$ retirados e com refletor de água leve. 


\section{ANÁLISE DAS INCERTEZAS DA REATIVIDADE DO SISTEMA}

O formalismo geral para a análise de incertezas pode ser dado pela teoria de propagação de erros [48]. Para uma determinada função $w$ que depende das variáveis $x$, $y, z, \ldots$, as propriedades dessa função podem ser determinadas por estas variáveis. Podese escrever a dependência de $w$ em função de $x, y, z, \ldots$, como:

$$
w=f(x, y, z, \ldots)
$$

A variância da função $\sigma_{w}^{2}$ de $w$ em termos das variâncias de $\sigma_{x}^{2}, \sigma_{y}^{2}, \sigma_{z}^{2}, \ldots$, para as variáveis $x, y, z, \ldots$, na qual podem ser medidas ou calculadas, são obtidas a partir da equação de propagação de erros:

$$
\begin{aligned}
\sigma_{w}^{2} & =\left(\frac{\partial w}{\partial x}\right)^{2} \sigma_{x}^{2}+\left(\frac{\partial w}{\partial y}\right)^{2} \sigma_{y}^{2}+\left(\frac{\partial w}{\partial z}\right)^{2} \sigma_{z}^{2}+\cdots \\
& +2\left(\frac{\partial w}{\partial x}\right)\left(\frac{\partial w}{\partial y}\right) \sigma_{x y}^{2}+2\left(\frac{\partial w}{\partial x}\right)\left(\frac{\partial w}{\partial z}\right) \sigma_{x z}^{2}+2\left(\frac{\partial w}{\partial y}\right)\left(\frac{\partial w}{\partial z}\right) \sigma_{y z}^{2}+\cdots
\end{aligned}
$$

Os primeiros três termos são as médias dos quadrados dos desvios ponderados pelo quadrado das derivadas parciais, e podem ser considerados como a média dos quadrados dos desvios em $w$ produzido pelas incertezas em $\mathrm{x}, \mathrm{y}$ e $\mathrm{z}$, respectivamente. Os últimos três termos são as médias dos termos cruzados envolvendo produtos de desvios em duas variáveis diferentes, ponderadas pelo produto das derivadas parciais correspondentes.

Os desvios das incertezas dos parâmetros cinéticos do refletor foram obtidos a partir do ajuste de mínimos quadrados. O software de análise de dados OriginLab ${ }^{\mathrm{TM}}$ foi empregado para a realização dos ajustes.

A partir da teoria de propagação de erros foi possível obter as incertezas dos valores das reatividades. A teoria de propagação de erros foi aplicada na equação (13) de reatividade, como pode-se ver a seguir: 


$$
\begin{gathered}
\rho=\left(\frac{\omega \tau_{c}\left(\tau_{r} \omega+1\right)+\omega f \tau_{r}+\left(\tau_{r} \omega+1\right)(1-f) \beta_{e f f}}{\omega \tau_{c}\left(\tau_{r} \omega+1\right)+\omega f \tau_{r}+\left(\tau_{r} \omega+1\right)(1-f)}\right) \\
\sigma_{\rho}^{2}=\left(\frac{\partial \rho}{\partial \omega}\right)^{2} \sigma_{\omega}^{2}+\left(\frac{\partial \rho}{\partial \tau_{c}}\right)^{2} \sigma_{\tau_{c}}^{2}+\left(\frac{\partial \rho}{\partial \tau_{r}}\right)^{2} \sigma_{\tau_{r}}^{2}+\left(\frac{\partial \rho}{\partial f}\right)^{2} \sigma_{f}^{2}+\left(\frac{\partial \rho}{\partial \beta_{e f f}}\right)^{2} \sigma_{\beta_{e f f}}^{2}+ \\
+2\left(\frac{\partial \rho}{\partial \tau_{c}}\right)\left(\frac{\partial \rho}{\partial \tau_{r}}\right) \sigma_{\tau_{c} \tau_{r}}^{2}+2\left(\frac{\partial \rho}{\partial \tau_{c}}\right)\left(\frac{\partial \rho}{\partial f}\right) \sigma_{\tau_{c} f}^{2}+2\left(\frac{\partial \rho}{\partial \tau_{r}}\right)\left(\frac{\partial \rho}{\partial f}\right) \sigma_{\tau_{r} f}^{2},
\end{gathered}
$$

Derivadas parciais de $\rho$ em função de $\omega, \tau_{\mathrm{c}}, \tau_{\mathrm{r}}, f$ e $\beta_{\text {eff: }}$ :

$$
\begin{aligned}
& \frac{\partial \rho}{\partial \omega}=\left(\frac{\tau_{c}\left(\tau_{r} \omega+1\right)+\omega \tau_{r} \tau_{c}+f \tau_{r}+\tau_{r}(1-f) \beta_{e f f}}{\omega \tau_{c}\left(\tau_{r} \omega+1\right)+\omega f \tau_{r}+\left(\tau_{r} \omega+1\right)(1-f)}\right)- \\
& \left(\frac{\left[\tau_{c}\left(\tau_{r} \omega+1\right)+\omega \tau_{r} \tau_{c}+f \tau_{r}+\tau_{r}(1-f)\right]\left[\omega \tau_{c}\left(\tau_{r} \omega+1\right)+\omega f \tau_{r}+\left(\tau_{r} \omega+1\right)(1-f) \beta_{e f f}\right]}{\left(\omega \tau_{c}\left(\tau_{r} \omega+1\right)+\omega f \tau_{r}+\left(\tau_{r} \omega+1\right)(1-f)\right)^{2}}\right) \\
& \frac{\partial \rho}{\partial \tau_{c}}=\left(\frac{\omega\left(\tau_{r} \omega+1\right)}{\left[\omega \tau_{c}\left(\tau_{r} \omega+1\right)+\omega f \tau_{r}+\left(\tau_{r} \omega+1\right)(1-f)\right]}\right)- \\
& \frac{\partial \rho}{\partial \tau_{r}}=\frac{\left(\frac{\omega\left(\tau_{r} \omega+1\right)\left[\omega \tau_{c}\left(\tau_{r} \omega+1\right)+\omega f \tau_{r}+\left(\tau_{r} \omega+1\right)(1-f) \beta_{e f f}\right]}{\left(\omega \tau_{c}\left(\tau_{r} \omega+1\right)+\omega f \tau_{r}+\left(\tau_{r} \omega+1\right)(1-f)\right)^{2}}\right)}{\left[\omega \tau_{c}\left(\tau_{r} \omega+1\right)+\omega f \tau_{r}+\left(\tau_{r} \omega+1\right)(1-f)\right]}- \\
& \left(\begin{array}{c}
\left.\frac{\left(\omega^{2} \tau_{c}+\omega f+\omega(1-f)\right)\left[\omega \tau_{c}\left(\tau_{r} \omega+1\right)+\omega f \tau_{r}+\left(\tau_{r} \omega+1\right)(1-f) \beta_{e f f}\right.}{2} \omega f\right) \\
\left(\omega \tau_{c}\left(\tau_{r} \omega+1\right)+\omega f \tau_{r}+\left(\tau_{r} \omega+1\right)(1-f)\right)^{2}
\end{array}\right) \\
& \frac{\partial \rho}{\partial f}=\left(\begin{array}{c}
\left.\frac{\partial \rho}{\omega \beta_{e f f}}=\frac{\left(\omega \tau_{c}\left(\tau_{r} \omega+1\right)+\omega f \tau_{r}+\left(\tau_{r} \omega+1\right)(1-f)\right)}{\left(\tau_{r} \omega+1\right)+\omega f \tau_{r}+\left(\tau_{r} \omega+1\right)(1-f)}\right)+\left(\frac{\omega \tau_{c}\left(\tau_{r} \omega+1\right)+\omega f \tau_{r}+\left(\tau_{r} \omega+1\right)(1-f) \beta_{e f f}}{\left(\omega \tau_{c}\left(\tau_{r} \omega+1\right)+\omega f \tau_{r}+\left(\tau_{r} \omega+1\right)(1-f)\right)^{2}}\right.
\end{array}\right)
\end{aligned}
$$

As matrizes de covariância e correlação e a análise das incertezas considerando estes valores estão descritas no Anexo A deste trabalho. 


\section{APLICAÇÃO DAS EQUAÇÕES DE AJUSTE PARA A OBTENÇÃO DOS PARÂMETROS CINÉTICOS DO REFLETOR}

Será descrito o processo de ajuste utilizando sucessivas iterações pelo método de mínimos. No método Levenberg-Marquardt $[49,50]$ a convergência para uma solução é completamente dependente da escolha inicial dos valores dos parâmetros. De tal forma, foram adotadas algumas condições para a convergência [48].

A primeira é considerar que a variação do chi-quadrado, $\chi^{2}$, se torna desprezível quando a variação por grau de liberdade, $\chi_{v}^{2}$, for menor que $1 \%$ para duas iterações consecutivas. A segunda diz respeito à escolha dos valores iniciais dos parâmetros. Se os parâmetros iniciais não forem escolhidos cuidadosamente, o método iterativo de mínimos quadrados pode convergir para um mínimo local com um valor inapropriado de $\chi^{2}$, normalmente um valor muito grande. Se isto acontecer, deve-se recomeçar o processo com novos valores iniciais dos parâmetros ou definir requisitos de convergência mais rígidos (por exemplo, $\Delta \chi_{v}^{2}<0.1 \%$ ) e executar novamente o processo com o objetivo de o programa alcançar o mínimo adequado. Algumas vezes é conveniente observar o processo de busca e realizar o corte manualmente quando aparecer um mínimo estável. Para a condição manual, o próprio software irá indicar que o chi-quadrado não pode ser reduzido.

Adotando estas condições, dada uma estimativa inicial para o conjunto de parâmetros ajustados $\tau_{c}, \tau_{r}$ e $f$, o procedimento a seguir foi desenvolvido para obter-se o melhor valor dos parâmetros ajustados:

i) Utilizar a equação exponencial com dois modos de decaimento para realizar o ajuste das curvas : $\operatorname{Rossi}(\tau)=A e^{-\omega 7 \tau}+B e^{-\omega 8 \tau}+C$

ii) Calcular $\chi_{v, i}^{2}$, onde $i$ representa a $i$-th iteração;

iii) Obter uma primeira estimativa do valor da reatividade utilizando a raiz $\omega_{7}$ obtida do ajuste com a equação da cinética pontual: $\rho=\omega \Lambda+\beta_{\text {eff }}$; 
iv) Executar o algoritmo Levenberg-Marquardt até que o mínimo aceitável seja encontrado. Mais precisamente, a rotina retorna para o melhor valor de ajuste quando $\chi_{v}^{2}$ for menor do que $1 \%$ entre duas iterações sucessivas;

v) Substituir a equação analítica das raízes da equação Inhour na equação exponencial com dois modos de decaimento descrita no item $i$.

$$
\omega_{7,8}=\frac{1}{2 \tau_{c} \tau_{r}(1-\rho)}\left(\begin{array}{l}
-\left[(1-\rho)\left(\tau_{r} f+\tau_{c}\right)+\tau_{r}\left(\beta_{e f f}-\rho\right)(1-f)\right]_{ \pm} \\
\pm \sqrt{\left[(1-\rho)\left(\tau_{r} f+\tau_{c}\right)+\tau_{r}\left(\beta_{e f f}-\rho\right)(1-f)\right]^{2}-4 \tau_{c} \tau_{r}(1-f)(1-\rho)\left(\beta_{e f f}-\rho\right)}
\end{array}\right) ;
$$

vi) Manter fixo os valores de $\left\{A, B, C, \beta_{\text {eff }}\right.$ e $\left.\rho\right\}$ e permitir que os parâmetros $\left\{\tau_{c}, \tau_{r}, f\right\}$ variem durante o ajuste;

vii) Rodar novamente o algoritmo de Levenberg-Marquardt até que o mínimo adequado seja encontrado. A rotina retornará com o melhor valor ajustado para os parâmetros $\left\{\tau_{c}, \tau_{r}, f\right\}$;

viii) Recalcular o valor da reatividade a partir da equação Inhour de duas regiões: $\rho=\left(\frac{\omega \tau_{c}\left(\tau_{r} \omega+1\right)+\omega f \tau_{r}+\left(\tau_{r} \omega+1\right)(1-f) \beta_{e f f}}{\omega \tau_{c}\left(\tau_{r} \omega+1\right)+\omega f \tau_{r}+\left(\tau_{r} \omega+1\right)(1-f)}\right)$;

ix) Calcular $\chi_{v, i+1}^{2}$ do ajuste final;

x) Se $\left|\chi_{v, i+1}^{2}-\chi_{v, i}^{2}\right|>1 \%$, atualizar a solução de teste e voltar para (i);

xi) Se $\left|\chi_{v, i+1}^{2}-\chi_{v, i}^{2}\right|<1 \%$, a convergência do método foi alcançada.

Esta rotina é realizada repetidamente até que o método tenha convergido e satisfeito a condição $(x i)$. Sendo assim, foram determinados desta forma os tempos de geração de nêutrons do núcleo $\left(\tau_{\mathrm{c}}\right)$ e do refletor $\left(\tau_{\mathrm{r}}\right)$ e a fração de retorno do refletor $(f)$. Os valores de reatividade do sistema obtidos através dos parâmetros cinéticos do refletor utilizando a metodologia descrita nesta seção estão expressos na seção de resultados. 


\section{PROCEDIMENTO EXPERIMENTAL}

Os experimentos realizados neste trabalho abrangem três configurações distintas e independentes. A primeira configuração de água leve $\left(\mathrm{H}_{2} \mathrm{O}\right)$ como moderador e refletor, onde nenhum material adicional foi posicionado no interior do núcleo, pois o reator nuclear IPEN/MB-01 apresenta em seu projeto a água leve como moderador. $\mathrm{Na}$ segunda configuração utilizou-se o refletor de aço inox, disponibilizado no formato de placas. Na terceira e última configuração uma caixa contendo água pesada $\left(\mathrm{D}_{2} \mathrm{O}\right)$ foi utilizada como refletor. Todos os experimentos levaram em conta a configuração padrão de 28x26 varetas combustíveis e os refletores de água pesada e de aço inox foram posicionados na face oeste do núcleo do reator.

A inserção de reatividade negativa para a obtenção dos estados subcríticos ocorreu por conta do procedimento de movimentação dos bancos de barras de controle, denominadas por BC\#1 e BC\#2 (Banco de Controle número 1 e número 2). Este procedimento foi escolhido por conta da sua praticidade operacional de se realizar a variação da reatividade. As posições de BC\#1 e BC\#2 no estado crítico variam para cada um dos três experimentos. Por conta disso, cada um dos três experimentos terá inicio em uma posição distinta. Os passos de inserção dos bancos de controle também variaram dependendo do experimento

Os detectores de nêutrons de ${ }^{3} \mathrm{He}$ e $\mathrm{BF}_{3}$ do tipo contador proporcional foram utilizados para a realização das medidas de densidades espectrais e para a obtenção das curvas de distribuição Rossi- $\alpha$. Os detectores foram posicionados na face leste do núcleo do reator, do lado oposto ao refletor.

As características destes detectores são descritas a seguir:

BF : Reuter Stokes, modelo: RS-P1-0820-201.

Sensibilidade à nêutrons térmicos: $~ 13 \mathrm{cps} / \mathrm{nv}$

Pressão do gás: $40 \mathrm{~cm} \mathrm{Hg}$

${ }^{3}$ He: Centronic, modelo: $31-\mathrm{He} 3-380 / 25$

Sensibilidade à nêutrons térmicos: $54 \mathrm{cps} / \mathrm{nv}$

Pressão do gás: $380 \mathrm{~cm} \mathrm{Hg}$ 
${ }^{3}$ He: Centronic, modelo: 50-He3-760/38E

Sensibilidade à nêutrons térmicos: $186 \mathrm{cps} / \mathrm{nv}$

Pressão do gás: $760 \mathrm{~cm} \mathrm{Hg}$

A figura 7 representa uma visão axial do núcleo do reator e ilustra a posição do detector (círculo preto) na face leste. A linha pontilhada representa a região central do núcleo no sentido leste-oeste.

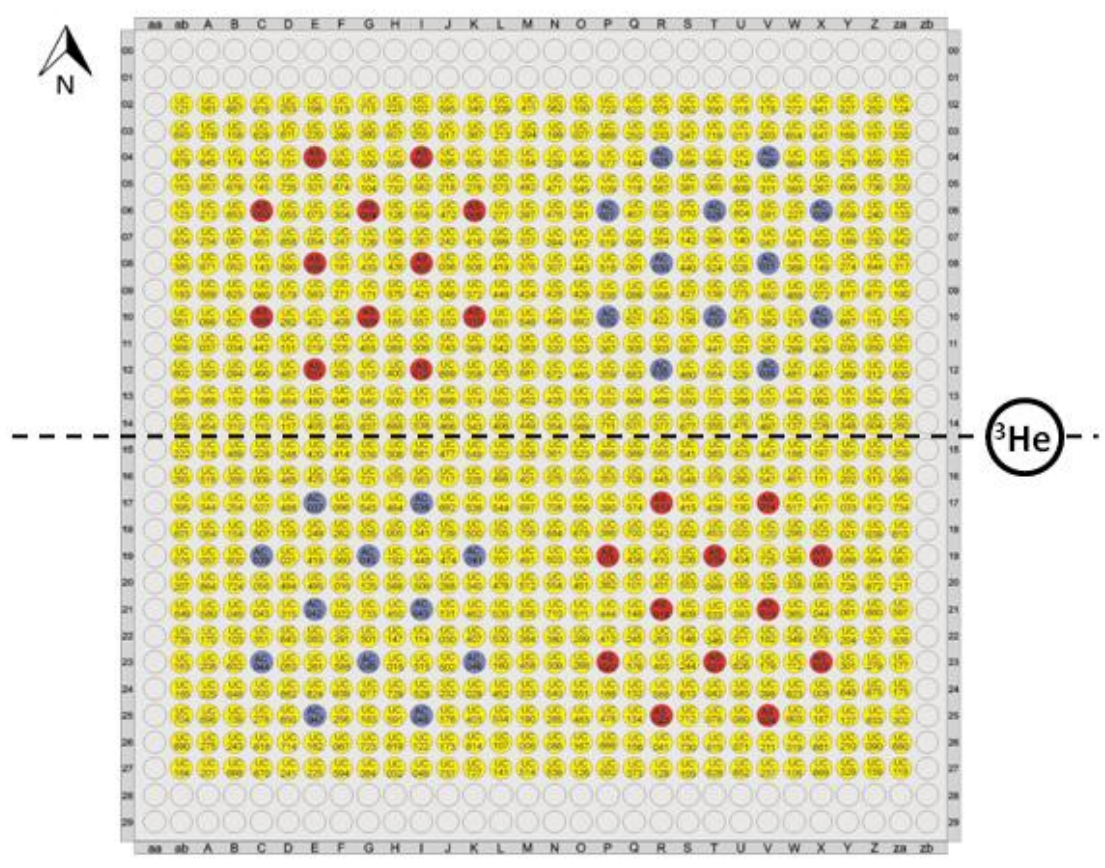

Figura 7 - Visão axial da configuração experimental do núcleo do reator IPEN/MB-01.

\subsection{ARRANJO EXPERIMENTAL - AÇO INOX (SS-304)}

Refletores pesados compostos por aço inox (Stainless Steel - SS), com espessuras de aproximadamente $10 \mathrm{~cm}$, estão sendo considerados como uma alternativa em Reatores de Água Leve (Light Water Reactors - LWR). Com isso, este tipo de material é empregado para limitar a perda radical de nêutrons rápidos do núcleo, mais especificamente por retro espalhamento. As principais melhorias esperadas por este tipo de refletor estão diretamente relacionadas com a melhora da reflexão de nêutrons, ou seja, a economia de material físsil pode ser observada em alguns casos implicando na melhoria da distribuição da potência radial e a redução da fluência de nêutrons rápidos 
através do vaso de pressão. Este último caso está diretamente associado a outras frentes do conhecimento, tais como a engenharia de materiais de danos por radiação, que a partir de estudos indiretos como estes, podem aumentar a vida útil de operação de uma planta nuclear.

Experimentos similares ao deste trabalho já foram realizados utilizando aço inox (SS-304) em outras instalações nucleares, porém o que torna este experimento único é como este material é disposto no núcleo do reator. Neste experimento o aço inox foi confeccionado no formato de placas ao invés de grandes blocos, permitindo o estudo do efeito do refletor em função da sua espessura, pois as placas podem ser inseridas individualmente para se obter a espessura de interesse. Apesar deste trabalho não focar na variação da espessura do refletor, foi adotada a espessura máxima, na qual se constatou, a partir de outros trabalhos, a inserção da reatividade positiva com a utilização de um determinado número de placas. Além disso, foi realizada a avaliação e a aprovação deste tipo de experimento para as placas de aço inox no International Reactor Physics Experiments (IRPhE).

O experimento com refletor de aço inox que foi realizado no reator IPEN/MB-01 abrangeu uma série de configurações subcríticas empregando a configuração padrão de $28 \times 26$ varetas combustíveis. O refletor foi constituído por 32 placas de aço inox e posicionado na face oeste do reator, como ilustra a figura 8. Cada uma das placas apresenta espessura de aproximadamente $3.0 \mathrm{~mm}$, sendo que todas as 32 placas permaneceram inseridas no núcleo durante todas as posições de bancos de controle deste experimento. As dimensões das placas podem ser observadas na ilustração da figura 9. 


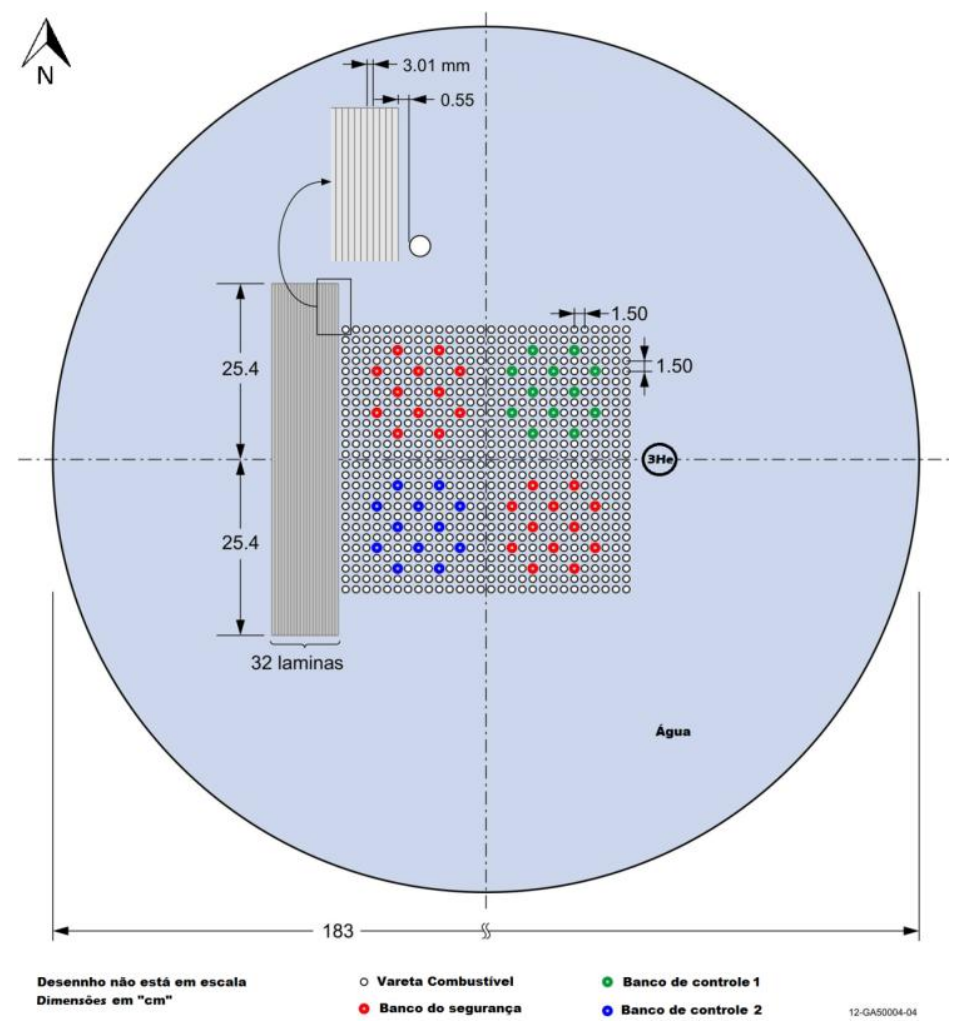

Figura 8 - Visão axial da configuração experimental do núcleo do reator IPEN/MB-01. Ao lado esquerdo da figura (face oeste) estão representadas as 32 placas de aço inox. A linha pontilhada representa a região central do núcleo e à direita (face leste) está posicionado o detector de hélio-3.
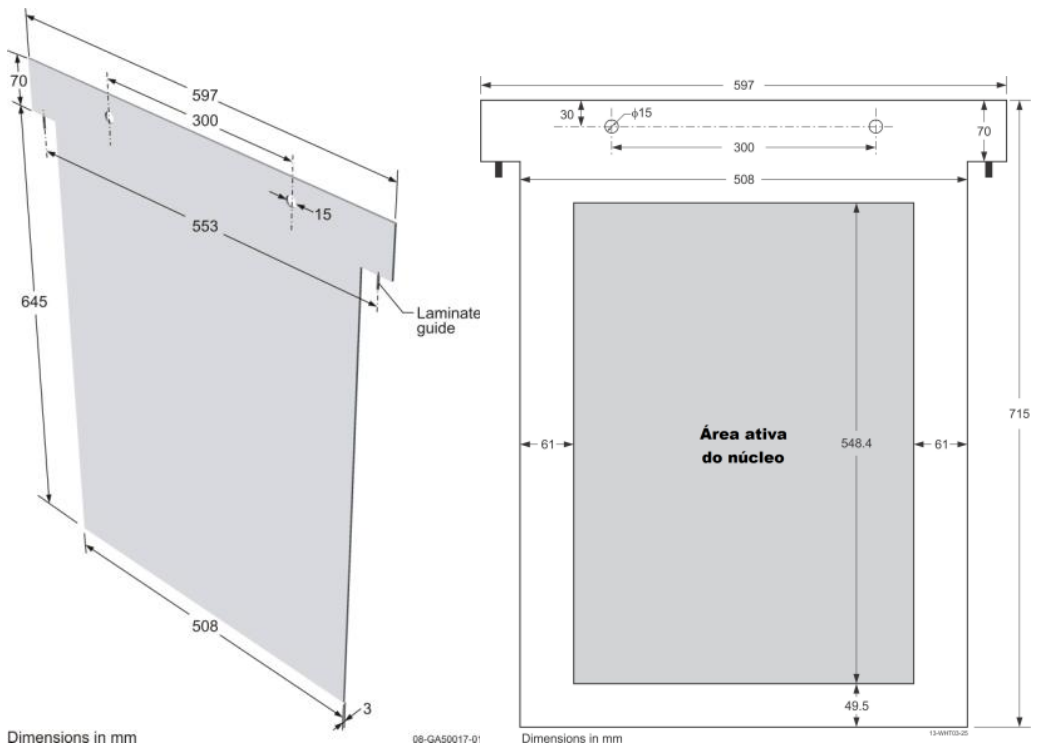

Figura 9 - Á esquerda está representada uma ilustração da placa de aço inox com as respectivas dimensões, dadas em centímetros. A figura da direita ilustra uma visão frontal da placa de aço inox em comparação com a região ativa do núcleo do reator nuclear IPEN/MB-01. 
O procedimento de segurança para a execução de experimentos em reatores nucleares $[51,52]$ prevê que um modelo (mock-up) do experimento seja construído antes do experimento ser executado. No caso deste experimento das placas de aço inox, todo o aparato experimento foi montado em tamanho real antes da sua execução.

Um mecanismo foi especialmente projetado e montado na face oeste do núcleo do reator para manter suspensas as placas de aço inox SS-304 na região do refletor. O suporte foi construído com aço inox e foi fixado na estrutura da instalação. O projeto de confecção do suporte das lâminas no núcleo foi construído baseando-se nas medidas reais do núcleo. O peso máximo que a estrutura do reator suporta é de aproximadamente $300 \mathrm{~kg}$. Esta é a razão pela qual o numero máximo de 32 placas de aço inox ter sido utilizado. A figura 10.a mostra o mock-up feito de madeira, especialmente para mostrar os detalhes do experimento e servir como protótipo para mostrar como o mecanismo e as placas devem ser montadas para a realização do experimento. A distância entre a região ativa do núcleo (última fileira de varetas combustíveis) e as placas é controlada por parafusos especiais posicionados no suporte. Há quatro parafusos: dois na face mostrada na figura 10.a e dois na parte de trás da montagem em madeira, nas mesmas posições.

A figura 10.b ilustra o sistema de compressão que foi desenvolvido para evitar que possíveis bolhas de ar fiquem presas entre as placas, fazendo com que as 32 placas sejam consideradas como um grande bloco. Este sistema é constituído por um disco de polietileno que está conectado com uma manivela acoplada a um trilho. A reatividade inserida pelo disco de compressao de polietileno e pelo suporte das placas foi medida e apresentou um valor de $5.5 \mathrm{pcm}$, pode-se considerar como um pequeno efeito na variação de reatividade, contudo será considerada como bias nas medidas teóricas e simulações. A manivela pode girar em ambos os sentidos, horário e anti-horário, para comprimir ou descomprimir as placas, respectivamente. Os detalhes podem ser observados na figura 10.b. As placas de aço inox são posicionadas em canaletas para garantir que as mesmas permaneçam na mesma posição durante a execução de todo o experimento. Na figura 10.c observa-se a indicação do local das canaletas.

Na figura 10 temos as fotos de todo o aparato experimental mock-up montado na sala de controle do reator. As fotos foram tiradas com algumas placas de aço inox acopladas ao suporte. 

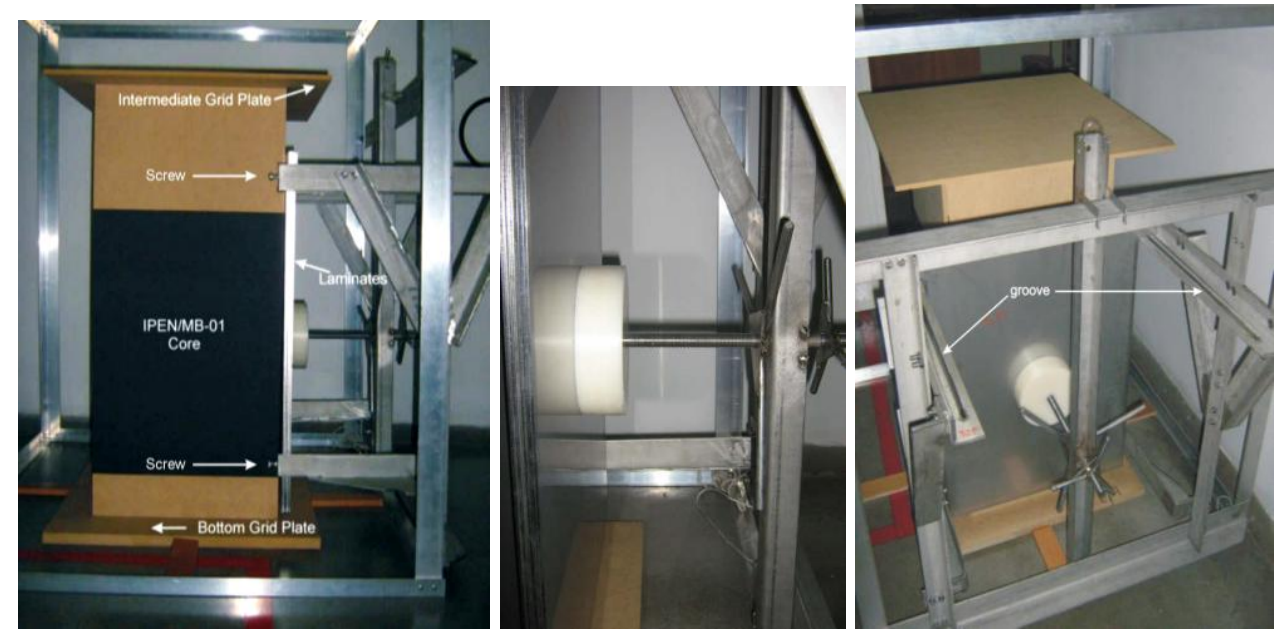

Figura 10 - (a) A foto da esquerda mostra a montagem do aparato experimental mock-up com algumas placas de aço inox. (b) A foto do meio representa o sistema de compressão das placas. (c) $\mathrm{Na}$ foto da direita pode-se observar o local de encaixe das placas (canaletas ou groove).

A tabela 1 contém os dados das massas e espessura de cada uma das placas utilizadas no experimento. Elas foram numeradas na mesma sequência que foram introduzidas no núcleo. O valor médio da espessura das placas e o respectivo desvio padrão é $3.01 \pm 0.01 \mathrm{~mm}$.

A composição química, densidade do material e dados geométricos das placas foram todos medidos no Instituto de Pesquisas Energéticas e Nucleares - IPEN/CNEN $-\mathrm{SP}$.

Tabela 1 - Massa e espessura das placas de aço inox SS-304

\begin{tabular}{ccc}
\hline Identificação da placa & Massa $(\mathbf{g})$ & $\begin{array}{c}\text { Espessura } \\
(\mathbf{m m})\end{array}$ \\
\hline $01 \mathrm{~F}$ & $8843.0(0.1)$ & $3.02(0.01)$ \\
$02 \mathrm{~F}$ & $8818.7(0.1)$ & $3.01(0.01)$ \\
$03 \mathrm{~F}$ & $8845.0(0.1)$ & $3.02(0.01)$ \\
$04 \mathrm{~F}$ & $8789.3(0.1)$ & $3.01(0.01)$ \\
$05 \mathrm{~F}$ & $8803.3(0.1)$ & $3.01(0.01)$ \\
$06 \mathrm{~F}$ & $8788.1(0.1)$ & $3.01(0.01)$ \\
$07 \mathrm{~F}$ & $8791.0(0.1)$ & $3.00(0.01)$ \\
$08 \mathrm{~F}$ & $8776.1(0.1)$ & $3.01(0.01)$ \\
$09 \mathrm{~F}$ & $8807.8(0.1)$ & $3.02(0.01)$ \\
$10 \mathrm{~F}$ & $8826.0(0.1)$ & $3.01(0.01)$ \\
$11 \mathrm{~F}$ & $8794.0(0.1)$ & $3.00(0.01)$ \\
$12 \mathrm{~F}$ & $8780.0(0.1)$ & $3.00(0.01)$ \\
$13 \mathrm{~F}$ & $8829.0(0.1)$ & $3.02(0.01)$ \\
$14 \mathrm{~F}$ & $8773.4(0.1)$ & $3.01(0.01)$ \\
$15 \mathrm{~F}$ & $8831.4(0.1)$ & $3.03(0.01)$ \\
$16 \mathrm{~F}$ & $8804.6(0.1)$ & $3.02(0.01)$ \\
$17 \mathrm{~F}$ & $8779.4(0.1)$ & $3.02(0.01)$
\end{tabular}




\begin{tabular}{lll}
$18 \mathrm{~F}$ & $8791.1(0.1)$ & $3.01(0.01)$ \\
$19 \mathrm{~F}$ & $8818.0(0.1)$ & $3.02(0.01)$ \\
$20 \mathrm{~F}$ & $8789.5(0.1)$ & $3.02(0.01)$ \\
$21 \mathrm{~F}$ & $8799.5(0.1)$ & $3.01(0.01)$ \\
$22 \mathrm{~F}$ & $8783.2(0.1)$ & $3.00(0.01)$ \\
$23 \mathrm{~F}$ & $8804.7(0.1)$ & $3.00(0.01)$ \\
$24 \mathrm{~F}$ & $8796.0(0.1)$ & $3.01(0.01)$ \\
$25 \mathrm{~F}$ & $8813.6(0.1)$ & $3.01(0.01)$ \\
$26 \mathrm{~F}$ & $8806.3(0.1)$ & $3.01(0.01)$ \\
$27 \mathrm{~F}$ & $8825.3(0.1)$ & $3.02(0.01)$ \\
$28 \mathrm{~F}$ & $8793.3(0.1)$ & $3.01(0.01)$ \\
$29 \mathrm{~F}$ & $8799.8(0.1)$ & $3.02(0.01)$ \\
$30 \mathrm{~F}$ & $8847.3(0.1)$ & $3.02(0.01)$ \\
$31 \mathrm{~F}$ & $8828.7(0.1)$ & $3.04(0.01)$ \\
$32 \mathrm{~F}$ & $8848.0(0.1)$ & $3.02(0.01)$ \\
\hline
\end{tabular}

Durante a execução do experimento, os bancos de segurança foram mantidos totalmente retirados do núcleo do reator. A distribuição da temperatura no núcleo e no refletor de todo o experimento foi medida e controlada por um conjunto de doze termopares e a média das temperaturas foi de $21.00 \pm 0.04{ }^{\circ} \mathrm{C}$. A importância de se manter a temperatura em torno de $21^{\circ} \mathrm{C}$ se dá pelo fato que as seções de choque e dados nucleares obtidos para as simulações computacionais utilizando o método de Monte Carlo, pelo código de física de reatores MCNP5 [53], são obtidas para esta temperatura. Caso contrário, deveria ser necessário recalculá-las para os novos valores de temperatura utilizando o código de tratamento de seções de choque NJOY [54]. 


\subsection{ARRANJO EXPERIMENTAL - ÁGUA PESADA $\left(\mathrm{D}_{2} \mathrm{O}\right)$}

O experimento com refletor de água pesada $\left(\mathrm{D}_{2} \mathrm{O}\right)$ foi elaborado com o intuito de se inserir uma caixa de alumínio, com 61.65 litros de volume interno, contendo água pesada na face oeste do núcleo do reator. Este experimento tem como objetivo dar continuidade aos experimentos de reatividade subcrítica com vários refletores no reator IPEN/MB-01. Assim, pretende-se concluir o banco de dados das medidas Rossi- $\alpha$ com o refletor de água pesada e estudar o efeito do refletor sobre o tempo de vida dos nêutrons nas regiões do núcleo e do refletor.

Uma vez que o deutério apresenta uma seção de choque de absorção menor que a do hidrogênio, o deutério diminui a energia do nêutron mais rapidamente para a faixa térmica da reação de fissão, com uma perda de nêutrons muito pequena [55]. A água pesada é extensivamente utilizada como refletor em reatores como HANARO, JRR-3, MITR e OPAL devido a sua alta economia de nêutrons quando comparada com outros materiais refletores como a água leve, berílio e grafite [56, 57, 58, 59]. Por conta disso, ao empregarmos este tipo de refletor aos experimentos deste projeto, foi possível realizar uma analise detalhada sobre o efeito de refletores em estados de reatividade subcrítica.

As características de pureza da água pesada são fundamentais para a realização de experimentos com este tipo de refletor [60]. Por conta disso uma análise química da concentração molar foi realizada pela Empresa "Neuquina de Servicios de Ingenieria" (ENSI), na Argentina. $\mathrm{O}$ resultado apresentado para a concentração molar de $\mathrm{D}_{2} \mathrm{O}$ foi de $99.49 \pm 0.02 \%$. A água pesada utilizada nos experimentos é proveniente do Centro de Desenvolvimento da Tecnologia Nuclear - CDTN. Este material foi doado pelo CDTN em 09/12/2009, com número de registro 11138 [61].

O experimento com refletor de água pesada realizado no reator IPEN/MB-01 abrangeu uma série de configurações subcríticas, onde a configuração padrão de 28x26 varetas combustíveis foi utilizada. Como já mencionado, o refletor foi constituído por uma caixa de alumínio contendo água pesada e posicionado na face oeste do reator. $\mathrm{O}$ 
refletor possui o formato de uma caixa prismática e foi construído com chapas de alumínio e detalhes externos sobre a caixa de alumínio podem ser vistos na figura 11.

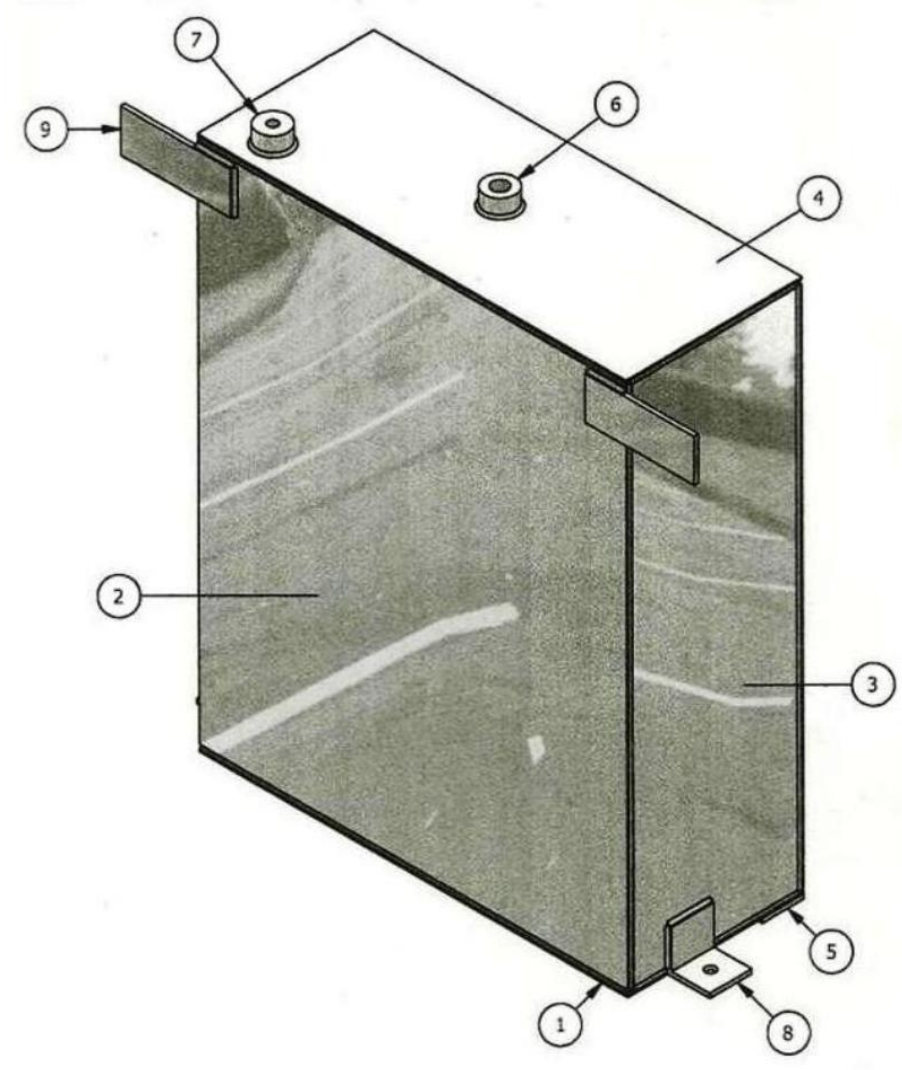

\begin{tabular}{|c|c|c|}
\hline 1 & Fundo & Ch: \#5,0 × 508 × 210 mm Alumínio 5052 \\
\hline 2 & Chapa: Posterior/Anterior & Ch: $\# 5,0$ × 620 × 508 mm Alumínio 5052 \\
\hline 3 & Chapa La & Ch: \#5,0 × $620 \times 200$ \\
\hline 4 & Tampa & Ch: \#5,0 × 508 × $210 \mathrm{~mm}$ Alumínio 5052 \\
\hline 5 & Apoio In & Ch: $\# 5,0 \times 50 \times 50 n$ \\
\hline 6 & Bocal Superior 1/2" NPT & Br. $\phi 36$ × 25 mm Aluminio 6351 \\
\hline 7 & Respiro 1/4" NPT & Br. $\phi 36$ × 25 mm Aluminio 6352 \\
\hline 8 & Aba de Fixação & Ch: $\# 5,0 \times 50 \times 50 \mathrm{~m}$ \\
\hline 9 & Aba Superior & Ch: \#5,0 x 130 x $50 \mathrm{~mm}$ Alumínio 5052 \\
\hline 10 & Reforço Interno & Ch: \#5,0 × $200 \times 25$ mm Alumínio 5052 \\
\hline
\end{tabular}

Figura 11 - Caixa refletora vista em perspectiva, dimensões das chapas de alumínio e indicações das partes que a constituem [61].

O detalhamento das dimensões do refletor está contido na figura 12. A espessura das chapas é de $5.0 \mathrm{~mm}$ e o volume interno da caixa é de aproximadamente 61.65 litros. Esta caixa possui válvulas de escape que servem para suspiro, dreno e transferências de água. 

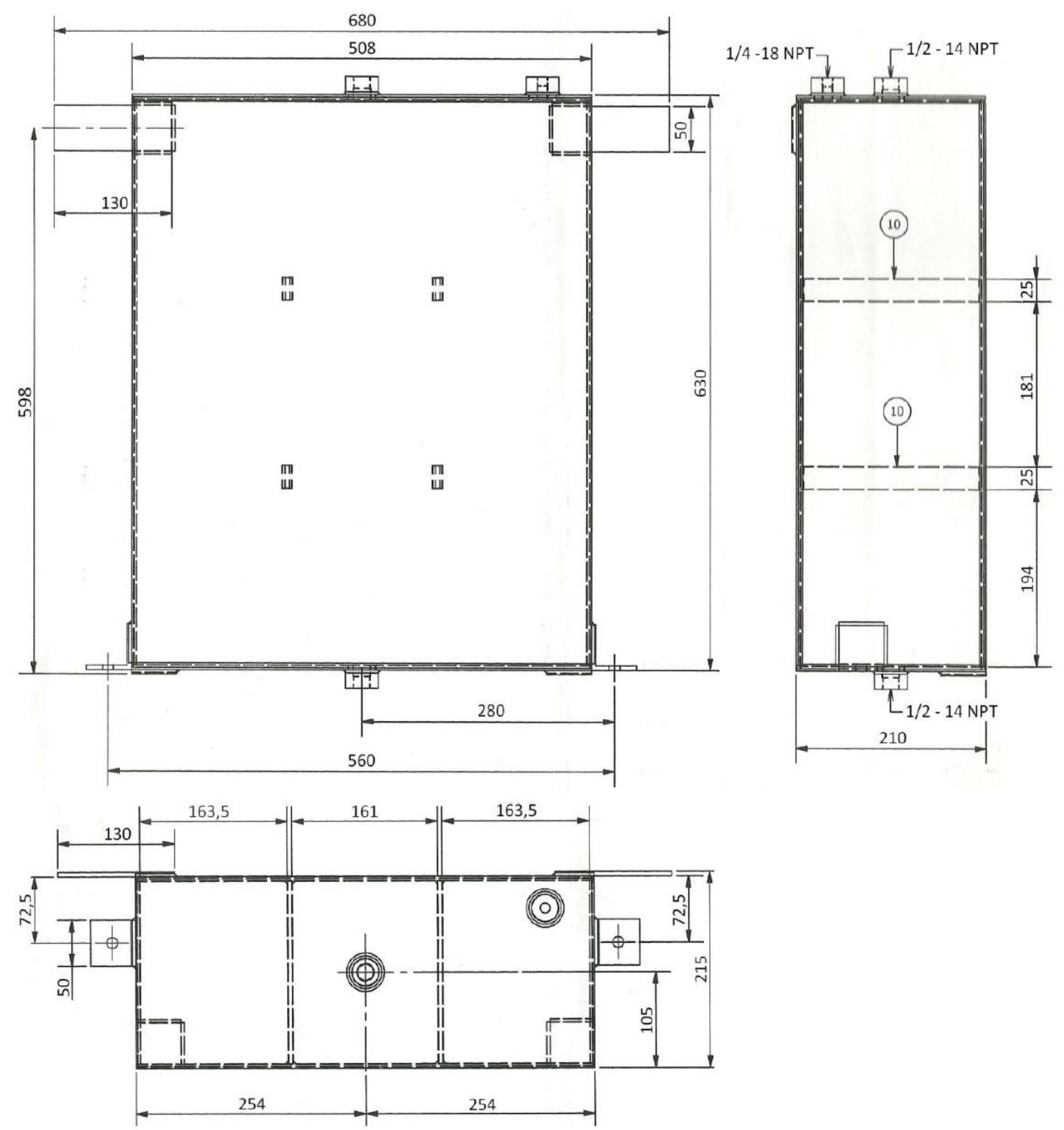

Figura 12 - Vista superior, laterais da caixa refletora [61].

Uma ilustração tridimensional do posicionamento da caixa de água pesada instalada no interior do tanque moderador, na face oeste e adjacente ao núcleo está representada pela figura 13 . 


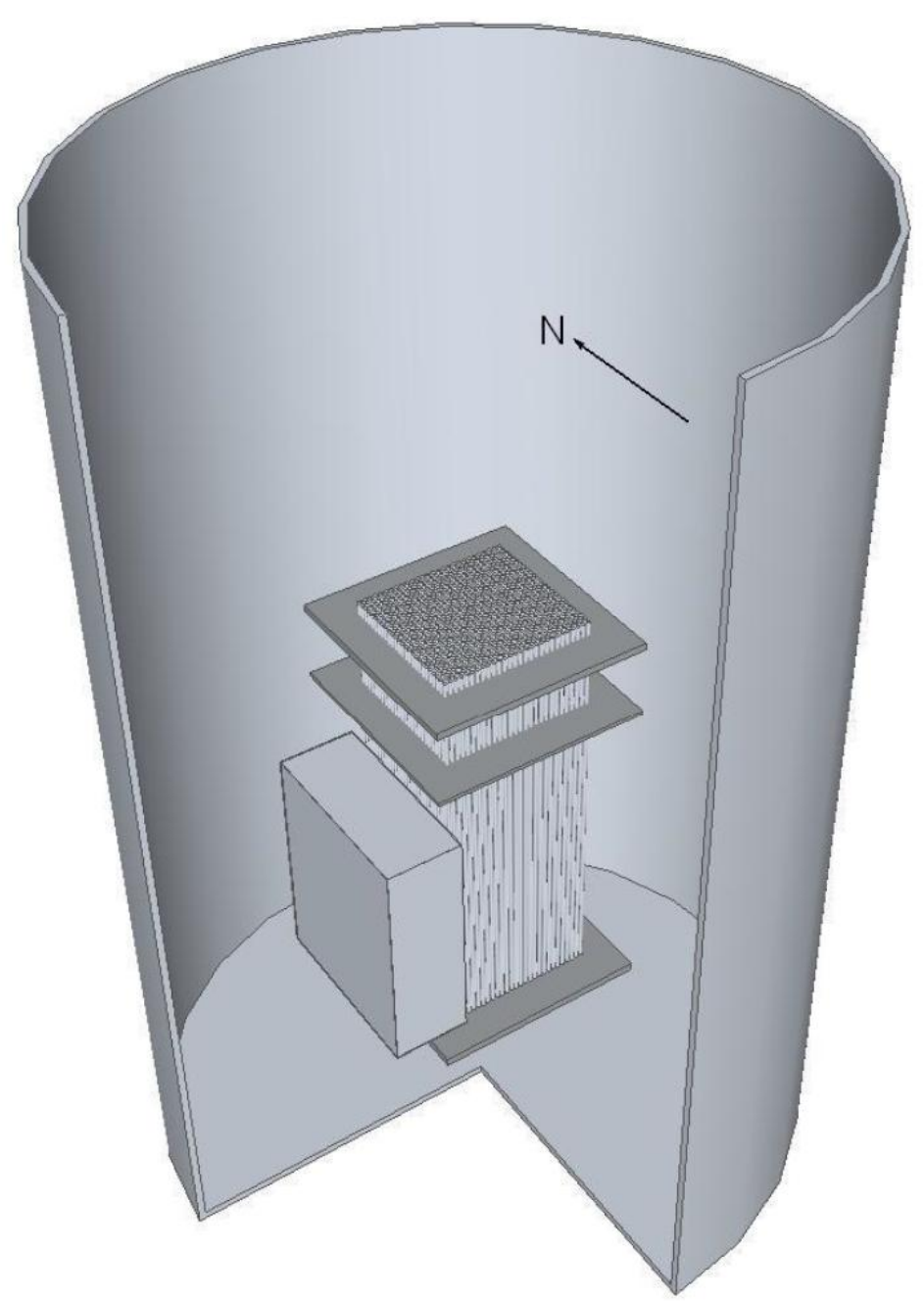

Figura 13 - Ilustração tridimensional mostrando um corte do tanque moderador onde se encontra o núcleo e o posicionamento da caixa de água pesada na face oeste [61].

O alumínio foi escolhido para a construção da caixa por conta das suas propriedades físicas relacionadas às seções de choque de absorção e de espalhamento de nêutrons térmicos. Para o alumínio, estas seções de choque são muito baixas para a faixa de energia dos nêutrons térmicos. Os valores são $\sigma_{\mathrm{a}}=0.24 \mathrm{~b}$ e $\sigma_{\mathrm{s}}=1.40 \mathrm{~b}$ [62]. Por conta disso, pode-se dizer que o alumínio apresenta baixíssima probabilidade de interação com os nêutrons térmicos. Analogamente, seria o mesmo que dizer que a caixa é transparente aos nêutrons térmicos, minimizando as interferências no fluxo de nêutrons do reator.

Primeiramente, a caixa refletora vazia foi instalada e fixada no suporte estrutural da lateral do núcleo do reator. Foram utilizados parafusos e calços para tal finalidade. 
Para o enchimento da caixa refletora com água pesada, utilizou-se o reservatório auxiliar de água pesada com mesmo volume que da caixa refletora, posicionado externamente ao núcleo. Acoplou-se o reservatório auxiliar a um sistema de ar comprimido. Após a conexão entre as caixas refletora e auxiliar, por um sistema de mangueiras e válvulas, foi introduzido o ar comprimido para bombear a água contida no reservatório auxiliar para a caixa refletora, até a transferência total da água pesada de um reservatório para o outro. Durante o processo não foi detectado nenhum tipo de vazamento nas conexões, mangueiras e válvulas. A figura 14 ilustra o procedimento descrito acima.

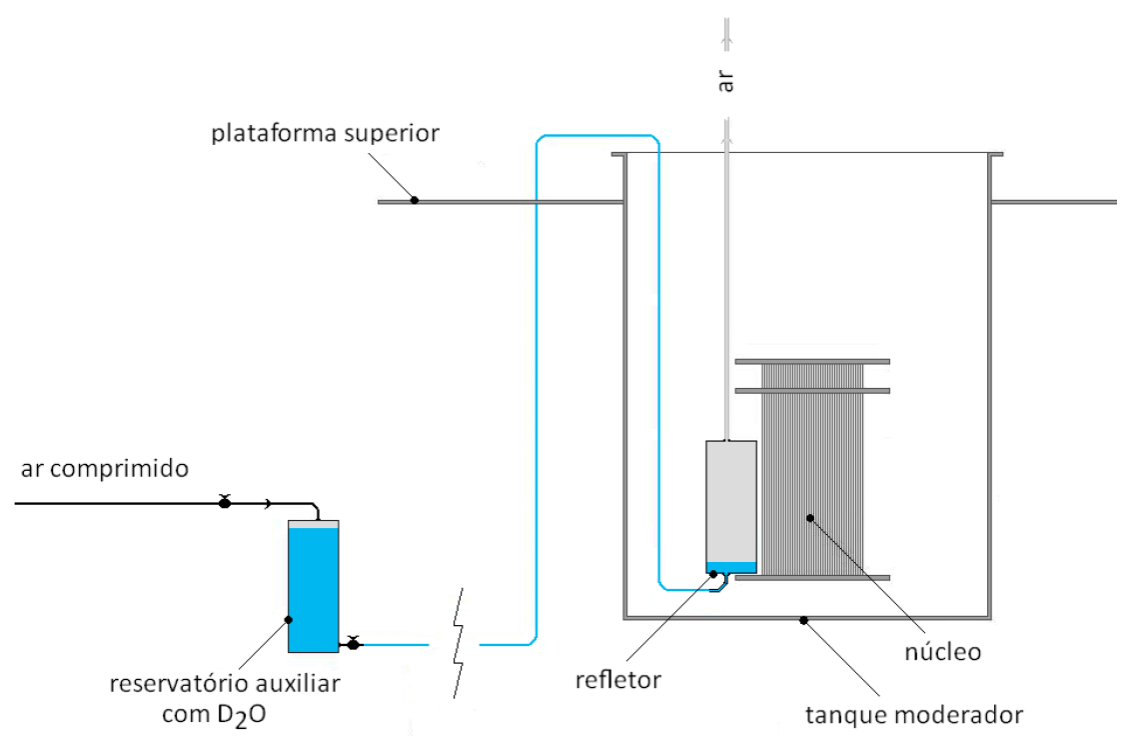

Figura 14 - Ilustração do procedimento de enchimento da caixa refletora com água pesada [61].

Após o enchimento da caixa refletora com $\mathrm{D}_{2} \mathrm{O}$, os experimentos de reatividade subcrítica aplicando-se as técnicas de analise de ruído de nêutrons foram iniciados. 


\section{RESULTADOS}

Os resultados de reatividade obtidos a partir do código computacional MCNP5 para as três configurações do núcleo estão expressos no gráfico da figura 15. Os valores de reatividade calculados pelo MCNP5 e os obtidos experimentalmente pela equação Inhour de duas regiões estão contidos nas tabelas 8, 9 e 10 da seção 10.4. As simulações foram realizadas com a inserção simultânea dos bancos de controle, com passos de $2.5 \%$. Para o calculo da reatividade simulada utilizou-se o fator de multiplicação $k_{\text {eff }}$.

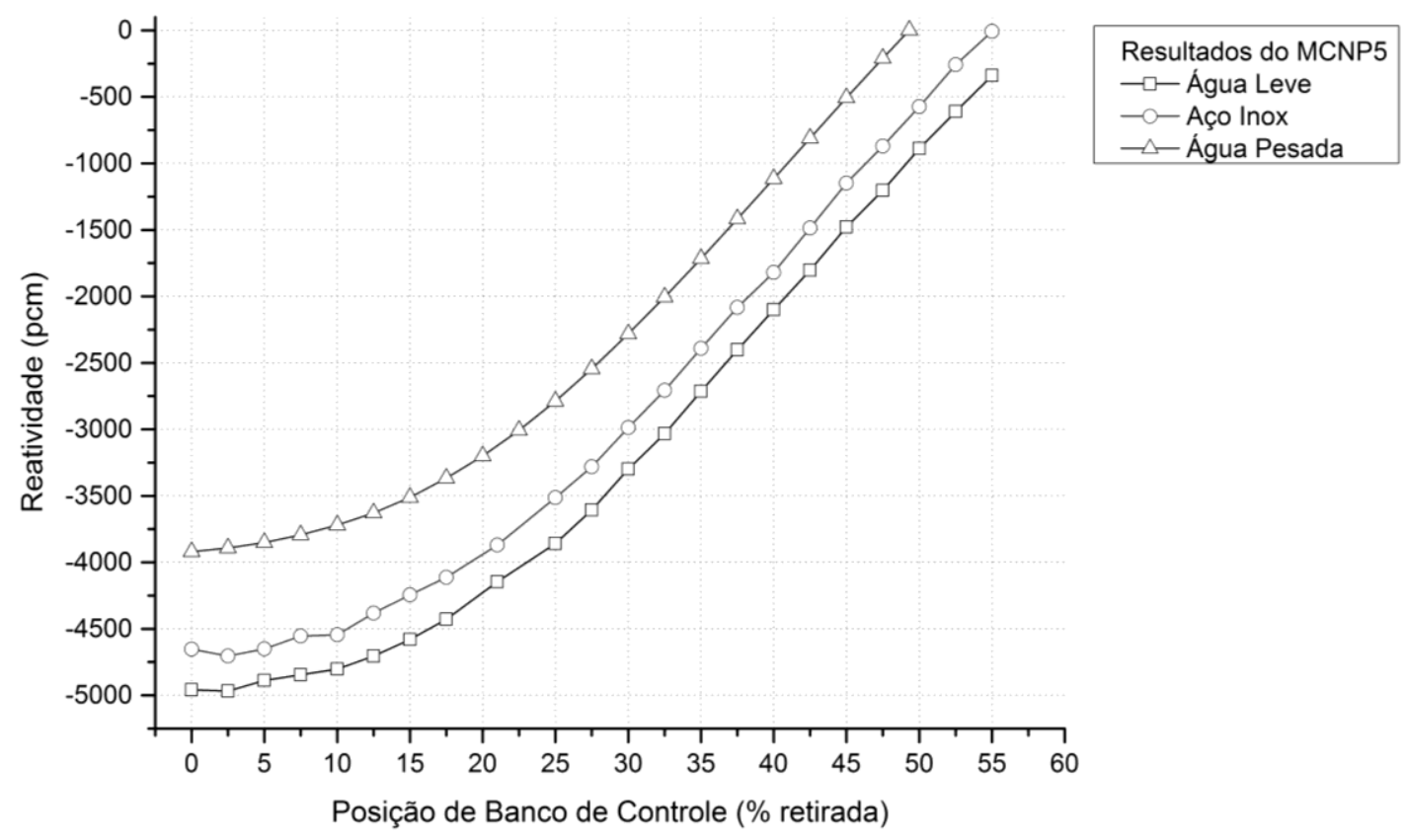

Figura 15 - Valores das reatividades obtidos pela simulação do código computacional MCNP5 para as três configurações do núcleo. Núcleo padrão, com refletor de água leve (quadrado), com refletor de aço inox (círculo) e com refletor de água pesada (triangulo). 


\section{1 ÁGUA LEVE}

Os resultados de reatividade obtidos a partir da equação Inhour de duas regiões para o experimento como o refletor de água leve estão representados na figura 16. Os bancos de controle foram inseridos simultaneamente a partir do estado crítico em passos de $2.5 \%$, porém os resultados apresentados levam em consideração apenas as curvas de distribuição Rossi-a onde os dois modos de decaimento exponencial foram evidenciados. Por conta disto, a posição inicial considerada dos bancos de controle foi de $32.5 \%$ e a final de $0.0 \%$ (totalmente inseridos). Além disso, a figura 16 também contém os valores de reatividade obtidos a partir do ajuste das curvas de densidades espectrais pela equação de cinética pontual. Na tabela 2 estão representados os valores dos parâmetros cinéticos do refletor $\left(\tau_{c}, \tau_{r}\right.$ e $\left.f\right)$, para o núcleo com refletor de água leve.

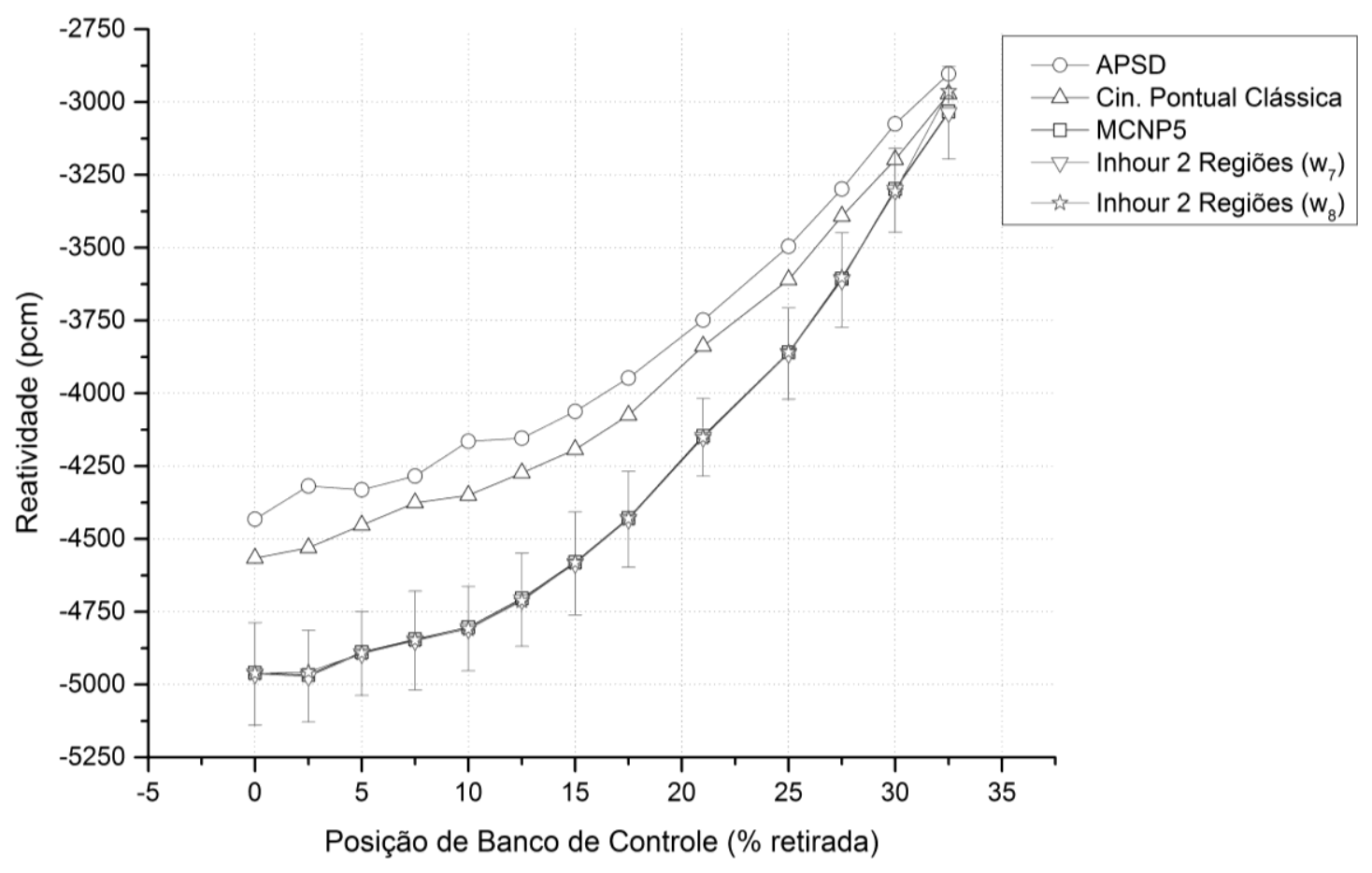

Figura 16 - Valores de reatividade para o núcleo padrão com refletor de água leve. 
Tabela 2 - Dados dos parâmetros cinéticos do refletor - configuração padrão com refletor de água leve.

\begin{tabular}{cccc}
\hline $\begin{array}{c}\text { Bancos de controle } \\
\text { (\% retirada) }\end{array}$ & $\boldsymbol{\boldsymbol { \tau } _ { \mathbf { c } }}$ & $\boldsymbol{\tau}_{\mathbf{r}}$ & $\boldsymbol{f}$ \\
& $(\boldsymbol{\mu s})$ & $(\boldsymbol{\mu s})$ & $(\mathbf{1 E - 3})$ \\
\hline 32.5 & $30.93(0.98)$ & $68.98(2.00)$ & $7.22(0.97)$ \\
30.0 & $30.92(0.91)$ & $63.37(1.95)$ & $11.99(0.99)$ \\
27.5 & $29.52(0.85)$ & $69.58(1.04)$ & $20.33(0.75)$ \\
25.0 & $29.61(0.81)$ & $65.53(1.18)$ & $23.90(0.98)$ \\
21.0 & $29.09(0.56)$ & $64.12(5.42)$ & $27.99(0.51)$ \\
17.5 & $28.72(0.71)$ & $64.81(6.79)$ & $29.50(0.65)$ \\
15.0 & $28.38(0.80)$ & $66.48(6.20)$ & $30.15(0.48)$ \\
12.5 & $28.19(0.74)$ & $67.96(8.48)$ & $31.96(0.64)$ \\
10.0 & $27.94(0.63)$ & $67.33(8.70)$ & $33.00(0.67)$ \\
7.5 & $27.98(0.79)$ & $71.30(9.34)$ & $31.86(0.64)$ \\
5.0 & $27.88(0.63)$ & $63.43(6.95)$ & $33.12(0.68)$ \\
2.5 & $28.61(0.71)$ & $62.83(8.13)$ & $33.99(0.69)$ \\
0.0 & $28.24(0.81)$ & $56.07(5.84)$ & $33.89(0.67)$ \\
\hline
\end{tabular}

Foram calculados os valores de reatividade $(\mathrm{pcm})$ do termo referente ao refletor da equação Inhour de duas regiões - equação (11). Estes resultados estão expressos na tabela 3 .

Tabela 3 - Reatividade calculada para o termo referente ao refletor de água leve

\begin{tabular}{|c|c|}
\hline $\begin{array}{c}\text { Bancos de controle } \\
\text { (\% retirada })\end{array}$ & $\rho_{\text {refletor }}=\frac{\omega f \tau_{r}}{k_{\text {eff }}(1-f)\left(\tau_{r} \omega+1\right)}$ \\
\hline 32.5 & -65.13 \\
\hline 30.0 & -105.23 \\
\hline 27.5 & -218.65 \\
\hline 25.0 & -253.60 \\
\hline 21.0 & -312.69 \\
\hline 17.5 & -357.44 \\
\hline 15.0 & -391.10 \\
\hline 12.5 & -435.77 \\
\hline 10.0 & -457.59 \\
\hline 7.5 & -473.26 \\
\hline 5.0 & -440.16 \\
\hline 2.5 & -441.27 \\
\hline 0.0 & -396.27 \\
\hline
\end{tabular}




\subsection{AÇO INOX}

Os resultados de reatividade obtidos a partir da equação Inhour de duas regiões para o experimento como com refletor de aço inox estão representados na figura 17. Os bancos de controle foram inseridos simultaneamente a partir do estado crítico em passos de $2.5 \%$, porém os resultados apresentados levam em consideração apenas as curvas de distribuição Rossi-a onde os dois modos de decaimento exponencial foram evidenciados. Por conta disto, a posição inicial considerada dos bancos de controle foi de $32.5 \%$ e a final de $0.0 \%$ (totalmente inseridos). Além disso, a figura 17 também contém os valores de reatividade obtidos a partir do ajuste das curvas de densidades espectrais pela equação de cinética pontual. Na tabela 4 estão representados os valores dos parâmetros cinéticos do refletor $\left(\tau_{c}, \tau_{r}\right.$ e $\left.f\right)$, para o núcleo com refletor de aço inox.

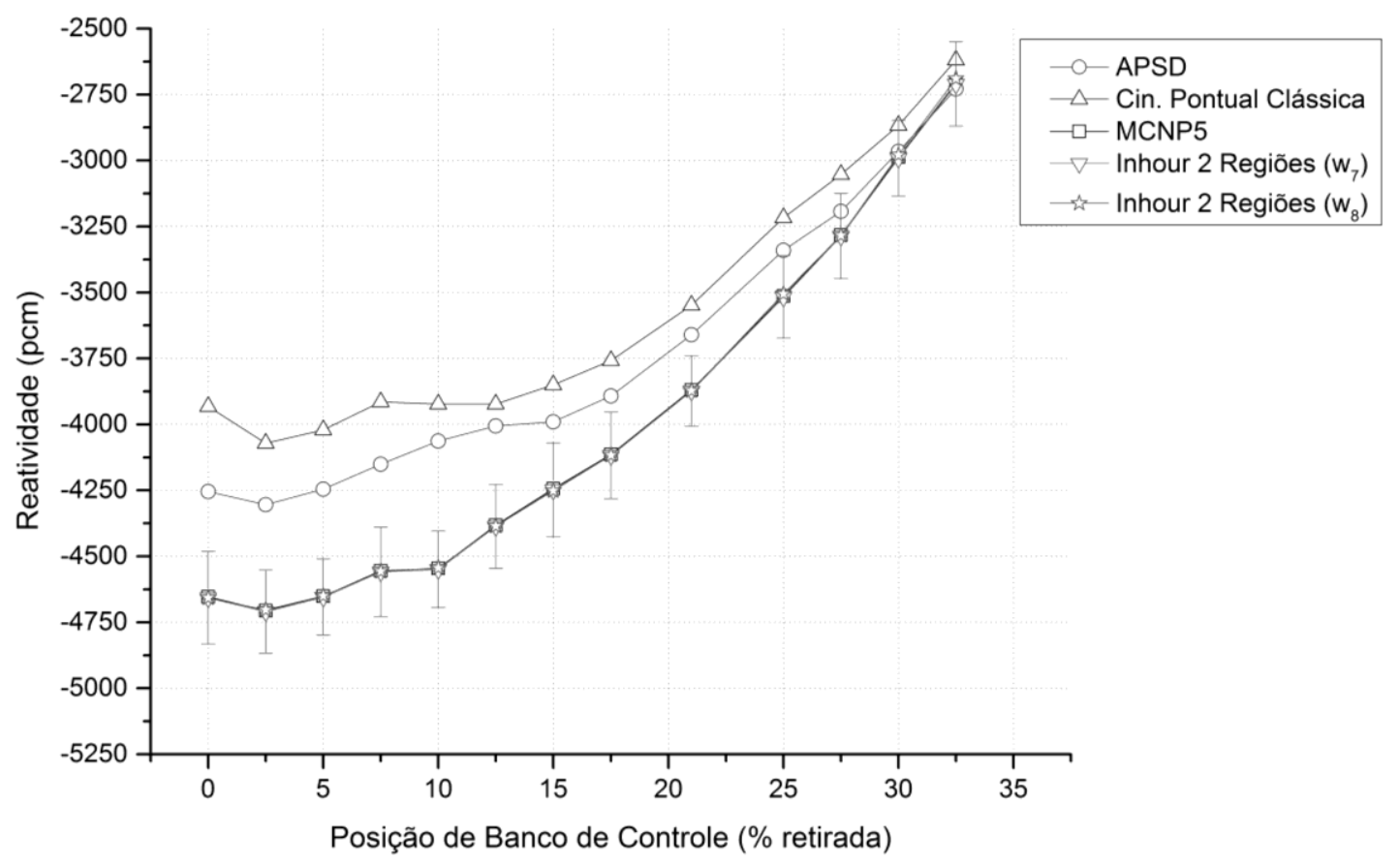

Figura 17 - Valores de reatividade para o núcleo padrão com refletor de aço inox. 
Tabela 4 - Dados referentes aos parâmetros cinéticos do refletor com a configuração padrão com refletor de aço inox.

\begin{tabular}{cccc}
\hline $\begin{array}{c}\text { Bancos de controle } \\
\text { (\% retirada) }\end{array}$ & $\boldsymbol{\tau}$ & $\boldsymbol{\tau}_{\mathbf{c}}$ & $\boldsymbol{f}$ \\
& $(\boldsymbol{\mu s})$ & $(\boldsymbol{\mu s})$ & $(\mathbf{1 E - 3})$ \\
\hline 32.5 & $30.18(0.92)$ & $75.00(4.97)$ & $9.99(0.98)$ \\
30.0 & $29.45(0.91)$ & $66.33(3.44)$ & $14.12(0.91)$ \\
27.5 & $28.90(0.56)$ & $75.21(7.34)$ & $21.36(0.46)$ \\
25.0 & $29.17(0.61)$ & $72.16(1.40)$ & $27.80(0.93)$ \\
21.0 & $29.76(0.59)$ & $70.40(6.43)$ & $28.95(0.49)$ \\
17.5 & $28.76(0.74)$ & $69.62(1.43)$ & $29.56(0.62)$ \\
15.0 & $28.25(0.56)$ & $71.39(1.58)$ & $30.52(0.46)$ \\
12.5 & $28.05(0.78)$ & $73.42(1.47)$ & $33.55(0.62)$ \\
10.0 & $27.50(0.95)$ & $91.49(1.81)$ & $34.50(0.59)$ \\
7.5 & $27.18(0.82)$ & $91.37(6.43)$ & $35.10(0.51)$ \\
5.0 & $27.24(0.90)$ & $88.82(7.74)$ & $34.90(0.57)$ \\
2.5 & $27.20(0.85)$ & $88.06(7.02)$ & $35.00(0.54)$ \\
0.0 & $26.60(0.90)$ & $101.15(9.67)$ & $34.01(0.56)$ \\
\hline
\end{tabular}

Foram calculados os valores de reatividade $(\mathrm{pcm})$ do termo referente ao refletor da equação Inhour de duas regiões - equação (11). Estes resultados estão expressos na tabela 5 .

Tabela 5 - Reatividade calculada para o termo referente ao refletor de aço inox

\begin{tabular}{cc}
\hline $\begin{array}{c}\text { Bancos de controle } \\
\text { (\% retirada) }\end{array}$ & $\rho_{\text {reffetor }}=\frac{\omega f \tau_{r}}{k_{\text {eff }}(1-f)\left(\tau_{r} \omega+1\right)}$ \\
\hline 32.5 & -91.07 \\
30.0 & -124.79 \\
27.5 & -233.29 \\
25.0 & -300.53 \\
21.0 & -325.27 \\
17.5 & -359.19 \\
15.0 & -397.85 \\
12.5 & -462.73 \\
10.0 & -626.38 \\
7.5 & -643.56 \\
5.0 & -633.91 \\
2.5 & -638.14 \\
0.0 & -724.69 \\
\hline
\end{tabular}




\section{3 ÁGUA PESADA}

Os resultados de reatividade obtidos a partir da equação Inhour de duas regiões para o experimento como com refletor de água pesada estão representados na figura 18 . Os bancos de controle foram inseridos simultaneamente a partir do estado crítico, porém os resultados apresentados levam em consideração apenas as curvas de distribuição Rossi-a onde os dois modos de decaimento exponencial foram evidenciados. Por conta disto, a posição inicial considerada dos bancos de controle foi de $22.5 \%$ e a final de $0.0 \%$ (totalmente inseridos). O passo inicial de inserção dos bancos foi de $2.5 \%$ e, a partir da posição de $20 \%$, passos de $5 \%$ até a posição final de $0.0 \%$ (totalmente inseridos). Além disso, a figura 18 também contém os valores de reatividade obtidos a partir do ajuste das curvas de densidades espectrais pela equação de cinética pontual. Na tabela 6 estão representados os valores dos parâmetros cinéticos do refletor $\left(\tau_{c}, \tau_{r}\right.$ e $\left.f\right)$, para o núcleo com refletor de água pesada.

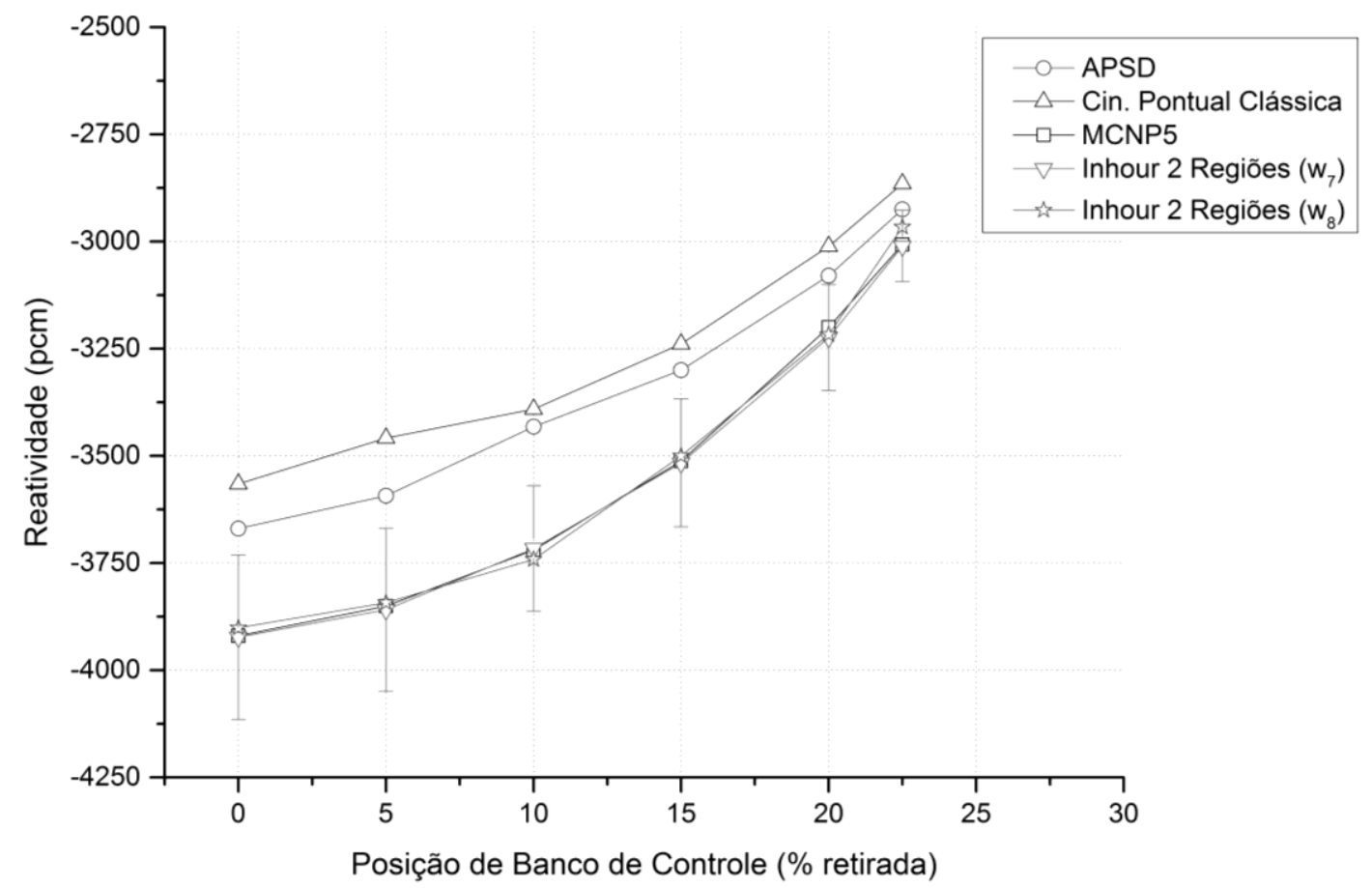

Figura 18 - Valores de reatividade para o núcleo padrão com refletor de água pesada. 
Tabela 6 - Dados referentes aos parâmetros cinéticos do refletor com a configuração padrão com refletor de água pesada $\left(\mathrm{D}_{2} \mathrm{O}\right)$.

\begin{tabular}{cccc}
\hline $\begin{array}{c}\text { Bancos de controle } \\
(\boldsymbol{\%} \text { retirada) }\end{array}$ & $\boldsymbol{\tau}_{\mathbf{c}}$ & $\boldsymbol{\tau}_{\mathbf{r}}$ & $\boldsymbol{f}$ \\
& $(\boldsymbol{\mu s})$ & $(\boldsymbol{\mu s})$ & $(\mathbf{1 E - 3})$ \\
\hline 22.5 & $29.75(0.16)$ & $39.47(2.15)$ & $29.07(2.12)$ \\
20.0 & $29.24(0.62)$ & $45.92(3.18)$ & $34.06(2.16)$ \\
15.0 & $28.93(0.81)$ & $43.94(1.03)$ & $43.27(1.60)$ \\
10.0 & $28.53(0.71)$ & $40.30(1.41)$ & $52.60(1.81)$ \\
5.0 & $27.82(0.92)$ & $39.82(1.51)$ & $62.90(2.03)$ \\
0.0 & $27.52(0.82)$ & $29.15(0.99)$ & $75.04(3.11)$ \\
\hline
\end{tabular}

Foram calculados os valores de reatividade $(\mathrm{pcm})$ do termo referente ao refletor da equação Inhour de duas regiões - equação (11). Estes resultados estão expressos na tabela 7.

Tabela 7 - Reatividade calculada para o termo referente ao refletor de água pesada

\begin{tabular}{cc}
\hline $\begin{array}{c}\text { Bancos de controle } \\
\text { (\% retirada) }\end{array}$ & $\rho_{\text {refletor }}=\frac{\omega f \tau_{r}}{k_{e f f}(1-f)\left(\tau_{r} \omega+1\right)}$ \\
\hline 22.5 & -145.99 \\
20.0 & -213.04 \\
15.0 & -277.59 \\
10.0 & -324.96 \\
5.0 & -400.76 \\
0.0 & -357.65 \\
\hline
\end{tabular}

\subsection{COMPARAÇÃO DOS VALORES DE REATIVIDADE}

Os valores calculados das reatividades pelo código computacional MCNP5 e os obtidos pela equação Inhour de duas regiões para as configurações do núcleo com refletor de água leve, refletor de aço inox e água pesada estão contidos, respectivamente, nas tabelas 8,9 e 10 . 
Tabela 8 - Valores de reatividade referentes ao núcleo com refletor de água leve

\begin{tabular}{ccc}
\hline $\begin{array}{c}\text { Bancos de controle } \\
\text { (\% retirada) }\end{array}$ & $\begin{array}{c}\text { MCNP5 } \\
(\mathbf{p c m})\end{array}$ & $\begin{array}{c}\text { Inhour 2 regiões } \boldsymbol{\omega}_{7} \\
(\mathbf{p c m})\end{array}$ \\
\hline 32.5 & -3032.71 & $-3036.81(170.25)$ \\
30.0 & -3298.64 & $-3302.75(157.15)$ \\
27.5 & -3606.71 & $-3610.87(173.03)$ \\
25.0 & -3859.45 & $-3863.59(171.81)$ \\
21.0 & -4146.99 & $-4151.18(159.76)$ \\
17.5 & -4428.39 & $-4432.59(205.45)$ \\
15.0 & -4580.04 & $-4584.28(216.71)$ \\
12.5 & -4704.74 & $-4708.97(222.68)$ \\
10.0 & -4803.40 & $-4808.21(213.11)$ \\
7.5 & -4845.12 & $-4849.34(242.38)$ \\
5.0 & -4889.06 & $-4893.29(201.52)$ \\
2.5 & -4967.15 & $-4971.51(224.46)$ \\
0.0 & -4959.45 & $-4963.71(226.36)$ \\
\hline
\end{tabular}

Tabela 9 - Valores de reatividade referentes ao núcleo com refletor de aço inox

\begin{tabular}{ccc}
\hline $\begin{array}{c}\text { Bancos de controle } \\
\text { (\% retirada) }\end{array}$ & $\begin{array}{c}\text { MCNP5 } \\
(\mathbf{p c m})\end{array}$ & $\begin{array}{c}\text { Inhour 2 regiões } \boldsymbol{\omega 7} \\
(\mathbf{p c m})\end{array}$ \\
\hline 32.5 & -2706.31 & $-2710.44(139.43)$ \\
30.0 & -2987.67 & $-2991.80(151.68)$ \\
27.5 & -3282.31 & $-3286.48(89.95)$ \\
25.0 & -3513.24 & $-3517.38(120.20)$ \\
21.0 & -3869.12 & $-3873.30(104.16)$ \\
17.5 & -4113.53 & $-4117.71(144.20)$ \\
15.0 & -4243.76 & $-4247.99(118.00)$ \\
12.5 & -4381.95 & $-4386.17(163.18)$ \\
10.0 & -4545.64 & $-4549.83(202.46)$ \\
7.5 & -4554.39 & $-4558.58(169.65)$ \\
5.0 & -4650.68 & $-4654.87(190.57)$ \\
2.5 & -4705.46 & $-4709.65(181.69)$ \\
0.0 & -4652.87 & $-4657.07(195.90)$ \\
\hline
\end{tabular}

Tabela 10 - Valores de reatividade referentes ao núcleo com refletor de água pesada

\begin{tabular}{ccc}
\hline $\begin{array}{c}\text { Bancos de controle } \\
\text { (\% retirada) }\end{array}$ & $\begin{array}{c}\text { MCNP5 } \\
\text { (pcm) }\end{array}$ & $\begin{array}{c}\text { Inhour } 2 \text { regiões } \omega_{7} \\
\text { (pcm) }\end{array}$ \\
\hline 22.5 & -3006.77 & $-3010.78(83.43)$ \\
20.0 & -3200.13 & $-3224.01(123.74)$ \\
15.0 & -3512.17 & $-3516.27(149.08)$ \\
10.0 & -3719.91 & $-3716.03(146.53)$ \\
5.0 & -3850.79 & $-3859.10(190.53)$ \\
0.0 & -3919.43 & $-3923.13(191.77)$ \\
\hline
\end{tabular}




\section{CONCLUSÕES}

Através da técnica de análise de ruído Rossi- $\alpha$ foi possível obter os parâmetros cinéticos do refletor $\left(\tau_{\mathrm{c}}, \tau_{\mathrm{r}}\right.$ e $\left.f\right)$ em estados subcríticos. No entanto, o ajuste das equações, pelo método de mínimos quadrados aos dados experimentais, foi realizado apenas quando o modelo de duas regiões, com dois modos de decaimento, foi levado em consideração.

Constatou-se que as equações da cinética pontual clássica não conseguem descrever satisfatoriamente os estados de subcriticalidade para as curvas Rossi- $\alpha$, pois a partir de um determinado nível de subcriticalidade evidencia-se o surgimento de uma segunda exponencial no inicio da curva Rossi- $\alpha$ - figura 5. Sendo assim, a aplicação das equações de cinética clássica fica restrita aos estados de reatividade próximos ao estado crítico.

O método de ajuste por mínimos quadrados com sucessivas iterações, descrito na seção 07, se mostrou eficiente para a obtenção dos parâmetros cinéticos do refletor $\left(\tau_{c}, \tau_{r}\right.$ e $\left.f\right)$ e, assim, ser determinada a reatividade subcrítica a partir da equação Inhour de duas regiões - equação (13). Pode-se afirmar que a partir dos parâmetros do refletor foi possível calcular a reatividade subcrítica com precisão, quando comparados com os valores obtidos pelo MCNP5.

Pela teoria de propagação de erros foi possível obter o desvio padrão das reatividades subcríticas com o erro variando em um intervalo de $3 \%$ a $5 \%$ do valor de reatividade obtido. As matrizes de covariância e de correlação foram consideradas para a determinação dos desvios padrões a partir da equação de propagação de erros.

O intervalo de inserção de bancos de controle para os refletores de água leve e aço inox foi de $32.5 \%$ até $0 \%$, sendo que as posições acima de $32.5 \%$ foram descartadas por conta da ausência do segundo modo de decaimento nas curvas Rossi- $\alpha$. Para o experimento com refletor de água pesada, o intervalo de inserção de bancos de controle foi de $22.5 \%$ até $0.0 \%$. Isso se deve ao fato da água pesada inserir uma reatividade positiva maior ao sistema quando comparado aos refletores de água leve e aço inox, 
influenciando diretamente na formação do segundo modo de decaimento nas curvas Rossi- $\alpha$.

As raízes da equação Inhour $\left(\omega_{7}\right.$ e $\left.\omega_{8}\right)$ satisfizeram a condição da equação do segundo grau. Os resultados obtidos para estas raízes, pelo ajuste de mínimos quadrados pela equação (17) se igualaram aos resultados obtidos pelo calculo das mesmas, via equação (15).

Através da caracterização dos detectores de nêutrons foi possível determinar o tempo morto dos detectores. Pela comparação dos menores valores de intervalo de tempo entre dois pulsos da curva Rossi- $\alpha$ com o tempo morto do detector é possível provar que a queda observada nos primeiros canais de distribuição das curvas Rossi- $\alpha$ não é oriunda do tempo morto do detector, mas do efeito do refletor. 


\section{ANEXO A - MATRIZES DE COVARIÂNCIA E CORRELAÇÃO}

Esta seção contém os valores das matrizes de covariância e de correlação para os parâmetros cinéticos do refletor $\left(\tau_{c}, \tau_{r}\right.$ e $\left.f\right)$ obtidos a partir do ajuste de mínimos quadrados da equação com dois modos de decaimento exponencial aos dados experimentais Rossi- $\alpha$. O programa OriginLab versão 9.0.0 (64-bits) foi utilizado para a realização dos ajustes via método de mínimos quadrados, na qual o algoritmo de Levenberg-Marquardt é empregado. As matrizes de covariância e correlação foram obtidas pela função de Análise de Variância (Analysis of variance - ANOVA).

Para conferir a consistência dos valores das matrizes de correlação, podem-se calcular os coeficientes de correlação de uma forma independente, ou seja, a partir da seguinte definição [48]:

$$
r_{x y}=\operatorname{Cor}(x, y)=\frac{\operatorname{Cov}(x, y)}{\sigma_{x} \sigma_{y}}=\frac{\sigma_{x y}^{2}}{\sigma_{x} \sigma_{y}},
$$

A seguir são apresentadas as matrizes de covariância e correlação dos três experimentos realizados neste trabalho. As matrizes estão na ordem em que os experimentos foram realizados, ou seja, primeiro para o refletor de água leve, em seguida para o refletor de aço inox e, por fim, para o refletor com caixa de água pesada.

\section{A.1 ÁGUA LEVE}

Tabela 11 - Matrizes de covariância e correlação para a posição de 32.5\% com refletor de água leve

\begin{tabular}{|c|ccc|c|ccc|}
\hline$\sigma_{x y}^{2}$ & $\tau_{\mathrm{c}}$ & $\tau_{\mathrm{R}}$ & $f$ & $r_{x y}$ & $\tau_{\mathrm{c}}$ & $\tau_{\mathrm{R}}$ & $f$ \\
\hline$\tau_{\mathrm{c}}$ & $9.6368 \mathrm{E}-13$ & $1.5954 \mathrm{E}-12$ & $9.1150 \mathrm{E}-10$ & $\tau_{\mathrm{c}}$ & 1 & 0.812 & 0.962 \\
$\tau_{\mathrm{R}}$ & $1.5954 \mathrm{E}-12$ & $4.0060 \mathrm{E}-12$ & $1.7406 \mathrm{E}-09$ & $\tau_{\mathrm{R}}$ & 0.812 & 1 & 0.901 \\
$f$ & $9.1150 \mathrm{E}-10$ & $1.7406 \mathrm{E}-09$ & $9.3161 \mathrm{E}-07$ & $f$ & 0.962 & 0.901 & 1 \\
\hline
\end{tabular}


Tabela 12 - Matrizes de covariância e correlação para a posição de 30.0\% com refletor de água leve

\begin{tabular}{|c|ccc|c|ccc|}
\hline$\sigma_{x y}^{2}$ & $\tau_{\mathrm{c}}$ & $\tau_{\mathrm{R}}$ & $f$ & $r_{x y}$ & $\tau_{\mathrm{c}}$ & $\tau_{\mathrm{R}}$ & $f$ \\
\hline$\tau_{\mathrm{c}}$ & $8.3222 \mathrm{E}-13$ & $1.4674 \mathrm{E}-12$ & $8.6248 \mathrm{E}-10$ & $\tau_{\mathrm{c}}$ & 1 & 0.824 & 0.953 \\
$\tau_{\mathrm{R}}$ & $1.4674 \mathrm{E}-12$ & $3.8107 \mathrm{E}-12$ & $1.7410 \mathrm{E}-09$ & $\tau_{\mathrm{R}}$ & 0.824 & 1 & 0.899 \\
$f$ & $8.6248 \mathrm{E}-10$ & $1.7410 \mathrm{E}-09$ & $9.8419 \mathrm{E}-07$ & $f$ & 0.953 & 0.899 & 1 \\
\hline
\end{tabular}

Tabela 13 - Matrizes de covariância e correlação para a posição de $27.5 \%$ com refletor de água leve

\begin{tabular}{|c|ccc|c|ccc|}
\hline$\sigma_{x y}^{2}$ & $\tau_{\mathrm{c}}$ & $\tau_{\mathrm{R}}$ & $f$ & $r_{x y}$ & $\tau_{\mathrm{c}}$ & $\tau_{\mathrm{R}}$ & $f$ \\
\hline$\tau_{\mathrm{c}}$ & $7.1857 \mathrm{E}-13$ & $7.3600 \mathrm{E}-13$ & $6.1177 \mathrm{E}-10$ & $\tau_{\mathrm{c}}$ & 1 & 0.831 & 0.965 \\
$\tau_{\mathrm{R}}$ & $7.3600 \mathrm{E}-13$ & $1.0916 \mathrm{E}-12$ & $7.1262 \mathrm{E}-10$ & $\tau_{\mathrm{R}}$ & 0.831 & 1 & 0.912 \\
$f$ & $6.1177 \mathrm{E}-10$ & $7.1262 \mathrm{E}-10$ & $5.5930 \mathrm{E}-07$ & $f$ & 0.965 & 0.912 & 1 \\
\hline
\end{tabular}

Tabela 14 - Matrizes de covariância e correlação para a posição de $25.0 \%$ com refletor de água leve

\begin{tabular}{|c|ccc|c|ccc|}
\hline$\sigma_{x y}^{2}$ & $\tau_{\mathrm{c}}$ & $\tau_{\mathrm{R}}$ & $f$ & $r_{x y}$ & $\tau_{\mathrm{c}}$ & $\tau_{\mathrm{R}}$ & $f$ \\
\hline$\tau_{\mathrm{c}}$ & $6.5722 \mathrm{E}-13$ & $7.7199 \mathrm{E}-13$ & $7.6949 \mathrm{E}-10$ & $\tau_{\mathrm{c}}$ & 1 & 0.804 & 0.971 \\
$\tau_{\mathrm{R}}$ & $7.7199 \mathrm{E}-13$ & $1.4028 \mathrm{E}-12$ & $1.0270 \mathrm{E}-09$ & $\tau_{\mathrm{R}}$ & 0.804 & 1 & 0.887 \\
$f$ & $7.6949 \mathrm{E}-10$ & $1.0270 \mathrm{E}-09$ & $9.5557 \mathrm{E}-07$ & $f$ & 0.971 & 0.887 & 1 \\
\hline
\end{tabular}

Tabela 15 - Matrizes de covariância e correlação para a posição de $21.0 \%$ com refletor de água leve

\begin{tabular}{|c|ccc|c|ccc|}
\hline$\sigma_{x y}^{2}$ & $\tau_{\mathrm{c}}$ & $\tau_{\mathrm{R}}$ & $f$ & $r_{x y}$ & $\tau_{\mathrm{c}}$ & $\tau_{\mathrm{R}}$ & $f$ \\
\hline$\tau_{\mathrm{c}}$ & $3.0805 \mathrm{E}-13$ & $2.5297 \mathrm{E}-12$ & $2.7370 \mathrm{E}-10$ & $\tau_{\mathrm{c}}$ & 1 & 0.841 & 0.967 \\
$\tau_{\mathrm{R}}$ & $2.5297 \mathrm{E}-12$ & $2.9371 \mathrm{E}-11$ & $2.4929 \mathrm{E}-09$ & $\tau_{\mathrm{R}}$ & 0.841 & 1 & 0.902 \\
$f$ & $2.7370 \mathrm{E}-10$ & $2.4929 \mathrm{E}-09$ & $2.6007 \mathrm{E}-07$ & $f$ & 0.967 & 0.902 & 1 \\
\hline
\end{tabular}

Tabela 16 - Matrizes de covariância e correlação para a posição de $17.5 \%$ com refletor de água leve

\begin{tabular}{|c|ccc|c|ccc|}
\hline$\sigma_{x y}^{2}$ & $\tau_{\mathrm{c}}$ & $\tau_{\mathrm{R}}$ & $f$ & $r_{x y}$ & $\tau_{\mathrm{c}}$ & $\tau_{\mathrm{R}}$ & $f$ \\
\hline$\tau_{\mathrm{c}}$ & $5.1291 \mathrm{E}-13$ & $4.1540 \mathrm{E}-12$ & $4.3602 \mathrm{E}-10$ & $\tau_{\mathrm{c}}$ & 1 & 0.854 & 0.941 \\
$\tau_{\mathrm{R}}$ & $4.1540 \mathrm{E}-12$ & $4.6128 \mathrm{E}-11$ & $4.0778 \mathrm{E}-09$ & $\tau_{\mathrm{R}}$ & 0.854 & 1 & 0.928 \\
$f$ & $4.3602 \mathrm{E}-10$ & $4.0778 \mathrm{E}-09$ & $4.1859 \mathrm{E}-07$ & $f$ & 0.941 & 0.928 & 1 \\
\hline
\end{tabular}

Tabela 17 - Matrizes de covariância e correlação para a posição de $15.0 \%$ com refletor de água leve

\begin{tabular}{|c|ccc|c|ccc|}
\hline$\sigma_{x y}^{2}$ & $\tau_{\mathrm{c}}$ & $\tau_{\mathrm{R}}$ & $f$ & $r_{x y}$ & $\tau_{\mathrm{c}}$ & $\tau_{\mathrm{R}}$ & $f$ \\
\hline$\tau_{\mathrm{c}}$ & $6.3927 \mathrm{E}-13$ & $4.1142 \mathrm{E}-12$ & $3.5737 \mathrm{E}-10$ & $\tau_{\mathrm{c}}$ & 1 & 0.829 & 0.935 \\
$\tau_{\mathrm{R}}$ & $4.1142 \mathrm{E}-12$ & $3.8528 \mathrm{E}-11$ & $2.6438 \mathrm{E}-09$ & $\tau_{\mathrm{R}}$ & 0.829 & 1 & 0.891 \\
$f$ & $3.5737 \mathrm{E}-10$ & $2.6438 \mathrm{E}-09$ & $2.2852 \mathrm{E}-07$ & $f$ & 0.935 & 0.891 & 1 \\
\hline
\end{tabular}


Tabela 18 - Matrizes de covariância e correlação para a posição de $12.5 \%$ com refletor de água leve

\begin{tabular}{|c|ccc|c|ccc|}
\hline$\sigma_{x y}^{2}$ & $\tau_{\mathrm{c}}$ & $\tau_{\mathrm{R}}$ & $f$ & $r_{x y}$ & $\tau_{\mathrm{c}}$ & $\tau_{\mathrm{R}}$ & $f$ \\
\hline$\tau_{\mathrm{c}}$ & $5.5417 \mathrm{E}-13$ & $5.2747 \mathrm{E}-12$ & $4.5280 \mathrm{E}-10$ & $\tau_{\mathrm{c}}$ & 1 & 0.835 & 0.955 \\
$\tau_{\mathrm{R}}$ & $5.2747 \mathrm{E}-12$ & $7.2008 \mathrm{E}-11$ & $4.8480 \mathrm{E}-09$ & $\tau_{\mathrm{R}}$ & 0.835 & 1 & 0.897 \\
$f$ & $4.5280 \mathrm{E}-10$ & $4.8480 \mathrm{E}-09$ & $4.0565 \mathrm{E}-07$ & $f$ & 0.955 & 0.897 & 1 \\
\hline
\end{tabular}

Tabela 19 - Matrizes de covariância e correlação para a posição de $10.0 \%$ com refletor de água leve

\begin{tabular}{|c|ccc|c|ccc|}
\hline$\sigma_{x y}^{2}$ & $\tau_{\mathrm{c}}$ & $\tau_{\mathrm{R}}$ & $f$ & $r_{x y}$ & $\tau_{\mathrm{c}}$ & $\tau_{\mathrm{R}}$ & $f$ \\
\hline$\tau_{\mathrm{c}}$ & $3.9963 \mathrm{E}-13$ & $4.6376 \mathrm{E}-12$ & $4.0533 \mathrm{E}-10$ & $\tau_{\mathrm{c}}$ & 1 & 0.843 & 0.959 \\
$\tau_{\mathrm{R}}$ & $4.6376 \mathrm{E}-12$ & $7.5730 \mathrm{E}-11$ & $5.2655 \mathrm{E}-09$ & $\tau_{\mathrm{R}}$ & 0.843 & 1 & 0.905 \\
$f$ & $4.0533 \mathrm{E}-10$ & $5.2655 \mathrm{E}-09$ & $4.4701 \mathrm{E}-07$ & $f$ & 0.959 & 0.905 & 1 \\
\hline
\end{tabular}

Tabela 20 - Matrizes de covariância e correlação para a posição de 7.5\% com refletor de água leve

\begin{tabular}{|c|ccc|c|ccc|}
\hline$\sigma_{x y}^{2}$ & $\tau_{\mathrm{c}}$ & $\tau_{\mathrm{R}}$ & $f$ & $r_{x y}$ & $\tau_{\mathrm{c}}$ & $\tau_{\mathrm{R}}$ & $f$ \\
\hline$\tau_{\mathrm{c}}$ & $6.1563 \mathrm{E}-13$ & $6.0030 \mathrm{E}-12$ & $4.7594 \mathrm{E}-10$ & $\tau_{\mathrm{c}}$ & 1 & 0.819 & 0.948 \\
$\tau_{\mathrm{R}}$ & $6.0030 \mathrm{E}-12$ & $8.7269 \mathrm{E}-11$ & $5.5111 \mathrm{E}-09$ & $\tau_{\mathrm{R}}$ & 0.819 & 1 & 0.922 \\
$f$ & $4.7594 \mathrm{E}-10$ & $5.5111 \mathrm{E}-09$ & $4.0941 \mathrm{E}-07$ & $f$ & 0.948 & 0.922 & 1 \\
\hline
\end{tabular}

Tabela 21 - Matrizes de covariância e correlação para a posição de 5.0\% com refletor de água leve

\begin{tabular}{|c|ccc|c|ccc|}
\hline$\sigma_{x y}^{2}$ & $\tau_{\mathrm{c}}$ & $\tau_{\mathrm{R}}$ & $f$ & $r_{x y}$ & $\tau_{\mathrm{c}}$ & $\tau_{\mathrm{R}}$ & $f$ \\
\hline$\tau_{\mathrm{c}}$ & $4.0108 \mathrm{E}-13$ & $3.6800 \mathrm{E}-12$ & $4.0705 \mathrm{E}-10$ & $\tau_{\mathrm{c}}$ & 1 & 0.836 & 0.938 \\
$\tau_{\mathrm{R}}$ & $3.6800 \mathrm{E}-12$ & $4.8311 \mathrm{E}-11$ & $4.3674 \mathrm{E}-09$ & $\tau_{\mathrm{R}}$ & 0.836 & 1 & 0.917 \\
$f$ & $4.0705 \mathrm{E}-10$ & $4.3674 \mathrm{E}-09$ & $4.6952 \mathrm{E}-07$ & $f$ & 0.938 & 0.917 & 1 \\
\hline
\end{tabular}

Tabela 22 - Matrizes de covariância e correlação para a posição de $2.5 \%$ com refletor de água leve

\begin{tabular}{|c|ccc|c|ccc|}
\hline$\sigma_{x y}^{2}$ & $\tau_{\mathrm{c}}$ & $\tau_{\mathrm{R}}$ & $f$ & $r_{x y}$ & $\tau_{\mathrm{c}}$ & $\tau_{\mathrm{R}}$ & $f$ \\
\hline$\tau_{\mathrm{c}}$ & $5.1198 \mathrm{E}-13$ & $4.8189 \mathrm{E}-12$ & $4.6566 \mathrm{E}-10$ & $\tau_{\mathrm{c}}$ & 1 & 0.828 & 0.943 \\
$\tau_{\mathrm{R}}$ & $4.8189 \mathrm{E}-12$ & $6.6157 \mathrm{E}-11$ & $5.1867 \mathrm{E}-09$ & $\tau_{\mathrm{R}}$ & 0.828 & 1 & 0.924 \\
$f$ & $4.6566 \mathrm{E}-10$ & $5.1867 \mathrm{E}-09$ & $4.7627 \mathrm{E}-07$ & $f$ & 0.943 & 0.924 & 1 \\
\hline
\end{tabular}

Tabela 23 - Matrizes de covariância e correlação para a posição de $0.0 \%$ com refletor de água leve

\begin{tabular}{|c|ccc|c|ccc|}
\hline$\sigma_{x y}^{2}$ & & & & & & & \\
$\mathrm{c}$ & $\tau_{\mathrm{R}}$ & $f$ & $\tau_{\mathrm{c}}$ & $\tau_{\mathrm{R}}$ & $f$ \\
\hline$\tau_{\mathrm{c}}$ & $6.6009 \mathrm{E}-13$ & $3.9543 \mathrm{E}-12$ & $5.1515 \mathrm{E}-10$ & $\tau_{\mathrm{c}}$ & 1 & 0.833 & 0.951 \\
$\tau_{\mathrm{R}}$ & $3.9543 \mathrm{E}-12$ & $3.4138 \mathrm{E}-11$ & $3.6229 \mathrm{E}-09$ & $\tau_{\mathrm{R}}$ & 0.833 & 1 & 0.93 \\
$f$ & $5.1515 \mathrm{E}-10$ & $3.6229 \mathrm{E}-09$ & $4.4454 \mathrm{E}-07$ & $f$ & 0.951 & 0.93 & 1 \\
\hline
\end{tabular}




\section{A.2 AÇO INOX}

Tabela 24 - Matrizes de covariância e correlação para a posição de 32.5\% com refletor de aço inox

\begin{tabular}{|c|ccc|c|ccc|}
\hline$\sigma_{x y}^{2}$ & $\tau_{\mathrm{c}}$ & $\tau_{\mathrm{R}}$ & $f$ & $r_{x y}$ & $\tau_{\mathrm{c}}$ & $\tau_{\mathrm{R}}$ & $f$ \\
\hline$\tau_{\mathrm{c}}$ & $8.4949 \mathrm{E}-13$ & $3.8781 \mathrm{E}-12$ & $8.5249 \mathrm{E}-10$ & $\tau_{\mathrm{c}}$ & 1 & 0.845 & 0.942 \\
$\tau_{\mathrm{R}}$ & $3.8781 \mathrm{E}-12$ & $2.4794 \mathrm{E}-11$ & $4.2878 \mathrm{E}-09$ & $\tau_{\mathrm{R}}$ & 0.845 & 1 & 0.877 \\
$f$ & $8.5249 \mathrm{E}-10$ & $4.2878 \mathrm{E}-09$ & $9.6408 \mathrm{E}-07$ & $f$ & 0.942 & 0.877 & 1 \\
\hline
\end{tabular}

Tabela 25 - Matrizes de covariância e correlação para a posição de 30.0\% com refletor de aço inox

\begin{tabular}{|c|ccc|c|ccc|}
\hline$\sigma_{x y}^{2}$ & $\tau_{\mathrm{c}}$ & $\tau_{\mathrm{R}}$ & $f$ & $r_{x y}$ & $\tau_{\mathrm{c}}$ & $\tau_{\mathrm{R}}$ & $f$ \\
\hline$\tau_{\mathrm{c}}$ & $8.2926 \mathrm{E}-13$ & $2.6830 \mathrm{E}-12$ & $7.9630 \mathrm{E}-10$ & $\tau_{\mathrm{c}}$ & 1 & 0.856 & 0.951 \\
$\tau_{\mathrm{R}}$ & $2.6830 \mathrm{E}-12$ & $1.1847 \mathrm{E}-11$ & $2.7819 \mathrm{E}-09$ & $\tau_{\mathrm{R}}$ & 0.856 & 1 & 0.879 \\
$f$ & $7.9630 \mathrm{E}-10$ & $2.7819 \mathrm{E}-09$ & $8.4548 \mathrm{E}-07$ & $f$ & 0.951 & 0.879 & 1 \\
\hline
\end{tabular}

Tabela 26 - Matrizes de covariância e correlação para a posição de $27.5 \%$ com refletor de aço inox

\begin{tabular}{|c|ccc|c|ccc|}
\hline$\sigma_{x y}^{2}$ & $\tau_{\mathrm{c}}$ & $\tau_{\mathrm{R}}$ & $f$ & $r_{x y}$ & $\tau_{\mathrm{c}}$ & $\tau_{\mathrm{R}}$ & $f$ \\
\hline$\tau_{\mathrm{c}}$ & $3.0986 \mathrm{E}-13$ & $3.6408 \mathrm{E}-13$ & $2.4554 \mathrm{E}-10$ & $\tau_{\mathrm{c}}$ & 1 & 0.891 & 0.956 \\
$\tau_{\mathrm{R}}$ & $3.6408 \mathrm{E}-13$ & $5.3885 \mathrm{E}-13$ & $2.9941 \mathrm{E}-10$ & $\tau_{\mathrm{R}}$ & 0.891 & 1 & 0.884 \\
$f$ & $2.4554 \mathrm{E}-10$ & $2.9941 \mathrm{E}-10$ & $2.1289 \mathrm{E}-07$ & $f$ & 0.956 & 0.884 & 1 \\
\hline
\end{tabular}

Tabela 27 - Matrizes de covariância e correlação para a posição de $25.0 \%$ com refletor de aço inox

\begin{tabular}{|c|ccc|c|ccc|}
\hline$\sigma_{x y}^{2}$ & $\tau_{\mathrm{c}}$ & $\tau_{\mathrm{R}}$ & $f$ & $r_{x y}$ & $\tau_{\mathrm{c}}$ & $\tau_{\mathrm{R}}$ & $f$ \\
\hline$\tau_{\mathrm{c}}$ & $3.7426 \mathrm{E}-13$ & $7.3481 \mathrm{E}-13$ & $5.4366 \mathrm{E}-10$ & $\tau_{\mathrm{c}}$ & 1 & 0.854 & 0.949 \\
$\tau_{\mathrm{R}}$ & $7.3481 \mathrm{E}-13$ & $1.9781 \mathrm{E}-12$ & $1.1472 \mathrm{E}-09$ & $\tau_{\mathrm{R}}$ & 0.854 & 1 & 0.871 \\
$f$ & $5.4366 \mathrm{E}-10$ & $1.1472 \mathrm{E}-09$ & $8.7690 \mathrm{E}-07$ & $f$ & 0.949 & 0.871 & 1 \\
\hline
\end{tabular}

Tabela 28 - Matrizes de covariância e correlação para a posição de $21.0 \%$ com refletor de aço inox

\begin{tabular}{|c|ccc|c|ccc|}
\hline$\sigma_{x y}^{2}$ & $\tau_{\mathrm{c}}$ & $\tau_{\mathrm{R}}$ & $f$ & $r_{x y}$ & $\tau_{\mathrm{c}}$ & $\tau_{\mathrm{R}}$ & $f$ \\
\hline$\tau_{\mathrm{c}}$ & $3.4406 \mathrm{E}-13$ & $3.2806 \mathrm{E}-13$ & $2.7968 \mathrm{E}-10$ & $\tau_{\mathrm{c}}$ & 1 & 0.869 & 0.961 \\
$\tau_{\mathrm{R}}$ & $3.2806 \mathrm{E}-13$ & $4.1423 \mathrm{E}-13$ & $2.9091 \mathrm{E}-10$ & $\tau_{\mathrm{R}}$ & 0.869 & 1 & 0.911 \\
$f$ & $2.7968 \mathrm{E}-10$ & $2.9091 \mathrm{E}-10$ & $2.4618 \mathrm{E}-07$ & $f$ & 0.961 & 0.911 & 1 \\
\hline
\end{tabular}


Tabela 29 - Matrizes de covariância e correlação para a posição de $17.5 \%$ com refletor de aço inox

\begin{tabular}{|c|ccc|c|ccc|}
\hline$\sigma_{x y}^{2}$ & $\tau_{\mathrm{c}}$ & $\tau_{\mathrm{R}}$ & $f$ & $r_{x y}$ & $\tau_{\mathrm{c}}$ & $\tau_{\mathrm{R}}$ & $f$ \\
\hline$\tau_{\mathrm{c}}$ & $5.4028 \mathrm{E}-13$ & $9.5671 \mathrm{E}-13$ & $4.4355 \mathrm{E}-10$ & $\tau_{\mathrm{c}}$ & 1 & 0.905 & 0.964 \\
$\tau_{\mathrm{R}}$ & $9.5671 \mathrm{E}-13$ & $2.0685 \mathrm{E}-12$ & $8.0666 \mathrm{E}-10$ & $\tau_{\mathrm{R}}$ & 0.905 & 1 & 0.896 \\
$f$ & $4.4355 \mathrm{E}-10$ & $8.0666 \mathrm{E}-10$ & $3.9185 \mathrm{E}-07$ & $f$ & 0.964 & 0.896 & 1 \\
\hline
\end{tabular}

Tabela 30 - Matrizes de covariância e correlação para a posição de $15.0 \%$ com refletor de aço inox

\begin{tabular}{|c|ccc|c|ccc|}
\hline$\sigma_{x y}^{2}$ & $\tau_{\mathrm{c}}$ & $\tau_{\mathrm{R}}$ & $f$ & $r_{x y}$ & $\tau_{\mathrm{c}}$ & $\tau_{\mathrm{R}}$ & $f$ \\
\hline$\tau_{\mathrm{c}}$ & $3.1391 \mathrm{E}-13$ & $7.9063 \mathrm{E}-13$ & $2.4624 \mathrm{E}-10$ & $\tau_{\mathrm{c}}$ & 1 & 0.893 & 0.947 \\
$\tau_{\mathrm{R}}$ & $7.9063 \mathrm{E}-13$ & $2.4971 \mathrm{E}-12$ & $6.6076 \mathrm{E}-10$ & $\tau_{\mathrm{R}}$ & 0.893 & 1 & 0.901 \\
$f$ & $2.4624 \mathrm{E}-10$ & $6.6076 \mathrm{E}-10$ & $2.1538 \mathrm{E}-07$ & $f$ & 0.947 & 0.901 & 1 \\
\hline
\end{tabular}

Tabela 31 - Matrizes de covariância e correlação para a posição de $12.5 \%$ com refletor de aço inox

\begin{tabular}{|c|ccc|c|ccc|}
\hline$\sigma_{x y}^{2}$ & $\tau_{\mathrm{c}}$ & $\tau_{\mathrm{R}}$ & $f$ & $r_{x y}$ & $\tau_{\mathrm{c}}$ & $\tau_{\mathrm{R}}$ & $f$ \\
\hline$\tau_{\mathrm{c}}$ & $6.1099 \mathrm{E}-13$ & $9.7023 \mathrm{E}-13$ & $4.5622 \mathrm{E}-10$ & $\tau_{\mathrm{c}}$ & 1 & 0.839 & 0.938 \\
$\tau_{\mathrm{R}}$ & $9.7023 \mathrm{E}-13$ & $2.1887 \mathrm{E}-12$ & $8.2114 \mathrm{E}-10$ & $\tau_{\mathrm{R}}$ & 0.839 & 1 & 0.892 \\
$f$ & $4.5622 \mathrm{E}-10$ & $8.2114 \mathrm{E}-10$ & $3.8718 \mathrm{E}-07$ & $f$ & 0.938 & 0.892 & 1 \\
\hline
\end{tabular}

Tabela 32 - Matrizes de covariância e correlação para a posição de $10.0 \%$ com refletor de aço inox

\begin{tabular}{|c|ccc|c|ccc|}
\hline$\sigma_{x y}^{2}$ & $\tau_{\mathrm{c}}$ & $\tau_{\mathrm{R}}$ & $f$ & $r_{x y}$ & $\tau_{\mathrm{c}}$ & $\tau_{\mathrm{R}}$ & $f$ \\
\hline$\tau_{\mathrm{c}}$ & $9.0580 \mathrm{E}-13$ & $1.5104 \mathrm{E}-12$ & $5.3920 \mathrm{E}-10$ & $\tau_{\mathrm{c}}$ & 1 & 0.875 & 0.952 \\
$\tau_{\mathrm{R}}$ & $1.5104 \mathrm{E}-12$ & $3.2894 \mathrm{E}-12$ & $9.8867 \mathrm{E}-10$ & $\tau_{\mathrm{R}}$ & 0.875 & 1 & 0.916 \\
$f$ & $5.3920 \mathrm{E}-10$ & $9.8867 \mathrm{E}-10$ & $3.5416 \mathrm{E}-07$ & $f$ & 0.952 & 0.916 & 1 \\
\hline
\end{tabular}

Tabela 33 - Matrizes de covariância e correlação para a posição de 7.5\% com refletor de aço inox

\begin{tabular}{|c|ccc|c|ccc|}
\hline$\sigma_{x y}^{2}$ & $\tau_{\mathrm{c}}$ & $\tau_{\mathrm{R}}$ & $f$ & $r_{x y}$ & $\tau_{\mathrm{c}}$ & $\tau_{\mathrm{R}}$ & $f$ \\
\hline$\tau_{\mathrm{c}}$ & $6.7395 \mathrm{E}-13$ & $4.6021 \mathrm{E}-13$ & $4.0198 \mathrm{E}-10$ & $\tau_{\mathrm{c}}$ & 1 & 0.871 & 0.957 \\
$\tau_{\mathrm{R}}$ & $4.6021 \mathrm{E}-13$ & $4.1423 \mathrm{E}-13$ & $3.0395 \mathrm{E}-10$ & $\tau_{\mathrm{R}}$ & 0.871 & 1 & 0.923 \\
$f$ & $4.0198 \mathrm{E}-10$ & $3.0395 \mathrm{E}-10$ & $2.6179 \mathrm{E}-07$ & $f$ & 0.957 & 0.923 & 1 \\
\hline
\end{tabular}

Tabela 34 - Matrizes de covariância e correlação para a posição de 5.0\% com refletor de aço inox

\begin{tabular}{|c|ccc|c|ccc|}
\hline$\sigma_{x y}^{2}$ & $\tau_{\mathrm{c}}$ & $\tau_{\mathrm{R}}$ & $f$ & $r_{x y}$ & $\tau_{\mathrm{c}}$ & $\tau_{\mathrm{R}}$ & $f$ \\
\hline$\tau_{\mathrm{c}}$ & $8.1064 \mathrm{E}-13$ & $6.1780 \mathrm{E}-13$ & $4.9160 \mathrm{E}-10$ & $\tau_{\mathrm{c}}$ & 1 & 0.886 & 0.944 \\
$\tau_{\mathrm{R}}$ & $6.1780 \mathrm{E}-13$ & $5.9980 \mathrm{E}-13$ & $4.0360 \mathrm{E}-10$ & $\tau_{\mathrm{R}}$ & 0.886 & 1 & 0.901 \\
$f$ & $4.9160 \mathrm{E}-10$ & $4.0360 \mathrm{E}-10$ & $3.3455 \mathrm{E}-07$ & $f$ & 0.944 & 0.901 & 1 \\
\hline
\end{tabular}


Tabela 35 - Matrizes de covariância e correlação para a posição de $2.5 \%$ com refletor de aço inox

\begin{tabular}{|c|ccc|c|ccc|}
\hline$\sigma_{x y}^{2}$ & $\tau_{\mathrm{c}}$ & $\tau_{\mathrm{R}}$ & $f$ & $r_{x y}$ & $\tau_{\mathrm{c}}$ & $\tau_{\mathrm{R}}$ & $f$ \\
\hline$\tau_{\mathrm{c}}$ & $7.1870 \mathrm{E}-13$ & $5.1192 \mathrm{E}-13$ & $4.4931 \mathrm{E}-10$ & $\tau_{\mathrm{c}}$ & 1 & 0.859 & 0.966 \\
$\tau_{\mathrm{R}}$ & $5.1192 \mathrm{E}-13$ & $4.9417 \mathrm{E}-13$ & $3.5637 \mathrm{E}-10$ & $\tau_{\mathrm{R}}$ & 0.859 & 1 & 0.924 \\
$f$ & $4.4931 \mathrm{E}-10$ & $3.5637 \mathrm{E}-10$ & $3.0102 \mathrm{E}-07$ & $f$ & 0.966 & 0.924 & 1 \\
\hline
\end{tabular}

Tabela 36 - Matrizes de covariância e correlação para a posição de $0.0 \%$ com refletor de aço inox

\begin{tabular}{|c|ccc|c|ccc|}
\hline$\sigma_{x y}^{2}$ & $\tau_{\mathrm{c}}$ & $\tau_{\mathrm{R}}$ & $f$ & $r_{x y}$ & $\tau_{\mathrm{c}}$ & $\tau_{\mathrm{R}}$ & $f$ \\
\hline$\tau_{\mathrm{c}}$ & $8.1591 \mathrm{E}-13$ & $7.5440 \mathrm{E}-13$ & $4.9304 \mathrm{E}-10$ & $\tau_{\mathrm{c}}$ & 1 & 0.864 & 0.96 \\
$\tau_{\mathrm{R}}$ & $7.5440 \mathrm{E}-13$ & $9.3439 \mathrm{E}-13$ & $4.9410 \mathrm{E}-10$ & $\tau_{\mathrm{R}}$ & 0.864 & 1 & 0.899 \\
$f$ & $4.9304 \mathrm{E}-10$ & $4.9410 \mathrm{E}-10$ & $3.2328 \mathrm{E}-07$ & $f$ & 0.96 & 0.899 & 1 \\
\hline
\end{tabular}

\section{A.3 ÁGUA PESADA}

Tabela 37 - Matrizes de covariância e correlação para a posição de $22.5 \%$ com refletor de aço inox

\begin{tabular}{|c|ccc|c|ccc|}
\hline$\sigma_{x y}^{2}$ & & & & & & & \\
$\tau_{\mathrm{c}}$ & $\tau_{\mathrm{R}}$ & $f$ & $\tau_{\mathrm{c}}$ & $\tau_{\mathrm{R}}$ & $f$ \\
\hline$\tau_{\mathrm{c}}$ & $5.1033 \mathrm{E}-13$ & $9.1023 \mathrm{E}-13$ & $1.2779 \mathrm{E}-09$ & $\tau_{\mathrm{c}}$ & 1 & 0.905 & 0.986 \\
$\tau_{\mathrm{R}}$ & $9.1023 \mathrm{E}-13$ & $1.9822 \mathrm{E}-12$ & $2.4215 \mathrm{E}-09$ & $\tau_{\mathrm{R}}$ & 0.905 & 1 & 0.948 \\
$f$ & $1.2779 \mathrm{E}-09$ & $2.4215 \mathrm{E}-09$ & $3.2914 \mathrm{E}-06$ & $f$ & 0.986 & 0.948 & 1 \\
\hline
\end{tabular}

Tabela 38 - Matrizes de covariância e correlação para a posição de $20.0 \%$ com refletor de aço inox

\begin{tabular}{|c|ccc|c|ccc|}
\hline$\sigma_{x y}^{2}$ & $\tau_{\mathrm{c}}$ & $\tau_{\mathrm{R}}$ & $f$ & $r_{x y}$ & $\tau_{\mathrm{c}}$ & $\tau_{\mathrm{R}}$ & $f$ \\
\hline$\tau_{\mathrm{c}}$ & $3.8208 \mathrm{E}-13$ & $1.7658 \mathrm{E}-12$ & $1.3152 \mathrm{E}-09$ & $\tau_{\mathrm{c}}$ & 1 & 0.899 & 0.985 \\
$\tau_{\mathrm{R}}$ & $1.7658 \mathrm{E}-12$ & $1.0097 \mathrm{E}-11$ & $6.4797 \mathrm{E}-09$ & $\tau_{\mathrm{R}}$ & 0.899 & 1 & 0.944 \\
$f$ & $1.3152 \mathrm{E}-09$ & $6.4797 \mathrm{E}-09$ & $4.6663 \mathrm{E}-06$ & $f$ & 0.985 & 0.944 & 1 \\
\hline
\end{tabular}

Tabela 39 - Matrizes de covariância e correlação para a posição de $15.0 \%$ com refletor de aço inox

\begin{tabular}{|c|ccc|c|ccc|}
\hline$\sigma_{x y}^{2}$ & $\tau_{\mathrm{c}}$ & $\tau_{\mathrm{R}}$ & $f$ & $r_{x y}$ & $\tau_{\mathrm{c}}$ & $\tau_{\mathrm{R}}$ & $f$ \\
\hline$\tau_{\mathrm{c}}$ & $6.6134 \mathrm{E}-13$ & $7.4989 \mathrm{E}-13$ & $1.2656 \mathrm{E}-09$ & $\tau_{\mathrm{c}}$ & 1 & 0.896 & 0.975 \\
$\tau_{\mathrm{R}}$ & $7.4989 \mathrm{E}-13$ & $1.0591 \mathrm{E}-12$ & $1.5539 \mathrm{E}-09$ & $\tau_{\mathrm{R}}$ & 0.896 & 1 & 0.946 \\
$f$ & $1.2656 \mathrm{E}-09$ & $1.5539 \mathrm{E}-09$ & $2.5476 \mathrm{E}-06$ & $f$ & 0.975 & 0.946 & 1 \\
\hline
\end{tabular}


Tabela 40 - Matrizes de covariância e correlação para a posição de $10.0 \%$ com refletor de aço inox

\begin{tabular}{|c|ccc|c|ccc|}
\hline$\sigma_{x y}^{2}$ & $\tau_{\mathrm{c}}$ & $\tau_{\mathrm{R}}$ & $f$ & $r_{x y}$ & $\tau_{\mathrm{c}}$ & $\tau_{\mathrm{R}}$ & $f$ \\
\hline$\tau_{\mathrm{c}}$ & $5.1033 \mathrm{E}-13$ & $8.9313 \mathrm{E}-13$ & $1.2675 \mathrm{E}-09$ & $\tau_{\mathrm{c}}$ & 1 & 0.888 & 0.978 \\
$\tau_{\mathrm{R}}$ & $8.9313 \mathrm{E}-13$ & $1.9822 \mathrm{E}-12$ & $2.4291 \mathrm{E}-09$ & $\tau_{\mathrm{R}}$ & 0.888 & 1 & 0.951 \\
$f$ & $1.2675 \mathrm{E}-09$ & $2.4291 \mathrm{E}-09$ & $3.2914 \mathrm{E}-06$ & $f$ & 0.978 & 0.951 & 1 \\
\hline
\end{tabular}

Tabela 41 - Matrizes de covariância e correlação para a posição de 5.0\% com refletor de aço inox

\begin{tabular}{|c|ccc|c|ccc|}
\hline$\sigma_{x y}^{2}$ & $\tau_{\mathrm{c}}$ & $\tau_{\mathrm{R}}$ & $f$ & $r_{x y}$ & $\tau_{\mathrm{c}}$ & $\tau_{\mathrm{R}}$ & $f$ \\
\hline$\tau_{\mathrm{c}}$ & $8.3936 \mathrm{E}-13$ & $1.2186 \mathrm{E}-12$ & $1.8064 \mathrm{E}-09$ & $\tau_{\mathrm{c}}$ & 1 & 0.879 & 0.973 \\
$\tau_{\mathrm{R}}$ & $1.2186 \mathrm{E}-12$ & $2.2897 \mathrm{E}-12$ & $2.9314 \mathrm{E}-09$ & $\tau_{\mathrm{R}}$ & 0.879 & 1 & 0.956 \\
$f$ & $1.8064 \mathrm{E}-09$ & $2.9314 \mathrm{E}-09$ & $4.1064 \mathrm{E}-06$ & $f$ & 0.973 & 0.956 & 1 \\
\hline
\end{tabular}

Tabela 42 - Matrizes de covariância e correlação para a posição de $0.0 \%$ com refletor de aço inox

\begin{tabular}{|c|ccc|c|ccc|}
\hline$\sigma_{x y}^{2}$ & $\tau_{\mathrm{c}}$ & $\tau_{\mathrm{R}}$ & $f$ & $r_{x y}$ & $\tau_{\mathrm{c}}$ & $\tau_{\mathrm{R}}$ & $f$ \\
\hline$\tau_{\mathrm{c}}$ & $6.7314 \mathrm{E}-13$ & $7.3812 \mathrm{E}-13$ & $2.4688 \mathrm{E}-09$ & $\tau_{\mathrm{c}}$ & 1 & 0.901 & 0.968 \\
$\tau_{\mathrm{R}}$ & $7.3812 \mathrm{E}-13$ & $9.9699 \mathrm{E}-13$ & $2.9424 \mathrm{E}-09$ & $\tau_{\mathrm{R}}$ & 0.901 & 1 & 0.948 \\
$f$ & $2.4688 \mathrm{E}-09$ & $2.9424 \mathrm{E}-09$ & $9.6628 \mathrm{E}-06$ & $f$ & 0.968 & 0.948 & 1 \\
\hline
\end{tabular}




\section{ANEXO B - TESTE DE CONSISTÊNCIA DAS RAÍZES DA EQUAÇÃO INHOUR DE DUAS REGIÕES}

Nesta seção temos o desenvolvimento para a obtenção da equação do segundo grau para as raízes da equação Inhour de duas regiões e a demonstração da manipulação algébrica deste processo.

$$
\rho=\omega \Lambda_{c}+\omega \frac{\Lambda_{r} f}{\left(\tau_{r} \omega+1\right)}+\sum_{i} \frac{\beta_{i} \omega}{\omega+\lambda_{i}}
$$

considerando $\omega>>\lambda_{i}$ e definindo $\Lambda_{c}=\frac{\tau_{c}}{k_{\text {eff }}(1-f)}$ e $\Lambda_{r}=\frac{\tau_{r}}{k_{\text {eff }}(1-f)}$, e

substituindo $\Lambda_{c}$ e $\Lambda_{r}$ em (B.1), temos que:

$$
\begin{aligned}
& \rho=\omega \frac{\tau_{c}(1-\rho)}{(1-f)}+\omega \frac{f \tau_{r}(1-\rho)}{\left(\tau_{r} \omega+1\right)(1-f)}+\beta_{e f f} \\
& \rho\left(\tau_{r} \omega+1\right)(1-f)=\omega \tau_{c}(1-\rho)\left(\tau_{r} \omega+1\right)+\omega f \tau_{r}(1-\rho)+\beta_{e f f}\left(\tau_{r} \omega+1\right)(1-f) \\
& \left(\rho \tau_{r} \omega+\rho\right)(1-f)=\left(\omega \tau_{c}-\omega \tau_{c} \rho\right)\left(\tau_{r} \omega+1\right)+\left(\omega f \tau_{r}-\omega f \tau_{r} \rho\right)+\left(\beta_{e f f} \tau_{r} \omega+\beta_{e f f}\right)(1-f) \\
& \left(\rho \tau_{r} \omega-\rho \tau_{r} \omega f+\rho-f \rho\right)=\omega^{2} \tau_{c} \tau_{r}+\omega \tau_{c}-\omega^{2} \tau_{c} \rho \tau_{r}-\omega \tau_{c} \rho+\omega f \tau_{r}-\omega f \tau_{r} \rho+\beta_{e f f} \tau_{r} \omega-\beta_{e f f} \tau_{r} \omega f+\beta_{e f f}-\beta_{e f f} f \\
& \omega\left(\rho \tau_{r}-\rho \tau_{r} f\right)+\rho(1-f)=\omega^{2}\left(\tau_{c} \tau_{r}-\tau_{c} \tau_{r} \rho\right)+\omega\left(\tau_{c}-\tau_{c} \rho+f \tau_{r}-f \tau_{r} \rho+\beta_{e f f} \tau_{r}-\beta_{e f f} \tau_{r} f\right)+\beta_{e f f}-\beta_{e f f} f \\
& \omega^{2}\left(\tau_{c} \tau_{r}-\tau_{c} \tau_{r} \rho\right)+\omega\left(\tau_{c}-\tau_{c} \rho+f \tau_{r}-f \tau_{r} \rho+\beta_{e f f} \tau_{r}-\beta_{e f f} \tau_{r} f-\rho \tau_{r}+\rho \tau_{r} f\right)-\rho(1-f)+\beta_{e f f}(1-f)=0 \\
& \omega^{2}\left(\tau_{c} \tau_{r}(1-\rho)\right)+\omega\left(\tau_{c}(1-\rho)+f \tau_{r}(1-\rho)+\beta_{e f f} \tau_{r}(1-f)-\rho \tau_{r}(1-f)\right)+(1-f)\left(\beta_{e f f}-\rho\right)=0 \\
& \left.\quad \omega^{2}\left\{\tau_{c} \tau_{r}(1-\rho)\right\}+\omega\left\{(1-\rho)\left(\tau_{c}+\tau_{r} f\right)+\tau_{r}\left(\beta_{e f f}-\rho\right)(1-f)\right\}+\left\{(1-f)\left(\beta_{e f f}-\rho\right)\right\}=0, \quad \text { B. } 2\right)
\end{aligned}
$$

Substituindo na equação (B.2) os valores dos parâmetros cinéticos do refletor, obtidos a partir do ajuste de mínimos quadrados, e os valores das raízes da equação Inhour de duas regiões, assim como a fração efetiva de nêutrons atrasados e a reatividade, foi realizado o teste de consistência.

Nas tabelas a seguir, encontram-se os valores para os termos da equação do segundo grau. 


\section{B.1 ÁGUA LEVE}

Tabela 43 - Teste de consistência utilizando a raiz $\omega_{7}$ e a equação do segundo grau com os dados do refletor de água leve

\begin{tabular}{ccccc}
\hline & $\mathbf{A}$ & $\mathbf{B}$ & $\mathbf{C}$ & $\mathbf{A}+\mathbf{B}$ \\
\hline $\begin{array}{c}\text { BC\#1 BC\#2 } \\
\text { (\% retirada) }\end{array}$ & $\boldsymbol{\omega}_{c} \tau_{r}(1-\rho)$ & $\left\{(1-\rho)\left(\tau_{c}+\tau_{r} f\right)+\tau_{r}\left(\beta_{e f f}-\rho\right)(1-f)\right\}$ & $(1-f)\left(\beta_{e f f}-\rho\right)$ & \\
\hline 32.5 & 0.0029547 & -0.0405494 & 0.0375947 & -0.0375947 \\
30.0 & 0.0030185 & -0.0430598 & 0.0400413 & -0.0400413 \\
27.5 & 0.0037457 & -0.0464679 & 0.0427222 & -0.0427222 \\
25.0 & 0.0038587 & -0.0488919 & 0.0450332 & -0.0450332 \\
21.0 & 0.0042097 & -0.0518492 & 0.0476395 & -0.0476395 \\
17.5 & 0.0047395 & -0.0550367 & 0.0502972 & -0.0502972 \\
15.0 & 0.0051483 & -0.0568830 & 0.0517347 & -0.0517347 \\
12.5 & 0.0054442 & -0.0582895 & 0.0528453 & -0.0528453 \\
10.0 & 0.0055943 & -0.0593422 & 0.0537479 & -0.0537479 \\
7.5 & 0.0059859 & -0.0601953 & 0.0542095 & -0.0542095 \\
5.0 & 0.0054903 & -0.0600541 & 0.0545639 & -0.0545639 \\
2.5 & 0.0054428 & -0.0607129 & 0.0552700 & -0.0552700 \\
0.0 & 0.0049895 & -0.0601720 & 0.0551825 & -0.0551825 \\
\hline
\end{tabular}

Tabela 44 - Teste de consistência utilizando a raiz $\omega_{8}$ e a equação do segundo grau com os dados do refletor de água leve

\begin{tabular}{|c|c|c|c|c|}
\hline & $\mathbf{A}$ & B & C & $\mathbf{A}+\mathbf{B}$ \\
\hline $\begin{array}{l}\text { BC\#1 BC\#2 } \\
\text { (\% retirada) }\end{array}$ & $\begin{array}{c}\omega^{2} \\
\tau_{c} \tau_{r}(1-\rho)\end{array}$ & $\begin{array}{c}\omega \\
\left\{(1-\rho)\left(\tau_{c}+\tau_{r} f\right)+\tau_{r}\left(\beta_{e f f}-\rho\right)(1-f)\right\}\end{array}$ & $(1-f)\left(\beta_{e f f}-\rho\right)$ & \\
\hline 32.5 & 0.4783399 & -0.5159346 & 0.0375947 & -0.0375947 \\
\hline 30.0 & 0.5311587 & -0.5712000 & 0.0400413 & -0.0400413 \\
\hline 27.5 & 0.4872704 & -0.5299926 & 0.0427222 & -0.0427222 \\
\hline 25.0 & 0.5255616 & -0.5705948 & 0.0450332 & -0.0450332 \\
\hline 21.0 & 0.5391224 & -0.5867619 & 0.0476395 & -0.0476395 \\
\hline 17.5 & 0.5337653 & -0.5840624 & 0.0502972 & -0.0502972 \\
\hline 15.0 & 0.5198755 & -0.5716102 & 0.0517347 & -0.0517347 \\
\hline 12.5 & 0.5129513 & -0.5657965 & 0.0528453 & -0.0528453 \\
\hline 10.0 & 0.5163848 & -0.5701327 & 0.0537479 & -0.0537479 \\
\hline 7.5 & 0.4909322 & -0.5451417 & 0.0542095 & -0.0542095 \\
\hline 5.0 & 0.5422716 & -0.5968355 & 0.0545639 & -0.0545639 \\
\hline 2.5 & 0.5612493 & -0.6165194 & 0.0552700 & -0.0552700 \\
\hline 0.0 & 0.6103087 & -0.6654912 & 0.0551825 & -0.0551825 \\
\hline
\end{tabular}


Tabela 45 - Teste de consistência da raiz $\omega_{7}$ com os dados do refletor de água leve

\begin{tabular}{cccc}
\hline BC\#1 BC\#2 & $\boldsymbol{\omega}_{7}$ Ajuste & $\boldsymbol{\omega}_{7}$ Calculado & \\
& & & \\
(\% retirada) & $\left(\mathbf{s}^{\mathbf{- 1}}\right)$ & $($ Equação 15) & $\boldsymbol{\Delta} \boldsymbol{\omega}_{7}$ \\
\hline 32.5 & $-1159.31(29.27)$ & -1159.31 & $2.30 \mathrm{E}-13$ \\
30.0 & $-1221.24(21.47)$ & -1221.24 & 0 \\
27.5 & $-1326.6(29.38)$ & -1326.6 & $4.50 \mathrm{E}-13$ \\
25.0 & $-1383.73(25.87)$ & -1383.73 & $4.50 \mathrm{E}-13$ \\
21.0 & $-1471.92(26.85)$ & -1471.92 & $4.50 \mathrm{E}-13$ \\
17.5 & $-1561.58(29.02)$ & -1561.58 & $4.50 \mathrm{E}-13$ \\
15.0 & $-1615.24(27.51)$ & -1615.24 & $2.30 \mathrm{E}-13$ \\
12.5 & $-1647.32(20.39)$ & -1647.32 & $2.30 \mathrm{E}-13$ \\
10.0 & $-1684.57(21.10)$ & -1684.57 & 0 \\
7.5 & $-1691.61(20.15)$ & -1691.61 & $2.30 \mathrm{E}-13$ \\
5.0 & $-1720.41(19.14)$ & -1720.41 & $1.10 \mathrm{E}-12$ \\
2.5 & $-1698.33(19.08)$ & -1698.33 & $4.60 \mathrm{E}-13$ \\
0.0 & $-1732.83(18.47)$ & -1732.83 & $4.50 \mathrm{E}-13$ \\
\hline
\end{tabular}

Tabela 46 - Teste de consistência da raiz $\omega_{8}$ com os dados do refletor de água leve

\begin{tabular}{cccc}
\hline BC\#1 BC\#2 & $\boldsymbol{\omega}_{\mathbf{8}}$ Ajuste & $\boldsymbol{\omega}_{\mathbf{8}}$ Calculado & \\
& & & \\
(\% retirada) & $\left(\mathbf{s}^{-1}\right)$ & & \\
\hline 32.5 & $-14750.19(3735.93)$ & -14750.6 & 0.42 \\
30.0 & $-16200.10(4044.57)$ & -16200.1 & 0.03 \\
27.5 & $-15130.49(1502.62)$ & -15130.6 & 0.14 \\
25.0 & $-16148.80(1250.00)$ & -16148.9 & 0.07 \\
21.0 & $-16657.30(1024.58)$ & -16657.3 & 0.01 \\
17.5 & $-16571.80(1228.67)$ & -16571.9 & 0.05 \\
15.0 & $-16231.26(726.91)$ & -16231.3 & 0.06 \\
12.5 & $-15990.05(866.07)$ & -15990 & 0.1 \\
10.0 & $-16184.65(912.21)$ & -16184.6 & 0.04 \\
7.5 & $-15319.51(886.01)$ & -15319.5 & 0.03 \\
5.0 & $-17097.96(839.08)$ & -17098 & 0.02 \\
2.5 & $-17245.60(801.71)$ & -17246 & 0.39 \\
0.0 & $-19168.70(1012.11)$ & -19164.8 & 3.89 \\
\hline
\end{tabular}




\section{B.2 AÇO INOX}

Tabela 47 - Teste de consistência utilizando a raiz $\omega_{7}$ e a equação do segundo grau com os dados do refletor de aço inox

\begin{tabular}{|c|c|c|c|c|}
\hline & $\mathbf{A}$ & B & C & $\mathbf{A}+\mathbf{B}$ \\
\hline $\begin{array}{l}\text { BC\#1 BC\#2 } \\
\text { (\% retirada) }\end{array}$ & $\begin{array}{c}\omega^{2} \\
\tau_{c} \tau_{r}(1-\rho)\end{array}$ & $\begin{array}{c}\omega \\
\left\{(1-\rho)\left(\tau_{c}+\tau_{r} f\right)+\tau_{r}\left(\beta_{e f f}-\rho\right)(1-f)\right\}\end{array}$ & $(1-f)\left(\beta_{e f f}-\rho\right)$ & \\
\hline 32.5 & 0.0026921 & -0.0369505 & 0.0342584 & -0.0342584 \\
\hline 30.0 & 0.0027808 & -0.0396704 & 0.0368896 & -0.0368896 \\
\hline 27.5 & 0.0034907 & -0.0429933 & 0.0395026 & -0.0395026 \\
\hline 25.0 & 0.0035547 & -0.0450422 & 0.0414875 & -0.0414875 \\
\hline 21.0 & 0.0039671 & -0.0488617 & 0.0448946 & -0.0448946 \\
\hline 17.5 & 0.0044513 & -0.0516895 & 0.0472382 & -0.0472382 \\
\hline 15.0 & 0.0048216 & -0.0532759 & 0.0484544 & -0.0484544 \\
\hline 12.5 & 0.0051150 & -0.0547538 & 0.0496388 & -0.0496388 \\
\hline 10.0 & 0.0064793 & -0.0576492 & 0.0511699 & -0.0511699 \\
\hline 7.5 & 0.0065136 & -0.0577359 & 0.0512224 & -0.0512224 \\
\hline 5.0 & 0.0066060 & -0.0587685 & 0.0521625 & -0.0521625 \\
\hline 2.5 & 0.0066938 & -0.0593796 & 0.0526858 & -0.0526858 \\
\hline 0.0 & 0.0074342 & -0.0596660 & 0.0522319 & -0.0522319 \\
\hline
\end{tabular}

Tabela 48 - Teste de consistência utilizando a raiz $\omega_{8}$ e a equação do segundo grau com os dados do refletor de aço inox

\begin{tabular}{|c|c|c|c|c|}
\hline & $\mathbf{A}$ & B & $\mathrm{C}$ & $\mathbf{A}+\mathbf{B}$ \\
\hline $\begin{array}{c}\text { BC\#1 BC\#2 } \\
\text { (\% retirada) }\end{array}$ & $\begin{array}{c}\omega^{2} \\
\tau_{c} \tau_{r}(1-\rho) \\
\end{array}$ & $\begin{array}{c}\omega \\
\left\{(1-\rho)\left(\tau_{c}+\tau_{r} f\right)+\tau_{r}\left(\beta_{e f f}-\rho\right)(1-f)\right\}\end{array}$ & $(1-f)\left(\beta_{e f f}-\rho\right)$ & \\
\hline 32.5 & 0.4359513 & -0.4702097 & 0.0342584 & -0.0342584 \\
\hline 30.0 & 0.4893652 & -0.5262548 & 0.0368896 & -0.0368896 \\
\hline 27.5 & 0.4470353 & -0.4865380 & 0.0395026 & -0.0395026 \\
\hline 25.0 & 0.4842049 & -0.5256924 & 0.0414875 & -0.0414875 \\
\hline 21.0 & 0.5080575 & -0.5529522 & 0.0448946 & -0.0448946 \\
\hline 17.5 & 0.5013047 & -0.5485430 & 0.0472382 & -0.0472382 \\
\hline 15.0 & 0.4869429 & -0.5353973 & 0.0484544 & -0.0484544 \\
\hline 12.5 & 0.4817173 & -0.5313560 & 0.0496388 & -0.0496388 \\
\hline 10.0 & 0.4041091 & -0.4552790 & 0.0511699 & -0.0511699 \\
\hline 7.5 & 0.4028099 & -0.4540322 & 0.0512224 & -0.0512224 \\
\hline 5.0 & 0.4118850 & -0.4640475 & 0.0521625 & -0.0521625 \\
\hline 2.5 & 0.4146793 & -0.4673651 & 0.0526858 & -0.0526858 \\
\hline 0.0 & 0.3669760 & -0.4192078 & 0.0522319 & -0.0522319 \\
\hline
\end{tabular}


Tabela 49 - Teste de consistência da raiz $\omega_{7}$ com os dados do refletor de aço inox

\begin{tabular}{|c|c|c|c|}
\hline $\begin{array}{l}\text { BC\#1 BC\#2 } \\
\text { (\% retirada) }\end{array}$ & $\begin{array}{c}\omega_{7} \text { Ajuste } \\
\left(\mathrm{s}^{-1}\right)\end{array}$ & $\begin{array}{l}\omega_{7} \text { Calculado } \\
\text { (Equação 15) }\end{array}$ & $\Delta \omega_{7}$ \\
\hline 32.5 & $-1076.03(17.88)$ & -1076.03 & $6.8 \mathrm{E}-13$ \\
\hline 30.0 & $-1175.63(20.67)$ & -1175.63 & 0 \\
\hline 27.5 & $-1246.92(5.81)$ & -1246.92 & $9.1 \mathrm{E}-13$ \\
\hline 25.0 & $-1277.28(14.65)$ & -1277.28 & $2.3 \mathrm{E}-13$ \\
\hline 21.0 & $-1350.11(6.29)$ & -1350.11 & 0 \\
\hline 17.5 & $-1461.19(8.44)$ & -1461.19 & $6.8 \mathrm{E}-13$ \\
\hline 15.0 & $-1514.28(7.04)$ & -1514.28 & $2.3 \mathrm{E}-13$ \\
\hline 12.5 & $-1542.46(9.73)$ & -1542.46 & 4.6E-13 \\
\hline 10.0 & $-1569.46(10.04)$ & -1569.46 & 0 \\
\hline 7.5 & $-1583.67(8.47)$ & -1583.67 & $4.5 \mathrm{E}-13$ \\
\hline 5.0 & $-1615.16(9.94$ & -1615.16 & 4.6E-13 \\
\hline 2.5 & $-1633.74(9.36)$ & -1633.74 & $6.8 \mathrm{E}-13$ \\
\hline 0.0 & $-1624.94(10.90)$ & -1624.94 & $4.6 \mathrm{E}-13$ \\
\hline
\end{tabular}

Tabela 50 - Teste de consistência da raiz $\omega_{8}$ com os dados do refletor de aço inox

\begin{tabular}{cccc}
\hline BC\#1 BC\#2 & $\boldsymbol{\omega}_{\mathbf{8}}$ Ajuste & $\boldsymbol{\omega}_{\mathbf{8}}$ Calculado & \\
(\% retirada) & $\left(\mathbf{s}^{-\mathbf{1}}\right)$ & $($ Equação 15) & $\boldsymbol{\Delta} \boldsymbol{\omega}_{\mathbf{8}}$ \\
\hline 32.5 & $-13692.80(2541.98)$ & -13692.90 & 0.10 \\
30.0 & $-15595.50(3210.55)$ & -15595.57 & 0.07 \\
27.5 & $-14110.86(1249.83)$ & -14110.89 & 0.03 \\
25.0 & $-14907.20(954.62)$ & -14907.27 & 0.07 \\
21.0 & $-15278.73(886.74)$ & -15278.75 & 0.02 \\
17.5 & $-15506.49(930.12)$ & -15506.52 & 0.03 \\
15.0 & $-15217.88(1201.30)$ & -15217.78 & 0.10 \\
12.5 & $-14968.72(962.65)$ & -14968.74 & 0.02 \\
10.0 & $-12394.39(845.53)$ & -12394.65 & 0.26 \\
7.5 & $-12453.82(785.62)$ & -12453.89 & 0.07 \\
5.0 & $-12753.40(933.27)$ & -12753.62 & 0.22 \\
2.5 & $-12858.80(941.96)$ & -12858.84 & 0.04 \\
0.0 & $-11416.67(1022.07)$ & -11416.67 & $4.2 \mathrm{E}-3$ \\
\hline
\end{tabular}




\section{A.3 ÁGUA PESADA}

Tabela 51 - Teste de consistência utilizando a raiz $\omega_{7}$ e a equação do segundo grau com os dados do refletor de água pesada

\begin{tabular}{|c|c|c|c|c|}
\hline & $\mathbf{A}$ & B & C & $A+B$ \\
\hline $\begin{array}{c}\text { BC\#1 BC\#2 } \\
\text { (\% retirada) }\end{array}$ & $\begin{array}{c}\omega^{2} \\
\tau_{c} \tau_{r}(1-\rho)\end{array}$ & $\stackrel{\omega}{\left\{(1-\rho)\left(\tau_{c}+\tau_{r} f\right)+\tau_{r}\left(\beta_{e f f}-\rho\right)(1-f)\right\}}$ & $(1-f)\left(\beta_{\text {eff }}-\rho\right)$ & \\
\hline 22.5 & 0.0015865 & -0.0381012 & 0.0365147 & -0.0365147 \\
\hline 20.0 & 0.0020089 & -0.0403955 & 0.0383866 & -0.0383866 \\
\hline 15.0 & 0.0021363 & -0.0429532 & 0.0408169 & -0.0408169 \\
\hline 10.0 & 0.0020959 & -0.0444072 & 0.0423113 & -0.0423113 \\
\hline 5.0 & 0.0021440 & -0.0453361 & 0.0431921 & -0.0431921 \\
\hline 0.0 & 0.0016244 & -0.0448490 & 0.0432246 & -0.0432246 \\
\hline
\end{tabular}

Tabela 52 - Teste de consistência utilizando a raiz $\omega_{8}$ e a equação do segundo grau com os dados do refletor de água pesada

\begin{tabular}{|c|c|c|c|c|}
\hline & $\mathbf{A}$ & B & $\mathbf{C}$ & $\mathbf{A}+\mathbf{B}$ \\
\hline $\begin{array}{l}\text { BC\#1 BC\#2 } \\
\text { (\% retirada) }\end{array}$ & $\begin{array}{c}\omega^{2} \\
\tau_{c} \tau_{r}(1-\rho) \\
\end{array}$ & $\begin{array}{c}\omega \\
\left\{(1-\rho)\left(\tau_{c}+\tau_{r} f\right)+\tau_{r}\left(\beta_{e f f}-\rho\right)(1-f)\right\}\end{array}$ & $(1-f)\left(\beta_{e f f}-\rho\right)$ & \\
\hline 22.5 & 0.8404319 & -0.8769466 & 0.0365147 & -0.0365147 \\
\hline 20.0 & 0.7335062 & -0.7718928 & 0.0383866 & -0.0383866 \\
\hline 15.0 & 0.7798648 & -0.8206817 & 0.0408169 & -0.0408169 \\
\hline 10.0 & 0.8541871 & -0.8964984 & 0.0423113 & -0.0423113 \\
\hline 5.0 & 0.8701343 & -0.9133264 & 0.0431921 & -0.0431921 \\
\hline 0.0 & 1.1501761 & -1.1934007 & 0.0432246 & -0.0432246 \\
\hline
\end{tabular}

Tabela 53 - Teste de consistência da raiz $\omega_{7}$ com os dados do refletor de água pesada

\begin{tabular}{|c|c|c|c|}
\hline $\begin{array}{c}\text { BC\#1 \#2 } \\
\text { (\% retirada) }\end{array}$ & $\begin{array}{c}\omega_{7} \text { Ajuste } \\
\left(s^{-1}\right)\end{array}$ & $\begin{array}{l}\omega_{7} \text { Calculado } \\
\text { (Equação 15) }\end{array}$ & $\Delta \omega_{7}$ \\
\hline 22.5 & $-1145.32(11.82)$ & -1145.32 & 0 \\
\hline 20.0 & $-1204.20(5.40)$ & -1204.20 & $4.55 \mathrm{E}-13$ \\
\hline 15.0 & $-1274.18(12.43)$ & -1274.18 & 0 \\
\hline 10.0 & $-1325.77(10.86)$ & -1325.77 & $4.55 \mathrm{E}-13$ \\
\hline 5.0 & -1365.15 (13.16) & -1365.15 & 0 \\
\hline 0.0 & $-1395.95(19.36)$ & -1395.95 & $2.27 \mathrm{E}-13$ \\
\hline
\end{tabular}


Tabela 54 - Teste de consistência da raiz $\omega_{8}$ com os dados do refletor de água pesada

\begin{tabular}{cccc}
\hline BC\#1 \#2 & $\boldsymbol{\omega}_{\mathbf{8}}$ Ajuste & \multicolumn{1}{c}{$\boldsymbol{\omega}_{\mathbf{8}}$ Calculado } & \\
& & & \\
(\% retirada) & $\left(\mathbf{s}^{\mathbf{1}}\right)$ & $($ Equação 15) & $\boldsymbol{\Delta} \boldsymbol{\omega}_{\mathbf{8}}$ \\
\hline 22.5 & $-26360.43(3650.11)$ & -26360.98 & 0.55 \\
20.0 & $-23010.14(2112.72)$ & -23010.26 & 0.12 \\
15.0 & $-24344.66(1156.26)$ & -24345.00 & 0.34 \\
10.0 & $-26765.42(1393.55$ & -26764.82 & 0.60 \\
5.0 & $-27501.32(1789.71)$ & -27501.79 & 0.47 \\
0.0 & $-37144.72(1561.60)$ & -37145.26 & 0.54 \\
\hline
\end{tabular}




\section{ANEXO C - CARACTERIZAÇÃO DOS DETECTORES DE NÊUTRONS}

Os novos detectores do reator IPEN/MB-01 foram adquiridos a partir do projeto de pesquisa "Adequação das Instalações para fornecimento de combustível para o RMB", nº 01.13.0389.00, pela Financiadora de Estudos e Projetos (FINEP).

A finalidade da compra se destina para o monitoramento da criticalização do reator durante a mudança o material combustível. Este material combustível será utilizado para a validação dos dados nucleares do Reator Multipropósito Brasileiro (RMB). Como a previsão para se iniciar os testes com o material combustível do RMB está prevista para o ano de 2019, os detectores serão utilizados para a aquisição de dados via técnica de ruído neutrônico. Por se tratar de detectores com uma maior sensibilidade a nêutrons térmicos, pretende-se realizar experimentos com níveis de subcriticalidade nunca antes atingidos. Nesse contexto, realizou-se o procedimento de caracterização destes detectores antes de serem utilizados em um experimento real.

A caracterização dos detectores tem como objetivo a obtenção das tensões de operação dos detectores, dos seus espectros energéticos e, por fim, a obtenção do tempo morto dos detectores. Este último é de fundamental importância, pois os eventos correlacionados detectados referentes ao efeito do refletor pela técnica de Rossi- $\alpha$ podem ser discriminados apenas com o conhecimento desta característica intrínseca do detector.

As tensões de operação foram obtidas utilizando uma fonte de Am-Be com atividade de $100 \mathrm{mCi}$. Os detectores foram posicionados a uma distancia de $10 \mathrm{~cm}$ da fonte. As contagens para cada detector foram adquiridas utilizando os módulos nucleares da ORTEC juntamente com o software MAESTRO. Como a radiação gama deve ser obrigatoriamente discriminada dos pulsos de nêutrons, para este propósito, os espectros energéticos foram obtidos posteriormente.

O tempo morto dos detectores foi obtido através da técnica de ruído neutrônico Rossi- $\alpha$. Devido ao fato da fonte radioativa de Am-Be seguir a distribuição de Poisson, 
a detecção dos eventos a partir deste método irá gerar uma curva na qual os dados experimentais flutuam em torno de um valor médio, como ocorre, por exemplo, com o ruído branco. Estes eventos ocorrem com uma taxa média conhecida e independente do tempo do evento ocorrido/detectado anteriormente. [63, 64]

Após a obtenção da curva de tensão de operação, do espectro energético e do tempo morto dos detectores, realizou-se um experimento real, posicionando os detectores dentro do núcleo, nas posições centrais da face leste do núcleo. Com os experimentos considerando a aquisição de dados a partir do reator, obteve-se as densidades espectrais de auto correlação (APSD) para os novos detectores. Estes resultados foram comparados com o detector já conhecido e que é atualmente utilizado para as medidas de análise de ruído. Uma comparação teórico/experimental foi realizada a partir dos dados simulados para estes experimentos a partir do código computacional MCNP5 com a biblioteca de dados nucleares ENDF/B-VII.0.

Para se obter os estados de subcriticalidade, os bancos de controle foram responsáveis pela inserção de reatividade negativa. A posição inicial dos bancos de controle foi em $55 \%$ retirados, até a posição final, com ambos os bancos totalmente inseridos. Durante toda a movimentação dos bancos de controle, foi empregada a configuração padrão de 28x26 varetas combustíveis.

Os detectores utilizados no processo de caracterização foram os contadores proporcionais gasosos de ${ }^{3} \mathrm{He}$ e de $\mathrm{BF}_{3}$, produzidos pela empresa CENTRONIC. As principais características dos detectores empregados neste trabalho estão descritas logo abaixo. O detector identificado como "A" foi utilizado como referencia durante o experimento, já os detectores "B" e "C" foram os utilizados tanto para a caracterização quanto no experimento.

\footnotetext{
A. ${ }^{3} \mathrm{He}$ : Centronic, modelo 50He3-760/38E Pressão do gás: $760 \mathrm{~cm} \mathrm{Hg}$ Sensibilidade à nêutrons térmicos: $~ 186 \mathrm{cps} / \mathrm{nv}$

B. ${ }^{3} \mathrm{He}$ : Centronic, modelo $100 \mathrm{He} 3-152 / 38 \mathrm{HS}$ Pressão do gás: $152 \mathrm{~cm} \mathrm{Hg}$ Sensibilidade à nêutrons térmicos: 202 cps/nv

C. $\mathrm{BF}_{3}$ : Centronic, modelo 107EB70-50HS Pressão do gás: $70 \mathrm{~cm} \mathrm{Hg}$ Sensibilidade à nêutrons térmicos: $~ 150 \mathrm{cps} / \mathrm{nv}$
} 
A figura 19 é uma fotografia tirada dos detectores.

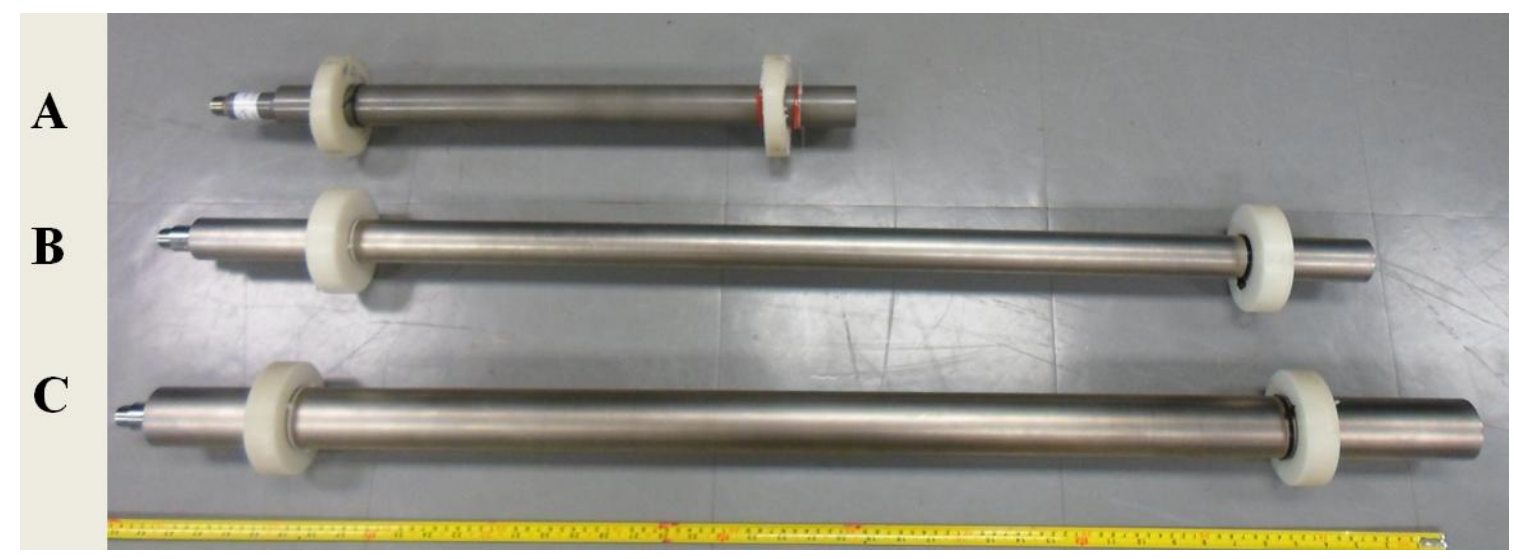

Figura 19 - Foto dos detectores utilizados no processo de caracterização. A distância medida pela fita métrica é de $110 \mathrm{~cm}$.

Além da técnica de Rossi- $\alpha$, também foi empregada a técnica de análise de ruído macroscópica, denominada por densidade espectral (APSD - Auto Power Spectral Density). Um diagrama dos equipamentos da eletrônica, do sistema de aquisição de dados, e do processamento dos dados está ilustrado na figura 20. De acordo com esta figura, os pulsos de nêutrons dos detectores são formatados e amplificados, respectivamente, pelo pré amplificador e pelo amplificador. Posteriormente estes pulsos são discriminados da radiação gama e dos ruídos espúrios através do modulo nuclear mono canal (Single Channel Analyzer - SCA) [65]. A opção utilizada para a discriminação entre dos pulsos foi atribuída pela opção "Lower Level discriminator". Os pulsos de saída deste módulo são pulsos lógicos negativos, padrão NIM [66], com largura de $25 \eta \mathrm{s}$ e amplitude de $-5 \mathrm{~V}$ e impedância de $50 \Omega$. Por fim, a placa de aquisição de dados do tipo multicanal "Multichannel Scaler" (MCS) [67] registra os pulsos lógicos em um determinado intervalo de tempo referente a cada canal da placa, este tempo é comumente definido como "dwell time" [68, 47]. 


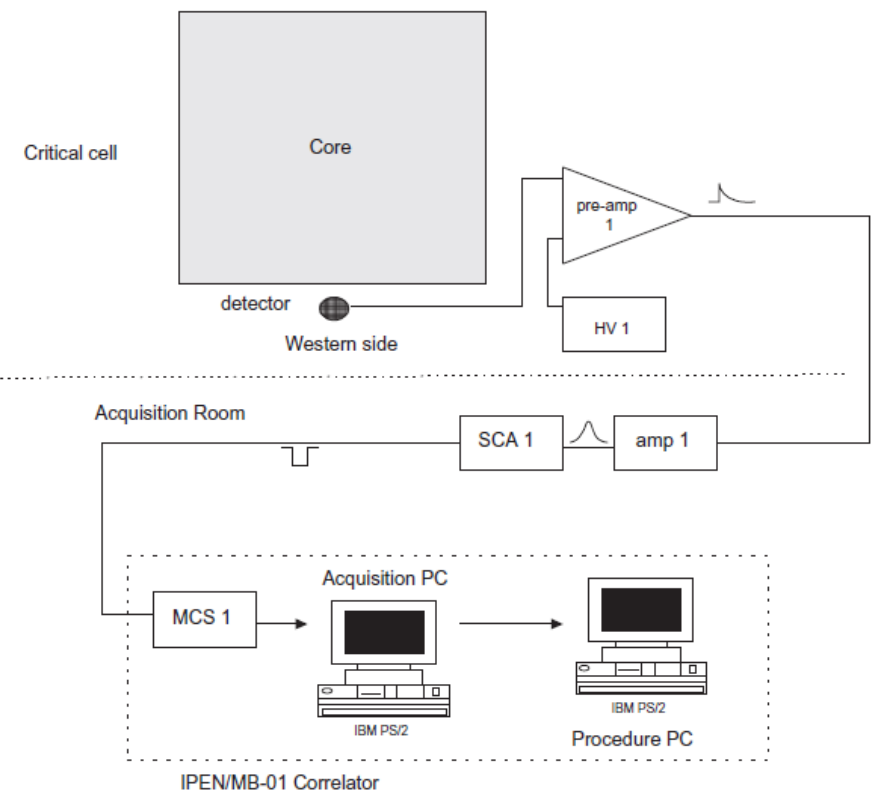

Figura 20 - Ilustração representando o diagrama da eletrônica, aquisição de dados e sistema de processamento de dados utilizados nas medidas de análise de ruído neutrônico.

O principio físico do método de Rossi- $\alpha$ baseia-se na diferença de tempo entre os pares de nêutrons detectados. A partir dessa quantificação dos pulsos de nêutrons, é possível realizar a correlação entre os eventos com ancestral comum, ou seja, detectar os nêutrons pertencentes à mesma cadeia de fissão. Por esta razão, somente 01 nêutron por canal deve ser detectado [41]. A figura 21 mostra o esquema da placa multicanal de aquisição de dados (MCS) para as densidades espectrais e para o método de Rossi- $\alpha$.

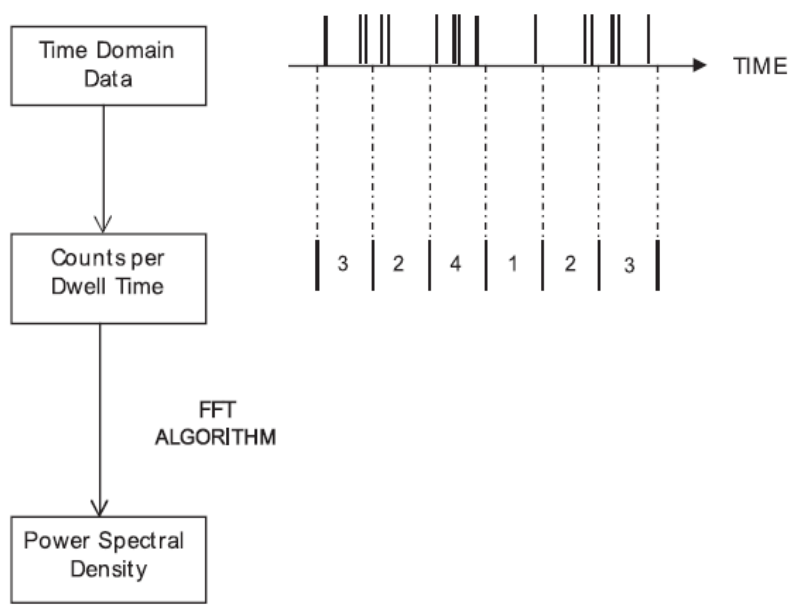

Figura 21 - Esquema do processamento de dados das densidades espectrais e curvas Rossi- $\alpha$.

A figura 22 mostra o sistema de aquisição de dados com os módulos nucleares e o arranjo experimental entre o detector e a fonte de nêutrons. 

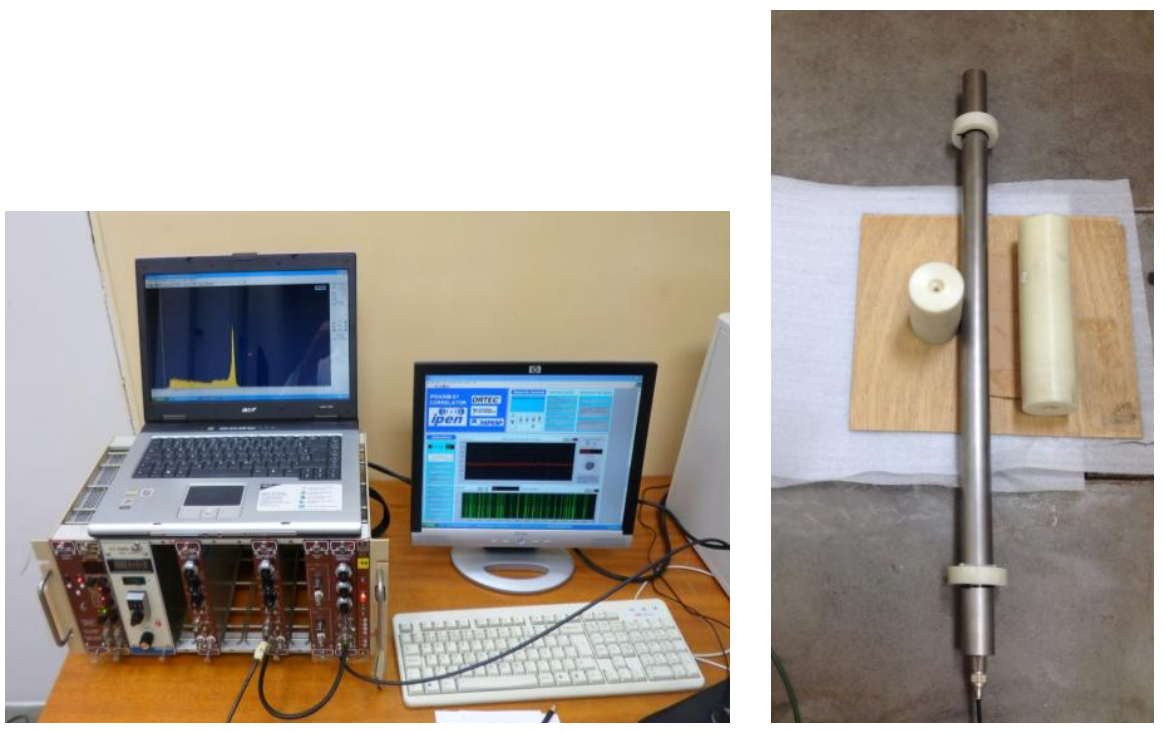

Figura 22 - Fotos do sistema de aquisição de dados com os módulos nucleares (esquerda) e o arranjo experimental entre o detector e a fonte de nêutrons (direita).

A figura 23 mostra o interior do cilindro de polietileno com a fonte e a distância entre detector e fonte, utilizando uma fita métrica.
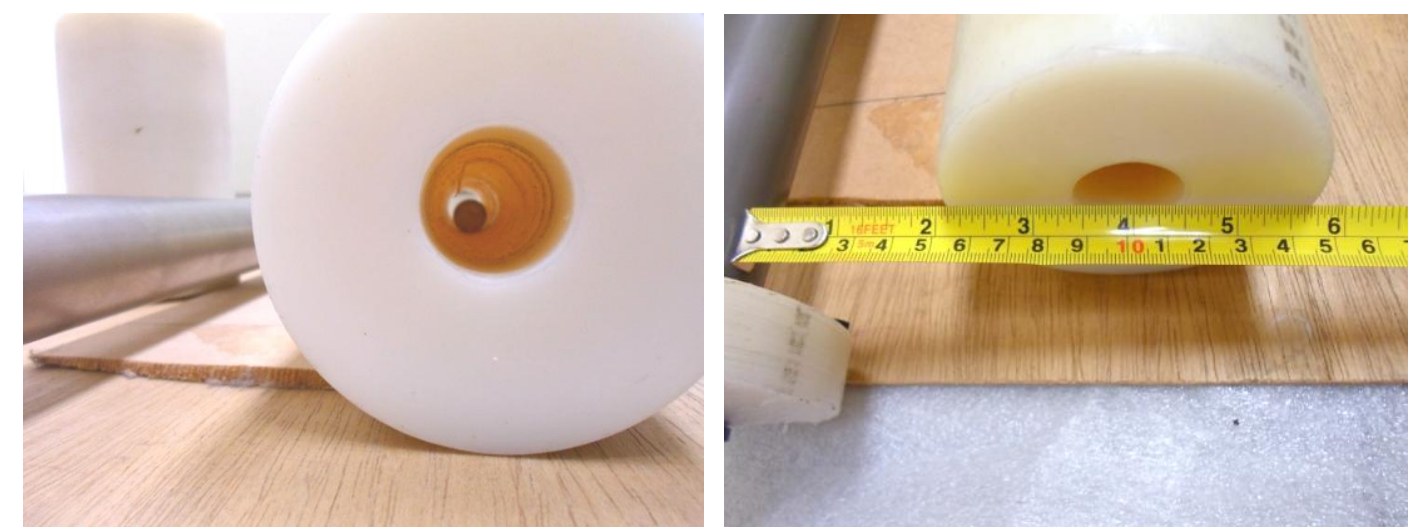

Figura 23 - Fotos do interior do cilindro de polietileno com a fonte de nêutrons (esquerda) e da distância entre detector e fonte, utilizando uma fita métrica (direita).

O polietileno é utilizado para este tipo de experimento por conta da sua alta densidade e abundância em átomos de hidrogênio. Por conta disso, é utilizado para diminuir a energia cinética dos nêutrons rápidos para a faixa de energia térmica. A distância entre o detector e a fonte de nêutrons é de $10 \mathrm{~cm}$ e a espessura do polietileno é de $3.5 \mathrm{~cm}$.

As curvas de tensão de operação dos detectores de ${ }^{3} \mathrm{He}$ e de $\mathrm{BF}_{3}$ estão ilustradas na figura 24. 

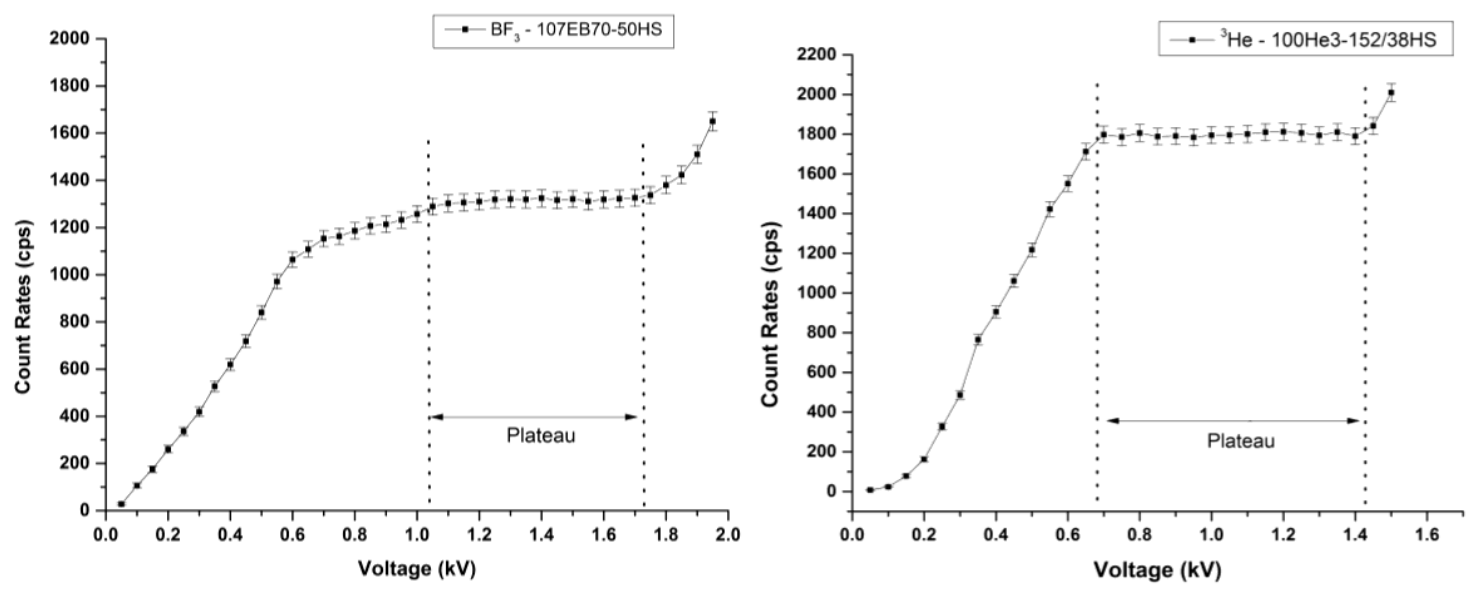

Figura 24 - Curvas de tensão de operação para o detector de $\mathrm{BF}_{3}$ (esquerda) e de ${ }^{3} \mathrm{He}$ (direita).

As curvas de tensão de operação dos detectores foram obtidas a partir do valor médio do plateau da região proporcional. Os valores de tensão encontrados foram $1375 \mathrm{~V}$ e $1050 \mathrm{~V}$ para os detectores de $\mathrm{BF}_{3}$ (107EB70-50HS) e ${ }^{3} \mathrm{He}(100 \mathrm{He} 3-152 / 38 \mathrm{HS})$, respectivamente. Esta região representa que o detector está trabalhando na região de proporcionalidade, na qual a tensão aplicada entre o fio do ânodo e o cátodo fornece um campo elétrico suficiente para desencadear o processo físico de multiplicação das cargas elétricas no gás [69].

Através dos valores médios das tensões dos plateaux, os espectros de energia dos detectores B e C foram obtidos a partir da utilização da fonte de Am-Be de $100 m \mathrm{Ci}$. Os espectros energéticos dos detectores de $\mathrm{BF}_{3}$ (107EB70-50HS) e ${ }^{3} \mathrm{He}(100 \mathrm{He} 3-$ 152/38HS) estão ilustrados a seguir na figura 25. Além disso, estes espectros foram obtidos utilizando os valores de tensões de no parágrafo anterior, $1375 \mathrm{~V}$ e $1050 \mathrm{~V}$.
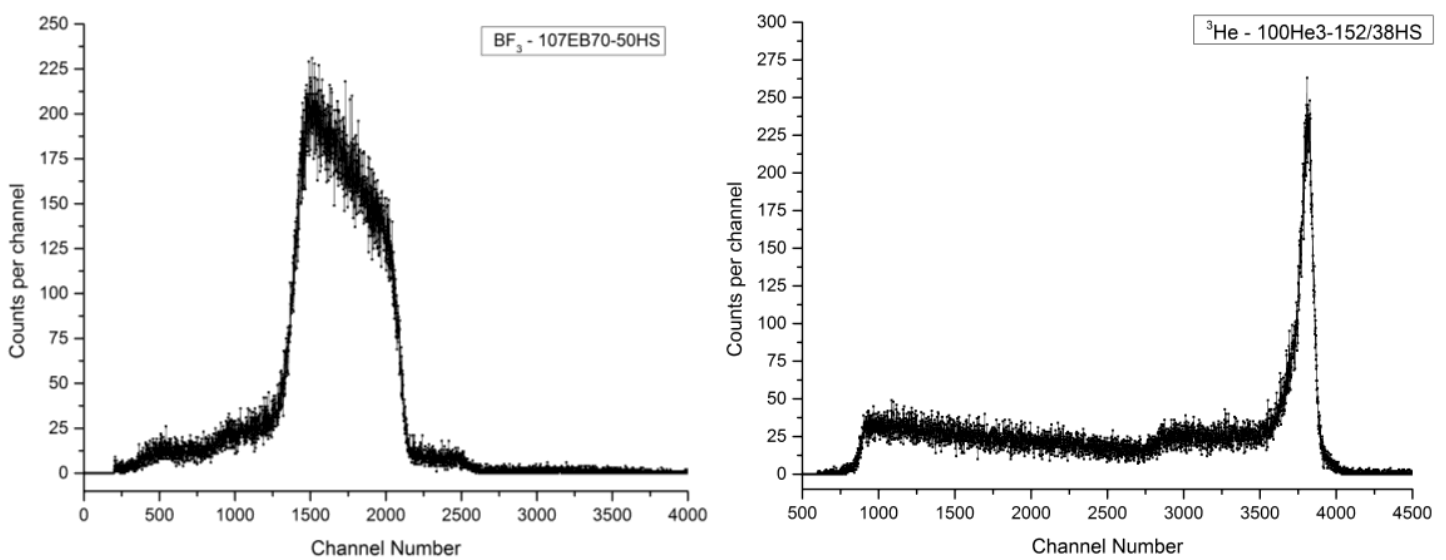

Figura 25 - Espectros energéticos dos detectores de $\mathrm{BF}_{3}$ (esquerda - C) e de ${ }^{3} \mathrm{He}$ (direita - B). 
$\mathrm{O}$ espectro energético do detector de ${ }^{3} \mathrm{He}(50 \mathrm{He} 3-760 / 38 \mathrm{E})$, denotado por A, também foi obtido. Como mencionado na seção5 deste trabalho, este detector foi utilizado para a obtenção das curvas Rossi- $\alpha$ para os estados mais subcríticos utilizando os refletores de água leve, aço inox e água pesada. A figura 26 ilustra o espectro energético para o detector A, obtido pela fonte de Am-Be de $100 \mathrm{mCi}$

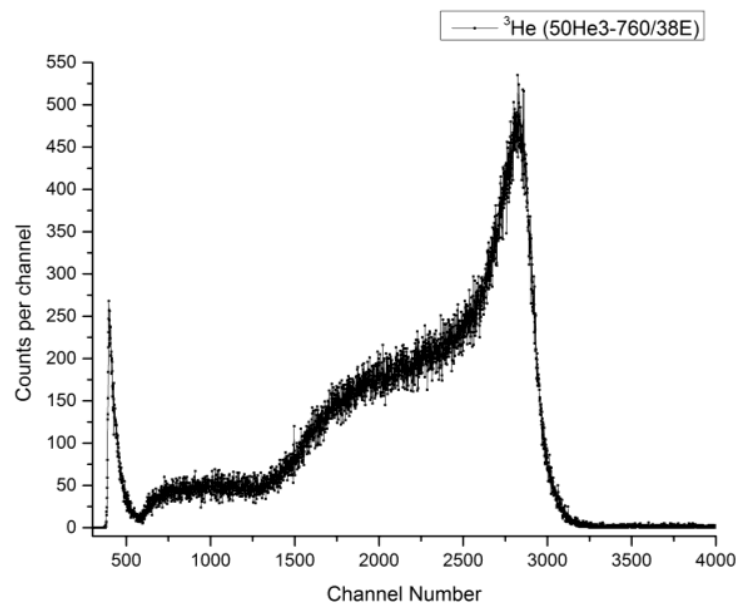

Figura 26 - Espectro energético do detector de ${ }^{3} \mathrm{He}(\mathrm{A})$.

A figura 27 contém os gráficos da determinação do tempo morto dos detectores de ${ }^{3} \mathrm{He}(100 \mathrm{He} 3-152 / 38 \mathrm{HS})$ e $\mathrm{BF}_{3}$ (107EB70-50HS) a partir do método de Rossi- $\alpha$. A contagem entre as diferenças de intervalos de tempo dos pares de pulsos de nêutrons está representada no eixo "Y", denotado por "contagem", enquanto que o tempo para cada evento correlacionado está representado no eixo " $X$ ”. É possível notar que o tempo morto para o detector de ${ }^{3} \mathrm{He}$ é aproximadamente 5.8 vezes maior do que o tempo morto do detector de $\mathrm{BF}_{3}$.
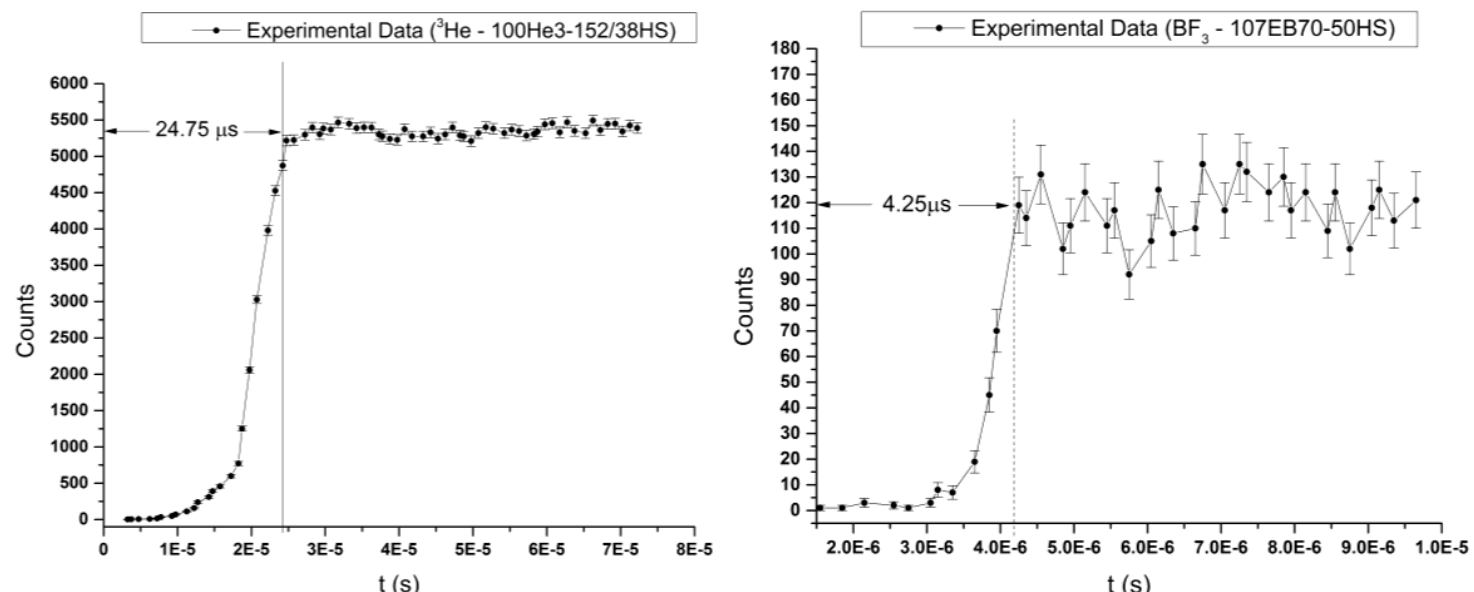

Figura 27 - Gráfico dos eventos correlacionados e determinação do tempo morto para o detector de ${ }^{3} \mathrm{He}$ (esquerda - B) e para o detector de $\mathrm{BF}_{3}$ (direita - C). 
Já para o detector de ${ }^{3} \mathrm{He}(50 \mathrm{He} 3-760 / 38 \mathrm{E})$, pode-se ver pela figura 28 que o tempo morto medido é de 11.13us.

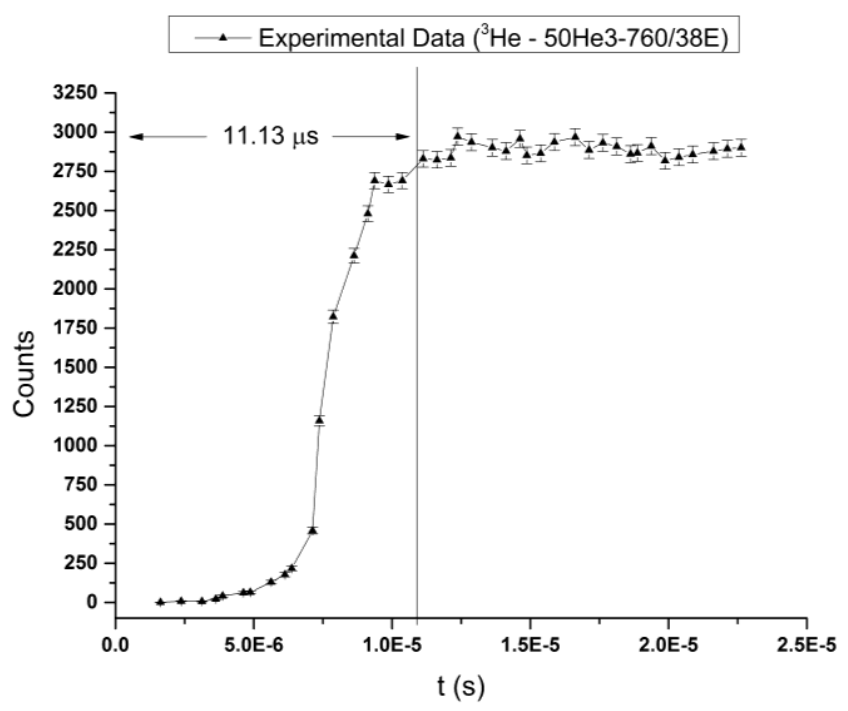

Figura 28 - Gráfico dos eventos correlacionados e determinação do tempo morto para o detector de ${ }^{3} \mathrm{He}$.

A tabela 55 contém os resultados para a constante de decaimento de nêutrons prontos $(\alpha)$ obtidos através do ajuste de mínimos quadrados aos dados experimentais do tipo APSD para cada posição de banco de controle utilizado neste experimento.

Tabela 55 - Constantes de decaimento de nêutrons prontos $(\alpha)$ obtidas pela cinética pontual

\begin{tabular}{cccc}
\hline $\begin{array}{c}\text { Bancos de } \\
\text { controle }\end{array}$ & ${ }^{3} \mathbf{H e}$ & $\mathbf{B F}_{3}$ & ${ }^{3} \mathbf{H e}$ \\
& & & \\
(\% retirada) & $\mathbf{5 0 H e 3 - 7 6 0 / 3 8 E}$ & $\mathbf{1 0 7 E B 7 0 - 5 0 H S}$ & $\mathbf{1 0 0 H e 3 - 1 5 2 / 3 8 H S}$ \\
\hline 55 & $-341.13(3.42)$ & $-325.82(2.50)$ & $-318.96(3.26)$ \\
50 & $-519.18(4.00)$ & $-498.46(3.20)$ & $-501.31(3.47)$ \\
40 & $-868.85(6.26)$ & $-844.11(6.43)$ & $-832.23(6.41)$ \\
30 & $-1192.44(10.05)$ & $-1135.14(10.97)$ & $-1125.55(10.47)$ \\
25 & $-1287.83(11.63)$ & $-1273.23(13.87)$ & $-1245.41(22.92)$ \\
20 & $-1422.04(13.45)$ & $-1397.16(16.53)$ & $-1353.57(13.07)$ \\
15 & $-1470.90(13.66)$ & $-1474.61(18.95)$ & $-1438.84(15.16)$ \\
10 & $-1551.58(14.95)$ & $-1466.66(19.41)$ & $-1514.85(16.39)$ \\
5 & $-1595.60(15.53)$ & $-1490.61(20.31)$ & $-1504.15(17.56)$ \\
0 & $-1596.41(15.91)$ & $-1461.72(20.01)$ & $-1526.84(16.16)$ \\
\hline
\end{tabular}


A figura 29 mostra os valores de reatividade para todos os passos de inserção dos bancos de controle deste experimento.

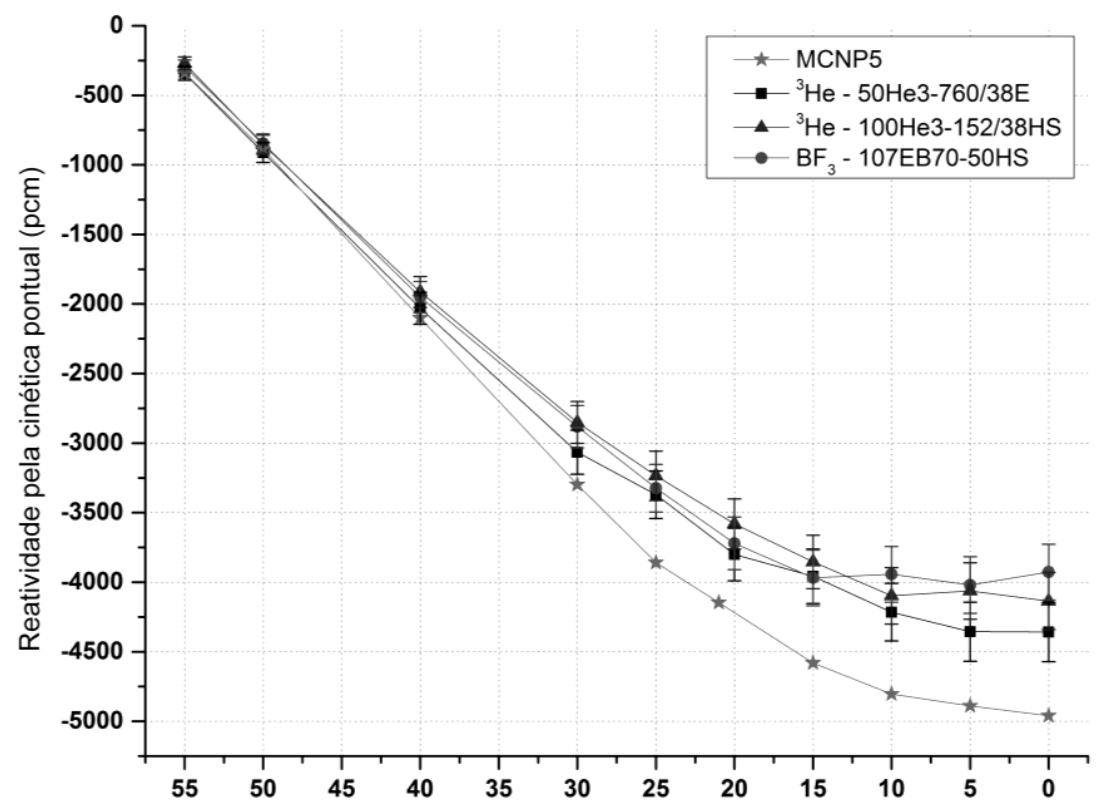

Figura 29 - Resultados de reatividade para cada passo de inserção de banco de controle.

O tempo de geração de nêutrons prontos $(\Lambda)$ e a fração efetiva de nêutrons atrasados $\left(\beta_{\mathrm{eff}}\right)$ foram mantidos constantes durante o método de ajuste por mínimos quadrados e seus valores foram, respectivamente, $(31.96 \pm 1.06) \mu$ s e $(750 \pm 19) \mathrm{pcm}$. Os valores destes parâmetros cinéticos foram extraídos do IRPhE Handbook [70].

Devido à alta sensibilidade do detector de hélio-3, o tempo morto obtido para este detector é maior do que o tempo morto do detector de $\mathrm{BF}_{3}$. O tempo morto obtido para o detector de ${ }^{3} \mathrm{He} \quad(100 \mathrm{He} 3-152 / 38 \mathrm{HS})$ e $\mathrm{BF}_{3} \quad(107 \mathrm{~EB} 70-50 \mathrm{HS})$ são, respectivamente, $24.75 \mu \mathrm{s}$ e $4.25 \mu \mathrm{s}$. Os efeitos do tempo morto provenientes do inicio da resposta dos detectores para os pulsos detectados e o comportamento da zona de transição para os detectores analisados estão de acordo com a literatura [71], onde estes fenômenos podem ser observados no início dos gráficos das figuras 27 e 28 .

Um aspecto que deve ser destacado em relação ao tempo morto do detector é a placa multicanal (MCS) de processamento e aquisição de dados. Durante o processo de aquisição de dados, esta não apresenta tempo morto entre os seus canais adjacentes [67], não interferindo na medida do tempo morto do detector. 
Os resultados de reatividade obtidos experimentalmente através das densidades espectrais para os detectores estão qualitativa e quantitativamente de acordo, quando comparados entre si. Pode-se ver este comportamento na figura 29 para os dados representados pelos símbolos quadrado, triangulo e circulo na qual são referentes aos detectores de ${ }^{3} \mathrm{He}$ e $\mathrm{BF}_{3}$.

Os resultados experimentais concordam entre si para um intervalo de $1 \sigma \mathrm{em}$ todas as posições de bancos de controle apesar das diferenças entre as suas propriedades físicas, gasosas, geométricas e das tensões operacionais. Estes resultados representam consistência para o método empregado e sugerem que os detectores estão medindo o mesmo fenômeno físico. Nesse caso, seria a preservação do processo de detecção dos nêutrons correlacionados, ou seja, pertencentes à mesma cadeia de fissão.

Os resultados calculados pelo código computacional MCNP5 estão de acordo com os resultados experimentais obtidos pelo ajuste não linear das densidades espectrais, isso para um determinado intervalo de reatividade subcrítica. A figura 29 mostra a concordância entre estes resultados de $55.0 \%$ até $40.0 \%$ dos bancos de controle retirados. Para uma representação em termos de reatividade, seria do intervalo de -350 pcm até -2500 pcm. Em estados de reatividade mais subcríticos, a diferença entre os resultados simulados e experimentais tendem a aumentar. Este comportamento já foi previsto anteriormente em outros trabalhos relacionados aos estudos da reatividade subcrítica [47].

O tempo morto do detector de ${ }^{3} \mathrm{He}(50 \mathrm{He} 3-760 / 38 \mathrm{E})$, que foi utilizado para os experimentos com refletores, apresentou um tempo morto de $11.13 \mu \mathrm{s}$. Isso significa que o detector não é capaz de registrar intervalos de tempo entre dois pulsos menores que este valor. A tabela 56 contém os menores valores de intervalo de tempo entre dois pulsos para todas as curvas experimentais de distribuição Rossi- $\alpha$. A partir desta comparação é possível provar que a queda observada nos primeiros canais de distribuição das curvas Rossi- $\alpha$ não é oriunda do tempo morto do detector, mas do efeito do refletor. 
Tabela 56 - Menores valores de intervalo de tempo entre dois pulsos para as curvas Rossi- $\alpha$

\begin{tabular}{|c|c|c|c|c|}
\hline $\begin{array}{c}\text { Bancos de controle } \\
\text { (\% retirada) }\end{array}$ & $\begin{array}{c}\text { Água Leve } \\
(\mu \mathrm{s})\end{array}$ & $\begin{array}{c}\text { Aço Inox } \\
(\mu s)\end{array}$ & $\begin{array}{c}\text { Bancos de controle } \\
\text { (\% retirada) }\end{array}$ & $\begin{array}{c}\text { Água Pesada } \\
(\mu s)\end{array}$ \\
\hline 32.5 & 52.63 & 50.33 & - & - \\
\hline 30.0 & 55.64 & 59.95 & - & - \\
\hline 27.5 & 67.19 & 62.16 & - & - \\
\hline 25.0 & 65.19 & 63.84 & - & - \\
\hline 21.0 & 64.52 & 62.01 & - & - \\
\hline 17.5 & 61.19 & 61.49 & - & - \\
\hline 15.0 & 53.54 & 65.45 & - & - \\
\hline 12.5 & 50.04 & 49.65 & 22.5 & 39.18 \\
\hline 10.0 & 50.80 & 45.57 & 20.0 & 47.46 \\
\hline 7.5 & 53.54 & 44.38 & 15.0 & 55.64 \\
\hline 5.0 & 50.04 & 41.96 & 10.0 & 36.52 \\
\hline 2.5 & 43.04 & 39.55 & 5.0 & 31.57 \\
\hline 0.0 & 49.19 & 13.15 & 0.0 & 41.18 \\
\hline
\end{tabular}

O método desenvolvido para a caracterização dos detectores de nêutrons será extremamente útil para os experimentos empregando as técnicas de analise de ruído de nêutrons, em especial para os métodos de Rossi- $\alpha$ e Feynman- $\alpha$. Como já mencionado anteriormente, a determinação do tempo morto dos detectores é importante para discriminar o efeito do refletor sobre o tempo de vida dos nêutrons em estados subcríticos de reatividade $[41,72,73]$. 


\section{REFERÊNCIAS BIBLIOGRÁFICAS}

[1] E. FERMI, R. P. FEYNMAN, F. DE HOFFMAN, "Theory of the Criticality of the Water Boiler and the Determination of the number of Delayed Neutrons," USAEC Report MDDC-383 (LADC-269), Los Alamos Scientific Laboratory, 1944.

[2] F. DE HOFFMAN, "Intensity Fluctuations of a Neutron Chain Reaction," USAEC Report MDDC-382 (LADC-256), Los Alamos Scientific Laboratory, 1946.

[3] F. DE HOFFMAN, "Statistical Aspects of Pile Theory," The Science and Engineering of Nuclear Power, vol. 2, 1949.

[4] R. P. FEYNMAN, F. DE HOFFMAN, R. SERBER, "Dispersion of the Neutron Emission in U-235 Fission," J. of Nuclear Energy 3, vol. 64, 1956.

[5] J. ORNDOFF, "Prompt-Neutron Periods of Metal Critical Assemblies," Nuclear Science Eng. vol. 2, Page 450, 1957.

[6] Random House, Dictionary of the English Language, 1961.

[7] American Institute of Physics Handbook, McGraw-Hill, 1963.

[8] V. D. ZIEL, Noise, Prentice-Hall, Inc., 1954

[9] C. E. COHN, Book Review, Nuclear Science Eng. vol. 45, 104, 1971.

[10] L. D. LANDAU, E. M. LIFSHITZ, Statistical Physics, Pergamon Press, 1959.

[11] M. M. R. WILliAMS, Random Processes in Nuclear Reactors, Pergamon Press, 1974.

[12] W. M. STACEY Jr., "Space-Time Nuclear Reactor Kinetics", Nuclear Science and Technology, vol. 5, Academic Press, 1969.

[13] E. D. COURANT, P. R. WALlACE, "Fluctuations of the Number of Neutrons in a Pile", Physical Review vol. 72, 1038, 1947.

[14] G. PERret, B. GeSlot, A. GRUEL, P. Blaise, J. Di-SAlVO, G. DE IZARRA, C. JAMMES, M. HURSIN, and A. PAUTZ, "Kinetic Parameter Measurements in the MINERVE Reactor," IEEE Transactions On Nuclear Science, vol. 64, no 1, 2017.

[15] E.GILAD, B. GESLOT, P. BLAISE, C. DUBI, "Sensitivity of power spectral density techniques to numerical parameters in analyzing neutron noise experiments," Progress in Nuclear Energy - Article In Press, 2017.

[16] S.B. DEGWEKER, R. RUDRA, "On the relation between Rossi alpha and Feynman alpha methods," Annals of Nuclear Energy, vol. 94, pp. 433-439, 2016.

[17] C. DUBI, A. KOLIN, P. BLAISE, B. GESLOT, E. GILAD, "Experimental validation of analytic formulas for the statistical uncertainty in the Feynman-a method," Annals of Nuclear Energy, vol. 106, pp. 84-90, 2017.

[18] Y. KITAMURA, T. MISAWA, "Theory of Feynman-alpha technique with masking window for accelerator-driven systems," Annals of Nuclear Energy, vol. 103, pp. 470-479, 2017.

[19] M. ARKANI, N. MATAJI-KOJOURI, "A newly designed multichannel scaling system: Validated by Feynman-a experiment in EHWZPR,” Nuclear Engineering and Design, vol. 305, pp. 213-221, 2016.

[20] E. GILAD, B. GESLOT, P. BLAISE, C. DUBI, "Sensitivity of power spectral density techniques to numerical parameters in analyzing neutron noise experiments," Progress in Nuclear Energy, Article In Press, 2017.

[21] G. DE IZARRA, C. JAMMES, B. GESLOT, J. DI-SALVO, AND C. DESTOUCHES, "SPECTRON, A neutron noise measurement system in frequency domain," Review of Scientific Instruments, vol. 86, 2015. 
[22] A. TALAMO, Y. GOHAR, F. GABRIELLI, A. RINEISKI, C. H. PYEON, "Advances in the computation of the Sjöstrand, Rossi, and Feynman distributions," Progress in Nuclear Energy, Article in Press, 2017.

[23] A. ROUCHON, A. ZOIA, R. SANCHEZ, "A new Monte Carlo method for neutron noise calculations in the frequency domain," Annals of Nuclear Energy, vol. 102, pp. 465-475, 2017

[24] E. SUVDANTSETSEG, J. WALLENIUS, "An assessment of prompt neutron reproduction time in a reflector dominated fast critical system: ELECTRA," Annals of Nuclear Energy, vol. 71, pp.159-165, 2014.

[25] D. CHIONIS, A. DOKHANE, H. FERROUKHI, A. PAUTZ, "On Causality Analysis of Nuclear Reactor Noise using Partial Directed Coherence," In: Physics of Reactors Conference - PHYSOR 2016, Sun Valley. La Grange Park: American Nuclear Society, pp. 1162-1171, ISBN: 978-1-5108-2573-4, 2016.

[26] International Atomic Energy Agency (IAEA), Research Reactors: Purpose and Future, 2013. 〈http://www.iaea.org/OurWork/ST/NE/NEFW/Technical_Areas/RRS/documents/RR_Purpose_and Future_BODY.pdf>. Acesso em: 26 out. 2017.

[27] G.I. BELL; S. GLASSTONE, Nuclear Reactor Theory, Van Nostrand Reinhold Company, 1970.

[28] G. D. SPRIGGS, et. al., "Two-Region Kinetic Model for Reflected Reactors", Annals of Nuclear Energy, vol. 24, no. 3, pp. 205-250, 1997.

[29] R. A. KARAN, "Measurement of Rossi-alpha in Reflected Reactors", Trans. Am. Nucl. Soc., vol. 7, no. 2, pp. 283, 1964.

[30] R. A. KARAN, "Spatial Dependence of the Decay Rates of Prompt-Neutron Chains in Reflected Reactors", Trans. Am. Nucl. Soc., vol. 8, no. 1, pp. 224, 1965.

[31] R. D. BUSCH; G. D. SPRIGGS, "Preliminary Results of a Rossi-alpha Experiment on the University of New Mexico's Agn-201 Experiment", Trans. Am. Nucl. Soc. vol. 71, 1994.

[32] G. S. BRUNSON; R. J. HUBER, "Two-Region Analysis of Pulsing Data in Fast Critical System", Nucl. Instr. and Methods, vol. 128, 1975.

[33] R. DINIZ, "Obtenção das Constantes de Decaimento e Abundâncias Relativas de Nêutrons Atrasados Através da Análise de Ruído em Reatores de Potência Zero,” Tese de Doutorado, IPEN, 2005.

[34] G. S. BRUNSON, "A Survey of Prompt-Neutron Lifetimes in Fast Critical Systems," ANL-6681 Argonne National Laboratory, 1963.

[35] A.I. MOGILNER, G. P. KRIVELEV, V.M. STECLOVSKY, D.M. SHVETZOV, "Comparison of Neutron Lifetime Measurement Results Made by Statistical and 1/v-Method," Proc. of a Symp. On Statistical Methods in Experimental Reactor Kinetics, and Related Techniques, RCN N69-14878, Reactor Centrum Nederland, Petten, Netherlands, 1969.

[36] R. AVERY, et.al., Proc. $2^{\text {nd }}$. Intern. Conf. Peaceful Uses Atomic Energy, vol. 12, pp. 151, 1958.

[37] R. AVERY, Proc. $2^{\text {nd }}$ Intern. Conf. Peaceful Uses Atomic Energy, vol. 12, pp. 182, 1958.

[38] C. E. COHN, "Reflected-reactor Kinetics,” Trans. Amer. Nucl. Soc., vol. 4, no. 1, pp. 73, 1961.

[39] C. E. COHN, "Reflected-reactor Kinetics," Nucl. Sci. Eng. vol. 13, no.12, 1962.

[40] E. GONNELLI, "O efeito do refletor sobre o tempo de vida neutrônico no Reator IPEN/MB-01," Dissertação (Mestrado), IPEN, 2013.

[41] R. Y. R. KURAMOTO, A. DOS SANTOS, R. JEREZ, R. DINIZ, "Absolute measurement of Beff based on Rossi- $\alpha$ experiments and the two-region model in the IPEN/MB-01 research reactor," Nuclear Science and Engineering, vol. 158, pp. 272-283, 2008.

[42] R. Y. R. KURAMOTO, A. DOS SANTOS, R. JEREZ, R. DINIZ, "Absolute measurement of ßeff based on Feynman- $\alpha$ experiments and the two-region model in the IPEN/MB-01 research reactor," Annals of Nuclear Energy, vol. 34, pp. 433-442, 2007.

[43] H. V DAM, "Inhour equation and kinetic distortion in a two-point reactor kinetic model," Annals of Nuclear Energy, vol. 23, no 14, pp. 1127-1142, 1996.

[44] C. E. COHN, “A Simplified Theory of Pile Noise,” Nucl. Sci. Eng., vol. 7, pp. 472-475, 1960. 
[45] D. L. HETRICK. Dynamics of Nuclear Reactor:The University of Chicago, 1971.

[46] J. A. THIE. Reactor Noise: Rowman and Littlefield, Inc., 1963.

[47] A. DOS SANTOS, S. M. LEE, R. DINIZ AND R. JEREZ, "A new experimental approach for subcritical reactivity determination of multiplying systems," Annals of Nuclear Energy, vol. 59, pp. 243-254, 2013.

[48] P. R. BEVINGTON AND D. K. ROBINSON, "Data Reduction and Error Analysis for the Physical Sciences," McGraw-Hill, 1969.

[49] C. HENRI AND P. GAVIN, "The Levenberg-Marquardt method for nonlinear least squares curve-fitting problems," Department of Civil and Environmental Engineering - Duke University, 2016

[50] W. H. Press, Numerical Recipes in C, Cambridge University Press, (1992)

[51] R. L. BORING, V. AGARWAL, J. C. JOE AND J. J. PERSENSKY, "Digital Full-Scope Mockup of a Conventional Nuclear Power Plant Control Room, Phase 1: Installation of a Utility Simulator at the Idaho National Laboratory," U.S. Department of Energy National Laboratory - Battelle Energy Alliance, 2012

[52] B. H. LEONARD, P. C. BERTELSON, E. E. WADE, "AETR Nuclear Mockup Design - AETR Nuclear Mockup Design," Contract No. AR(11-1)688, Chicago Operations Office - U.S. Atomic Energy Commission, 1959

[53] X-5 MONTE CARLO TEAM, "MCNP - a General Monte Carlo n-Particle Transport Code, version 5," LA-UR-03-1987, Los Alamos National Laboratory, Los Alamos, NM, 2003.

[54] R. E. MACFARLANE, D.W. MUIR, AND R.M. BOUICORT, "NJOY - Code System for Producing Pointwise and Multigroup Neutron and Photon Cross Sections from ENDF Data," LA-12740-M, Los Alamos National Laboratory, Los Alamos, NM (1994).

[55] J.A. AYRES, C.A. TRILLING, "Heavy water and organic fluids as neutron moderator and reflector materials," Nuclear Engineering and Design, vol. 14, pp. 363-389, 1971.

[56] D. JO, J. PARK, H. CHAE, "Development of thermal hydraulic and margin analysis code for steady state forced and natural convective cooling of plate type fuel research reactors," Progress in Nuclear Energy, vol. 71, pp. 39-51, 2014.

[57] E. H. WILSON, F. E. DUNN, T. H. NEWTON JR., L. HU, "Safety analysis of the MIT nuclear reactor for conversion to LEU fuel," In: 5th International Symposium of Material Testing Reactors, Columbia, MO USA. Oct. 22-25, 2012.

[58] S. KIM, "The OPAL (Open Pool Australian Light-Water) reactor in Australia," Nuclear Engineering and Technology, vol. 38, pp. 443-448, 2006.

[59] N. ONISHI, M. ISSHIKI, H. TAKAHASHI, M. TAKAYANAGI, "Safety Design Concept and Analysis for the Upgraded JRR-3," IAEA-SM-310, 1990.

[60] J. G. KIM, Y. S. PARK, Y. K. H. K. SONG, "Analysis of the HDO content in heavy water by ATRFTIR," Journal of Radioanalytical and Nuclear Chemistry, vol. 287, pp. 723-728, 2011.

[61] R. M. MAEDA, "Determinação Experimental de Parâmetros de Física de Reatores utilizando Refletores de Água Pesada no Reator IPEN/MB-01," Dissertação (Mestrado), IPEN, 2012.

[62] J. R. LAMARSH, "Introduction to Nuclear Reactor Theory," Massachusets: Addison-Wesley, 1966.

[63] F. A. HAIGHT, Handbook of the Poisson Distribution. New York: John Wiley \& Sons, 1967.

[64] J. F. C. KINGMAN, Poisson Processes. New York: Oxford University Press, 1993

[65] ORTEC ${ }^{\circledR}$ manual users guide, “550A Single Channel Analyzer User’s Manual," Oak Ridge, TN, U.S.A.

[66] U.S DEPARTMENT OF ENERGY, U.S NIM COMMITTEE, "Standard NIM Instrumentation System," DOE/ER-0457T, May, 1990.

[67] ORTEC $^{\circledast}$ manual users guide, "MCS-pci ${ }^{\mathrm{TM}}$ (A73-B32) Hardware and Software User's Manual," Oak Ridge, TN, U.S.A.

[68] Y. KITAMURA, M. MATOBA, T. MISAWA, H. UNESAKI, AND S. SHIROYA, "Reactor noise experiments by using acquisition system for time series data of pulse train," Journal of Nuclear Science and Engineering, vol. 36, no 8, pp. 653-660, 1999. 
[69] G. F. KNOLL, Radiation Detection and Measurement: John Wiley \& Sons, 3rd ed. 2000.

[70] A. DOS SANTOS et al., IPEN (MB01)-LWR-COEF-KIN-RESR-001: reactor physics experiments in the IPEN/MB-01 research reactor facility. In: International Handbook of Evaluated Reactor Physics Benchmark Experiments. NEA/NSC, Paris, pp. 1-142, 2009.

[71] P. BAETEN, M. BRUGGEMAN AND R. CARCHON, "Single- and multi-deadtime parameter corrections of one- and two-dimensional Rossi-alpha distributions for time interval analysis in neutron coincidence counting," Nuclear Instruments and Methods in Physics Research A, vol. 390, pp. 345-358, 1997.

[72] E. GONNELLI, L. N. PINTO, A. DOS SANTOS, AND R. DINIZ, "The Determination of Reflector Kinetic Parameters through ROSSI- $\alpha$ Experiments in the IPEN/MB-01 Reactor," In: Physics of Reactors Conference - PHYSOR 2016, Sun Valley. La Grange Park: American Nuclear Society, pp. 2692-2697, ISBN: 978-1-5108-2573-4, 2016.

[73] E. GONNELLI, S. M. LEE, L. N. PINTO, H. R. LANDIM, R. DINIZ, R. JEREZ, and A. DOS SANTOS, "An alternative experimental approach for subcritical configurations of the IPEN/MB-01 nuclear reactor," Journal of Physics, Conference Series (Online), vol. 630, 2015. 